\title{
Supramolecular Structures in the Presence of lonic Liquids
}

\author{
Xinghai Shen, Qingde Chen, Jingiing Zhang and Pei Fu \\ College of Chemistry and Molecular Engineering, Peking University, Beijing 100871, \\ P. R. China
}

\section{Introduction}

Supramolecular chemistry is defined as "chemistry beyond the molecule", bearing on the organized entities of higher complexity that result from the association of two or more chemical species held together by intermolecular forces (Lehn, 1988, 1995). Supramolecular chemistry may be divided into two broad and partially overlapping areas concerning: (1) supermolecules, well-defined and discrete oligomolecular species that result from the intermolecular association of a few components (a receptor and its substrate(s)) following a built-in scheme based on the principles of molecular recognition; (2) supramolecular assemblies, polymolecular entities that result from the spontaneous association of a large undefined number of components into a specific phase having more or less well-defined microscopic organization and macroscopic characteristics depending on its nature (such as micelles, microemulsions, vesicles, films, layers, membranes, mesomorphic phase and so on) (Lehn, 1995). Investigation on supramolecular systems is receiving more and more attention (Beletskaya et al., 2009; Constable, 2008; Descalzo et al., 2006; He et al., 2008b; Metrangolo et al., 2008; Oshovsky et al., 2007).

Different from simple inorganic salts (such as $\mathrm{NaCl}$ ) who often melt at very high temperature, ionic liquids (ILs) are a kind of organic salts that are liquid at or near room temperature, always taking $100{ }^{\circ} \mathrm{C}$ as an upper limit. Figure 1 shows the structures of some typical cations and anions of ILs. The imidazolium, especially 1-alkyl-3-methylimidazolium $\left(\mathrm{C}_{\mathrm{n}} \mathrm{mim}^{+}\right)$, is one of the most popular cations. So far, ILs have attracted much attention and been widely used as an attractive class of green solvents in the filelds of chemical reactions, organic and material syntheses, solvent extraction, and electrochemistry because of their negligible vapor pressure, nonflammability, high thermal and chemical stability, high polarity, wide electrochemical window and tunable physicochemical properties (Chiappe \& Pieraccini, 2005; Dupont, 2004; Leclercq \& Schmitzer, 2009a; Weingartner, 2008; Welton, 1999; Zhao et al., 2002).

In the field of supramolecular chemistry, ILs could either participate directly in the assembly of supramolecular organizations, or influence the assembly of various supramolecular structures in a certain way, leading to the appearance of many novel and interesting phenomena. In addition, there exist three-dimensional supramolecular networks with polar and non-polar regions in imidazolium ILs, which can be used as powerful supramolecular receptors (Dupont, 2004; Leclercq \& Schmitzer, 2009a). Therefore, this review will summarize the work in the literature, concerning the above novel and 


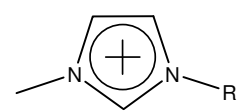

I

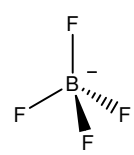

VI

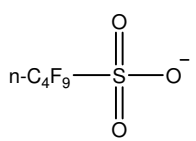

XI

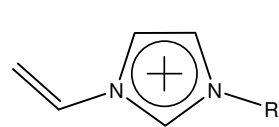

II

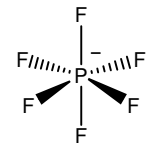

VII

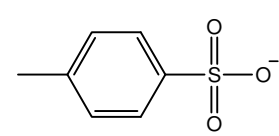

XII

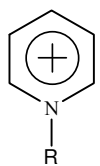

III<smiles>O=S(=O)(NS(=O)(=O)C(F)(F)F)C(F)(F)F</smiles>

VIII<smiles>O=S(=O)([O-])[O-]</smiles>

XIII<smiles>[R][N+]([R])([R5])[B]</smiles>

IV<smiles>[N]N[N]</smiles>

IX<smiles>[B]C(C)c1ccccc1</smiles>

XIV<smiles>[R5][P+]([R5])([R5])[B]</smiles>

V<smiles>O=S(=O)([O-])C(F)(F)F</smiles><smiles>O=C([O-])C12CC3CC(CC(C3)C1)C2</smiles>

XV

Fig. 1. Structures of some typical cations and anions of ionic liquids: I: 1-alkyl-3methylimidazolium $\left(\mathrm{C}_{\mathrm{n}} \mathrm{mim}^{+}\right)$; II: 1-alkyl-3-vinylimidazolium $\left(\mathrm{C}_{\mathrm{n}}\right.$ vim $\left.{ }^{+}\right)$;

III: 1-alkylpyridinium $\left(\mathrm{C}_{\mathrm{n}} \mathrm{Py}^{+}\right)$; IV: tetraalkylammonium; V: tetraalkylphosphonium; VI: tetrafluoroborate $\left(\mathrm{BF}_{4}^{-}\right)$; VII: hexafluorophosphate $\left(\mathrm{PF}_{6}^{-}\right)$; VIII: bis(trifluoromethylsulfonyl)imide $\left(\mathrm{Tf}_{2} \mathrm{~N}^{-}\right)$; IX: dicyanimide $\left((\mathrm{CN})_{2} \mathrm{~N}^{-}\right)$; $\mathrm{X}$ : trifluoromethanesulfonate $\left(\mathrm{TfO}^{-}\right)$; $\mathrm{XI}$ : nonafluorobutanesulfonate $\left(\mathrm{NfO}^{-}\right)$; XII: tosylate $\left(\mathrm{OTos}^{-}\right)$; XIII: alkylsulfate $\left(\mathrm{C}_{\mathrm{n}} \mathrm{OSO}_{3}{ }^{-}\right)$; $\mathrm{XIV}$ : tetraphenylborate $\left(\mathrm{TPhB}^{-}\right)$; $\mathrm{XV}$ : adamantylcarboxylate $\left(\mathrm{AdCO}_{2}{ }^{-}\right)$.

interesting phenomena. The IL-relevant supramolecular systems include not only inclusion complexes with cyclodextrins (CDs), cucurbit[n]urils, calixarenes as host molecules, but also micelles, microemulsions, liquid crystals (LCs), gels. Supramolecular structures based on the host network of ILs themselves will also be presented. Furthermore, the effects of ILs on the assembly of supramolecuar systems (such as rotaxanes and polyrotaxanes, etc.) will be discussed.

\section{Supermolecules systems formed by ionic liquids with different host molecules}

\subsection{Ionic liquids as guests for native and modified cyclodextrins}

\subsubsection{New structures and properties}

Supramolecular systems formed by ILs with CDs demonstrate new structures and properties. ILs can affect the lower critical solution temperature (LCST) of polymers consisted of CDs (Amajjahe et al., 2008; Amajjahe \& Ritter, 2008a). Amajjahe et al. (Amajjahe et al., 2008) investigated the influence of three different 1-butyl-3-vinylimidazolium ILs $\left[\mathrm{C}_{4} \operatorname{vim}\right]\left[\mathrm{Tf}_{2} \mathrm{~N}\right],\left[\mathrm{C}_{4} \mathrm{vim}\right][\mathrm{NfO}]$ and $\left[\mathrm{C}_{4} \mathrm{vim}\right]\left[\mathrm{AdCO}_{2}\right]$ as guests on the LCST values of poly(NIPAAM-co- $\beta$-CD Methacrylate) (PNCM). The copolymer PNCM can form supramolecular polyelectrolyte-type structures, so-called pseudopolyanions through hostguest interactions with suitable ionic guests. This increased hydrophilicity of pseudopolyanions results from the free carboxylate $\left(\mathrm{AdCO}_{2}^{-}\right)$and sulfonate $\left(\mathrm{NfO}^{-}\right)$groups, which are preferentially located in the aqueous phase and therefore responsible for the 
increased LCST values. However, the complexation of $\mathrm{Tf}_{2} \mathrm{~N}^{-}$leads to a decreased LCST value because the hydrophobic $\mathrm{Tf}_{2} \mathrm{~N}^{-}$is preferentially located in the centre of the CD-cavity. With the increasing hydrophobicity of ILs, the cloud point of PNCM is reduced. Besides, the shrinkage and expansion behavior of pseudopolyanions could be controlled by supramolecular interaction of the CD components with three different ILs.

ILs can influence the properties of CDs and vice versa. The poly $\left(\left[\mathrm{C}_{4} \mathrm{vim}\right]\left[\mathrm{Tf}_{2} \mathrm{~N}\right]\right)$ showed a pseudo-LCST effect in the presence of CD (Amajjahe \& Ritter, 2008a). It was found that the $\mathrm{CD}$ ring complexes only the polymer anion and slips off at higher temperature when the poly(IL) becomes insoluble in water. The polymerization of ILs can be controlled by CDs (Amajjahe \& Ritter, 2008b). The monomer $\left[\mathrm{C}_{4} \mathrm{vim}\right]\left[\mathrm{Tf}_{2} \mathrm{~N}\right]$ cannot polymerize in water in the presence of $\beta-C D$ by radical mechanism, which is the result of the complex formation and the spatial ion pair separation leading to quasi "naked vinylimidazolium cations" (Figure 2). This effect should be compensated with the addition of a foreign salt because of cationcation repulsion and then polymerization occurs. As a result, the controllable polymerization is realized.

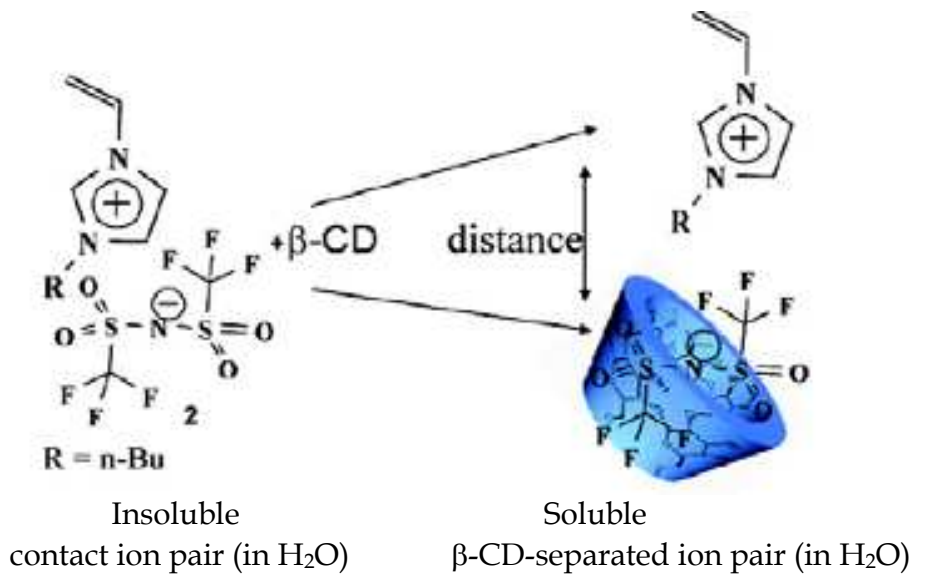

Fig. 2. Host-guest complex formation of $\left[\mathrm{C}_{4} \mathrm{vim}\right]\left[\mathrm{Tf}_{2} \mathrm{~N}\right]$ with $\beta-\mathrm{CD}$ at $298 \mathrm{~K}$ in water. Reprinted from Amajjahe \& Ritter (2008b).

Besides, imidazolium salts can also be employed as carbine precursor for organometallic catalysis, where hydrogen/deuterium exchange reaction of the $\mathrm{C}(2)$-proton occurs. Formation of the inclusion complexes (ICs) of imidazolium salts with the native $\beta-C D$ and the heptakis-(2,6-di-O-methyl)- $\beta-C D(D M-\beta-C D)$ is a simple and efficient method to modify the acidity of the imidazolium $\mathrm{H}(2)$ and its environment (Leclercq \& Schmitzer, 2009b). Encapsulation of 1, 3-disubstituted imidazolium chloride by $\beta$-CDs results in the inhibition of the $\mathrm{H}(2) / \mathrm{D}$ exchange in the complex.

Recently, Leclercq et al. (Leclercq et al., 2009a) discovered that the imidazolium surfactants $\left[\mathrm{C}_{12} \mathrm{mim}\right]$ and $\left[\mathrm{C}_{16} \mathrm{mim}\right]$ can be used as "micellar promoters" in catalyzing hydroformylation reactions. Because of the inclusion of surfactants in the CDs, the addition of $\alpha-C D$ can modulate the aggregation properties of the surfactants. At high temperature, the supramolecular interactions of the imidazolium surfactants favor the micellization process. And by decreasing the temperature, CDs complex the surfactant monomers and destabilize the micelles. 


\subsubsection{Interaction between ionic liquids and cyclodextrins}

The new properties of ILs on the addition of CDs originate from the interaction between ILs and CDs, mostly the inclusion complexation between them. Thus, the study on this topic is important. Various methods have been applied to investigate the interaction between ILs and CDs, such as the solubility (Gao et al., 2005a), infrared spectroscopy (Li et al., 2007c), ultra-violet spectroscopy, XRD (Gao et al., 2006c; Gao et al., 2005a; Li et al., 2007c), conductivity (Amajjahe \& Ritter, 2008b; He et al., 2009), TGA (Gao et al., 2006c; Gao et al., 2005a; Li et al., 2007c), affinity CE (ACE) (Francois et al., 2007), NMR (Amajjahe \& Ritter, 2008b; Gao et al., 2006c; He et al., 2009; Li et al., 2007c), fluorescence competition (He \& Shen, 2008; He et al., 2009), microcalorimetry (Amajjahe et al., 2008; Amajjahe \& Ritter, 2008b; Li et al.), surface tension measurements (Gao et al., 2006c) and so on. By these methods, the formation constants of ICs, the stoichiometry for ILs and CDs can be obtained. Gao et al. (Gao et al., 2005a) investigated the system of $\left[\mathrm{C}_{4} \mathrm{mim}\right]\left[\mathrm{PF}_{6}\right]$ and $\beta-\mathrm{CD}$ using NMR and suggested that the whole imidazolium cation $\left(\mathrm{C}_{4} \mathrm{mim}^{+}\right)$was probably included into the cavity of $\beta-\mathrm{CD}$, while the $\mathrm{PF}_{6}{ }^{-}$ion dissociated near the $\beta$-CD. They also studied ICs formation of $\beta-\mathrm{CD}$ with three kinds of IL surfactants, $\left[\mathrm{C}_{12} \mathrm{mim}\right]\left[\mathrm{PF}_{6}\right],\left[\mathrm{C}_{14} \mathrm{mim}\right]\left[\mathrm{PF}_{6}\right]$, and $\left[\mathrm{C}_{16} \mathrm{mim}\right]\left[\mathrm{PF}_{6}\right]$ (Gao et al., 2006c). There were two kinds of inclusion complexations, i.e., 1:1 and 1:2 $(\beta-\mathrm{CD} / \mathrm{IL})$ stoichiometries for $\beta-\mathrm{CD}-\left[\mathrm{C}_{12} \mathrm{mim}\right]\left[\mathrm{PF}_{6}\right]$ and $\beta-\mathrm{CD}-\left[\mathrm{C}_{14} \mathrm{mim}\right]\left[\mathrm{PF}_{6}\right]$ ICs, and only 1:1 stoichiometry for $\beta-\mathrm{CD}-\left[\mathrm{C}_{16} \mathrm{mim}\right]\left[\mathrm{PF}_{6}\right]$ ICs due to the strong steric inhibition of $\left[\mathrm{C}_{16} \mathrm{mim}\right]\left[\mathrm{PF}_{6}\right]$. Unlike the possible structure suggested for the $\left[\mathrm{C}_{4} \mathrm{mim}\right]\left[\mathrm{PF}_{6}\right] / \beta-\mathrm{CD}$ inclusion complex, only the alkyl side chain on the imidazolium ring of these three ILs entered into the cavity of $\beta$-CD. The similar result was obtained by $\mathrm{Li}$ et al. (Li et al., 2007c), which indicated that only the alkyl side chain of the $\left[\mathrm{C}_{12} \mathrm{mim}\right]\left[\mathrm{PF}_{6}\right]$ was included into the cavity of $\beta$-CD. Francois et al. (Francois et al., 2007) developed ACE method to characterize the complex formation between seven cations of various imidazolium-based ILs $\left(\left[\mathrm{C}_{2} \mathrm{mim}\right]\left[\mathrm{Tf}_{2} \mathrm{~N}\right],\left[\mathrm{C}_{4} \mathrm{mim}\right]\left[\mathrm{Tf}_{2} \mathrm{~N}\right],\left[\mathrm{C}_{4} \mathrm{mim}\right]\left[\mathrm{BF}_{4}\right]\right.$, 1-butyl-2,3-dimethylimidazolium tetrafluoroborate $\left(\left[\mathrm{C}_{4} \mathrm{dmim}\right]\left[\mathrm{BF}_{4}\right]\right),\left[\mathrm{C}_{8} \mathrm{mim}\right] \mathrm{Br},\left[\mathrm{C}_{10} \mathrm{mim}\right]\left[\mathrm{BF}_{4}\right]$ and $\left.\left[\mathrm{C}_{12} \mathrm{mim}\right]\left[\mathrm{BF}_{4}\right]\right)$ and eight neutral CDs ( $\alpha-C D, \beta-C D, \gamma-C D$, hydroxypropyl-a-CD (HP- $\alpha-C D)$, hydroxypropyl- $\beta-C D$ (HP- $\beta-\mathrm{CD})$, hydroxypropyl- $\gamma-\mathrm{CD}$ (HP- $\gamma-\mathrm{CD})$, heptakis-(2,6-di-O-methyl)- $\beta-\mathrm{CD}$ (DM- $\beta-\mathrm{CD})$ and heptakis-(2,3,6-tri-O-methyl)- $\beta-C D$ (TM- $\beta-C D)$ ). According to classical nonlinear and linear treatments, they obtained the complex stoichiometry and formation constant $\mathrm{K}$. The majority of systems followed a 1:1 complexation stoichiometry model but in four cases $\left(\left[\mathrm{C}_{10} \mathrm{mim}\right]\left[\mathrm{BF}_{4}\right],\left[\mathrm{C}_{12} \mathrm{mim}\right]\left[\mathrm{BF}_{4}\right]\right.$ and $\left.\mathrm{a}-\mathrm{CD}, \mathrm{DM}-\beta-\mathrm{CD}\right)$ a 1:2 stoichiometry was better satisfied. It was established that the main factor influencing the strength of the inclusion complexation was the length of alkyl side chain on the imidazolium ring. The presence of a methyl group at the $\mathrm{C}(2)$ position and the nature of anion associated to the imidazolium cation in the IL did not show significant influence on the complexation constant obtained. Also, the size of the CD cavity noticeably impacts the stability of the 1:1 complexes, with stronger complexes being given by $\beta-C D$. Furthermore, it was shown that two CD molecules can likely be threaded along $C_{10}$ and $C_{12}$ alkyl side chains and there was no inclusion of the imidazolium ring into the cavity of $\beta-C D$. Mostly, the interaction of CDs and ILs are studied in aqueous solution. Recently, it was investigated that the dissolution of $\beta-C D$ could be enhanced in some hydrophilic ILs and 1:1 inclusion complexes were formed between $\beta$-CD and imidazolium cations of the ILs (Zheng et al.).

Differently, several inclusion complexes of $\beta-C D$ with anion of ILs were also reported. As mentioned in Section 2.1.1, the anion $\mathrm{Tf}_{2} \mathrm{~N}^{-}$of $\left[\mathrm{C}_{4} \mathrm{vim}\right]\left[\mathrm{Tf}_{2} \mathrm{~N}\right]$ formed exclusively host-guest 
complex with $\beta$-CD (Amajjahe et al., 2008; Amajjahe \& Ritter, 2008b). Similarly, the anion $\mathrm{PF}_{6}{ }^{-}$but not the cation $\mathrm{C}_{4} \mathrm{vim}^{+}$was found to be accommodated by $\beta-\mathrm{CD}$. We reported that $\left[\mathrm{C}_{4} \mathrm{mim}\right]\left[\mathrm{PF}_{6}\right],\left[\mathrm{C}_{4} \mathrm{mim}\right]\left[\mathrm{BF}_{4}\right]$, and $\left[\mathrm{C}_{4} \mathrm{mim}\right] \mathrm{Cl}$ formed 1:1 inclusion complexes with $\beta-\mathrm{CD}$, respectively (He \& Shen, 2008). Through ${ }^{19} \mathrm{~F}$ NMR, we also found that $\mathrm{PF}_{6}{ }^{-}$and $\mathrm{BF}_{4}{ }^{-}$could interact with $\beta$-CD but the latter interaction was relatively weak.

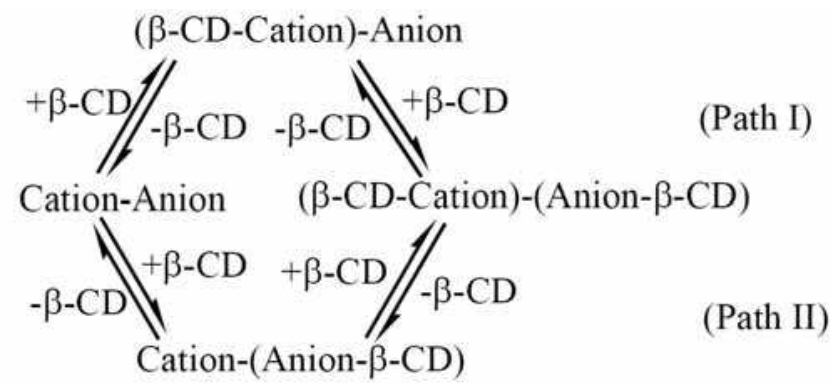

Fig. 3. Two-Step Equilibrium in an IL/ $\beta$-CD System (Path I: the cation interacts with $\beta-C D$ more strongly than the anion does, Path II: the anion interacts with $\beta$-CD more strongly than the cation does). Reprinted from He et al. (2009).

Considering the above studies, a general pattern in the IL/ $\beta$-CD system and a two-step equilibrium was brought forward as shown in Figure 3. It was confirmed that the alkyl side chain on the imidazolium ring but not the imidazolium ring itself entered into the cavity of $\beta$-CD. As for the IL $\left[\mathrm{C}_{12} \mathrm{mim}\right]\left[\mathrm{Tf}_{2} \mathrm{~N}\right]$, the cation and the anion both exhibited strong interactions with $\beta-C D$ simultaneously (He et al., 2009). It was suggested that the strength of the interaction of various cations and anions in ILs with $\beta$-CD follows the following order: $\mathrm{NfO}^{-}>\mathrm{C}_{12} \mathrm{mim}^{+}>\mathrm{Tf}_{2} \mathrm{~N}^{-} \sim \mathrm{AdCO}_{2}^{-} \sim \mathrm{C}_{10} \mathrm{mim}^{+}>\mathrm{C}_{8} \mathrm{mim}^{+}>$1-hexyl-2,3-dimethylimidazolium cation $\left(\mathrm{C}_{6} \mathrm{dmim}^{+}\right) \sim \mathrm{PF}_{6}^{-}>\mathrm{BF}_{4}^{-}>$1-butyl-2,3-dimethylimidazolium cation $\left(\mathrm{C}_{4} \mathrm{dmim}^{+}\right) \sim \mathrm{C}_{4} \mathrm{vim}^{+} \sim \mathrm{C}_{4} \mathrm{mim}^{+}>\mathrm{Cl}^{-}$.

Leclercq et al. (Leclercq \& Schmitzer, 2008) discovered multiple equilibria in the complexation of dibenzylimidazolium bromide by CDs. In aqueous solution, dibenzylimidazolium bromide forms dimeric assemblies by T-stacking between an acidic proton of the imidazolium and the benzyl aromatic ring of another cation (Figure 4). This dimeric association can be disturbed by the addition of native CDs. The control of the majority species in solution can be made by the judicious choice of $C D$ concentration and its

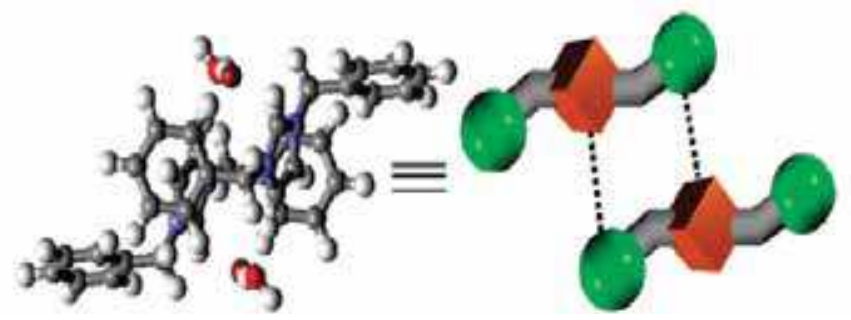

Fig. 4. Structure of the dibenzylimidazolium bromide water dimer obtained by PM3 in accordance with the crystalline structure and the conventional representation adopted in this study. Reprinted from Leclercq \& Schmitzer (2008). 


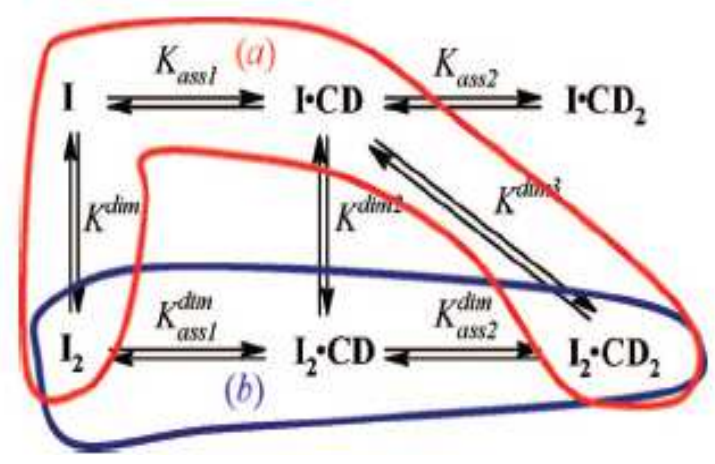

Fig. 5. Equilibrium distributions for the formation of $I_{2} \cdot C_{2}$ from $I_{2}$ in the presence of (a) $\alpha$ $\mathrm{CD}$ and (b) $\beta$-CD. I and $\mathrm{I}_{2}$ represent the dibenzylimidazolium bromide salt and the dimer, respectively. Reprinted from Leclercq \& Schmitzer (2008).

macrocycle size. The dimer is complexed directly by $\beta-C D$, whereas in the presence of $a-C D$, the dimer is dissociated to form a 1:1 IC; at higher concentration, this 1:1 complex can dimerize (Figure 5).

\section{2 lonic liquids as guests for Cucurbit[n]uril system}

Cucurbit[n] uril (CBn) is another important host molecule in supramolecular chemsitry. The complex formation of ILs and CBns is not all the same with CDs because of the different structure between them (Montes-Navajas et al., 2008). $\mathrm{C}_{1} \mathrm{mim}^{+}$forms a fairly stable complex with Cucurbit[7]uril (CB7), similarly, as the numbers of carbon atoms in the aliphatic chain grows, from $\mathrm{C}_{1} \mathrm{mim}^{+}$to $\mathrm{C}_{6} \mathrm{mim}^{+}$, the binding constant between ILs and CB7 increases (Miskolczy et al., 2009). However, further lengthening of the alkyl group destabilizes the complex, because a growing segment of the carbon chain cannot be confined in CB7. When inclusion complexes between 1,1'-dialky-3,3'-(1,4-phenylene)bisimidazolium dibromide salts and CB7 were studied, the stoichiometry of the complexes not only depends on the alkyl chains, but also lies on the relative concentration of the imidazolium salt and CB7 (Noujeim et al., 2009). Unlike $\beta-C D$, the fact that the anion barely influences the binding constant of IL-CB7 complexes is probably due to the significant negative charge density of the carbonyl-laced portals of CB7, which hinders the interaction with anions. Moreover, CB7 has a less polar cavity than $\beta-C D$, which disfavors the ion pairing. St-Jacques et al. (St-Jacques et al., 2008) studied the position of charge-diffuse peralkylated onium cations, $\mathrm{NR}_{4}{ }^{+}, \mathrm{PR}_{4}{ }^{+}$and $\mathrm{SR}_{3}{ }^{+}(\mathrm{R}=\mathrm{Me}$, $\mathrm{Et}, \mathrm{nPr}, \mathrm{nBu}$ ), which could be the cations of ILs, in the cavity of CB7. With cationic guests, the stability constants of the $\mathrm{CB}$ are larger that those of the corresponding CDs and can be several orders of magnitude larger when the guest is a dication. Different cations prefer to locate in different positions of $\mathrm{CB}$. With simple hydrophilic cations, such as protons, alkali metal and alkali earth cations and transition metal ions, the preferred binding location(s) on $\mathrm{CB}$ are the carbonyl-lined portals, to take advantage of the ion-dipole interactions. With cationic organic or organometallic guests, very strong binding is achieved when the cationic portion(s) of the guest can be positioned near the portals. However, as these charge-diffuse peralkylated onium cations, when considering size selectivity, with the smaller guests inside its cavity, rather than at the carbonyl-lined portals by the study of NMR. At the same time, they discovered that the stability constants are dependent on the size and coordination number of the central atom and 
the size and hydrophobicity of the alkyl group. The CB7 has a preference for Et over Me for $\mathrm{NR}_{4}{ }^{+}$and $\mathrm{SR}_{3}{ }^{+}$and the opposite for $\mathrm{PR}_{4}{ }^{+}$, with trends of $\mathrm{PMe}_{4}{ }^{+}>\mathrm{NMe}_{4}{ }^{+}>\mathrm{SMe}_{3}{ }^{+}$and $\mathrm{SEt}_{3}{ }^{+}>$ $\mathrm{NEt}_{4}{ }^{+}>\mathrm{PEt}_{4}{ }^{+}$in binding constants with CB7.

Cucurbit[6]uril (CB6) is poorly soluble in water and insoluble in organic solvents. The interaction of $\mathrm{CB} 6$ and $\left[\mathrm{C}_{\mathrm{n}} \mathrm{mim}\right] \mathrm{Br}$ was found to significantly increase the solubility of $\mathrm{CB} 6$ in neutral water (Zhao et al., 2010). CB6 was pulled into neutral water through encapsulation of an imidazolium-based IL (Liu et al., 2008). According to ${ }^{1} \mathrm{H}$ NMR titration experiments, $\mathrm{C}_{2} \mathrm{mim}^{+}$and $\mathrm{C}_{4} \mathrm{mim}^{+}$demonstrated different binding modes with CB6. The small changes in alkyl chain length can dramatically increase the solubility of CB6. Besides, 2:1 stoichiometry between $\mathrm{C}_{2} \mathrm{mim}^{+}$and $\mathrm{CB} 6$ provides opportunities for a new type of selfassembly with CB6. However, the formation of 1:1 complex between $\mathrm{C}_{2} \mathrm{mim}^{+}$and CB6 was found recently (Kolman et al., 2009). The supramolecular interaction between series of 1alkyl-3-methylimidazolium guests with variable alkyl substituent lengths and CB6 in the solution and the solid state was studied. All imidazolium guests form 1:1 complexes with CB6. However, the mode of inclusion binding depends on the length of the alkyl substituent (Figure 6). The imidazolium aromatic ring is polarized upon complexation with CB6 and the electron density shifts from the nitrogen located in the proximity of the carbonyl portal of CB6 toward the opposite nitrogen atom.

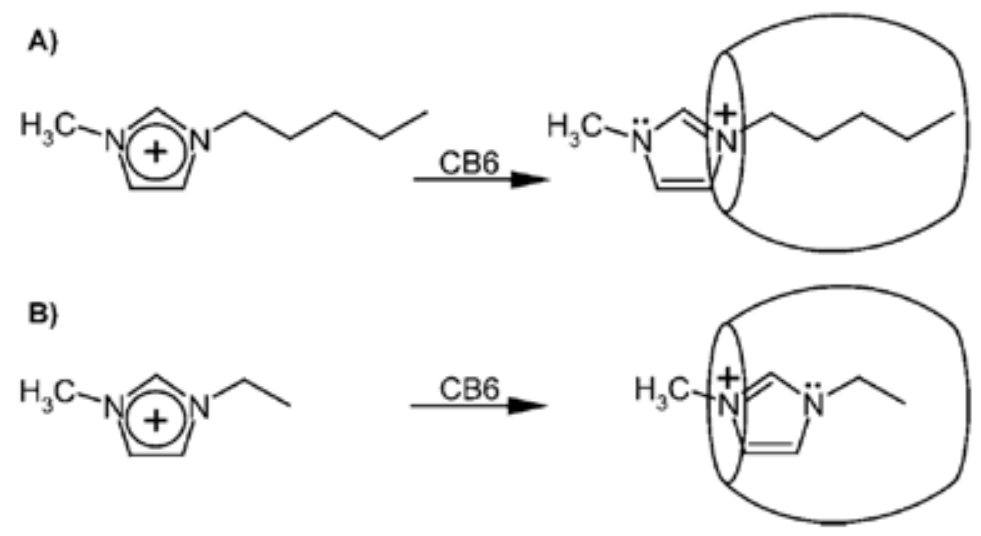

Fig. 6. Two different modes of inclusion binding between 1-alkyl-3-methylimidazolium guests and CB6. Reprinted from Kolman et al. (2009).

Commonly, inclusion complex formation with CB7 can be applied to enhance the fluorescence response of guest (Megyesi et al., 2008), for example berberine, a clinically important natural alkaloid. When using CB7 as macrocyclic host compound, a very stable 1:1 inclusion complex formed and led to about 500-fold fluorescence intensity enhancement, which can facilitate the detection of berberine even below nanomolar concentration. The change of association constant and the fluorescence quantum yield of the complex can be accomplished by the addition of $\mathrm{NaCl}$. Interestingly, 1-alkyl-3-methylimidazolium type ILs can modify the fluorescent properties of the complex much more efficiently than $\mathrm{NaCl}$. It is the result that the formation of ternary complex by time-resolved fluorescence studies. The results can be applied in enzyme assays, because berberine fluorescence is insensitive to the environment, such as $\mathrm{pH}$ and the other compounds. On the other hand, inclusion complex formation can be used to separation processes. Because $\left[\mathrm{C}_{\mathrm{n}} \mathrm{mim}\right] \mathrm{Br}$ is only capable of 
binding with $C B 7$ in a $C B 5 / C B 7$ mixture, $C B 7-\left[C_{n} \operatorname{mim}\right][B r]$ can be removed from the mixture and realize the isolation of CB7 (Jiao et al., 2010). Besides, it is also a green process since imidazolium ILs can be reused.

\section{3 lonic liquids as guests for Calixarene system}

Inazumi et al. (Inazumi et al., 2007) studied the inclusion complexation of $p$ sulfonatocalix[6]arene (Calix-S6) with three kinds of phenothiazine dyes in a mixture of $\left[\mathrm{C}_{4} \mathrm{mim}\right]\left[\mathrm{BF}_{4}\right]$ and ethanol. It was found that a competing complexation happened between the included dye and the IL molecules and that the 1:1 inclusion complex was formed by $\mathrm{C}_{4} \mathrm{mim}^{+}$ and Calix-S6. Very recently, the inclusion complex formation of $\mathrm{C}_{\mathrm{n}} \mathrm{mim}^{+}$type ILs with Calix-S6 and $p$-sulfonatocalix[4]arene (Calix-S4) was verified by the fluorescence competition method with berberine alkaloid as fluorescent probe (Miskolczy \& Biczok, 2009). The stability of $\mathrm{C}_{\mathrm{n}} \mathrm{mim}^{+}$-Calix-S4 complex was significantly larger than that of $\mathrm{C}_{\mathrm{n}} \mathrm{mim}^{+}$-Calix-S6 supramolecules due to better size match in the former case. The influence of the length of the aliphatic side chain was opposite for Calix-S4 and Calix-S6. The lengthening of the aliphatic side chain of the imidazolium moiety diminished the equilibrium constant of the complexation with Calix-S4, but enhanced the stability of Calix-S6 complexes. The larger conformational mobility of Calix-S6 compared to that of Calix-S4 rendered the larger macrocycle more adaptable to the geometrical features of $\mathrm{C}_{\mathrm{n}} \mathrm{mim}^{+}$permitting stronger host-guest interaction when the aliphatic chain of $\mathrm{C}_{n} \mathrm{mim}^{+}$is longer. They demonstrated that the electrostatic attraction between $\mathrm{C}_{n} \mathrm{mim}^{+}$ion and the sulfonato groups at the upper rim of calixarene macrocycle was not the dominant driving force of complexation. As for the anions, the strength of $\mathrm{C}_{\mathrm{n}} \mathrm{mim}^{+}$inclusion in Calix-S6 was anion independent. It was different from the characteristics of ILs in $\beta$-CD because of ion pair formation within the $\beta$-CD cavity. In the case of $\mathrm{C}_{\mathrm{n}} \mathrm{mim}^{+}$-Calix-S6 complex, such an interaction is not feasible because the negative charge of the macrocycle prevents anion ingression into the cavity of the host. Ling et al. reported the multicomponent materials containing Calix-S4, imidazolium or bis-imidazolium cations, phosphonium cations and different lanthanide ions (Ling et al., 2009, 2010a, b). It was investigated that the imidazolium head group resided in the calixarene cavity and the terminus of alkyl chain penetrated the adjacent hydrophobic bi-layer, comprising of the calixarenens and phosphonium ions.

\section{Supramolecular assemblies based on ionic liquids}

Generally, amphiphilic molecules self-assemble to form micelle, microemulsion, lyotropic liquid crystal and vesicle. Moreover, long-chain ILs can act as ionic surfactants and form similar self-assembly in water or oil. Qiu et al. summarized the studies of IL based microemulsions from the perspective of the role of ILs (Qiu \& Texter, 2008). ILs participated in the formation of the microemulsions, in which ILs replaced oil, water or surfactants. Hao et al. reviewed the self-assembled structures (such as micelles, microemulsions, liquid crystals and vesicle) in ILs, which acted as the solvent (Hao \& Zemb, 2007). In this part, we summarized the IL based organized assemblies, in which IL participated in the formation of micelles, microemulsions, vesicles and liquid crystals rather than acted as solvents.

\subsection{IL based micelles (ionic liquid as surfactant)}

Micelles generally form in water and the hydrophobic effect is the main driving force. Recently, micelles formed in nonaqueous polar solvents (including ILs) have been reported. 
Because of the existence of electrostatic repulsion among the hydrophilic groups, surfactant molecules are kept apart and loosely arranged, which may result in the larger size of the aggregates in ILs than that in aqueous systems (Figure 7) (Li et al., 2008a). In addition, the aggregation of amphiphilic copolymers and surfactant-like ILs in ILs was reported.

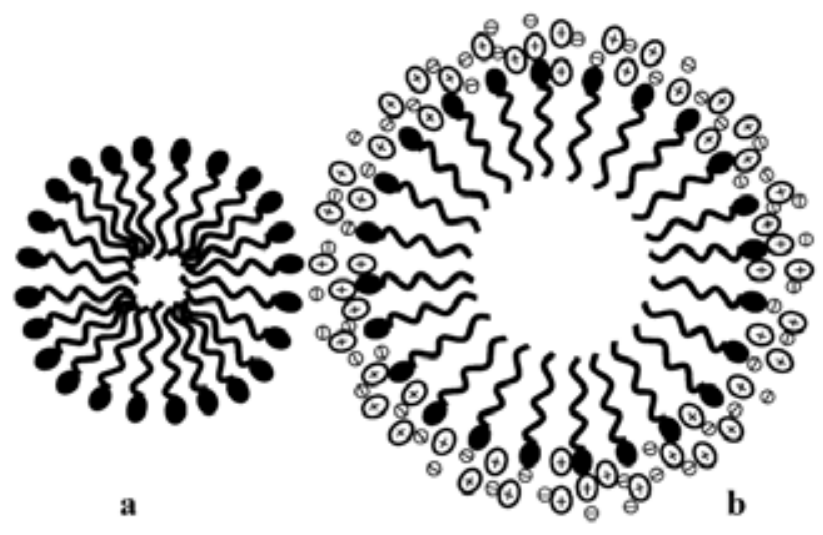

Fig. 7. Schematic representation of long-chain IL aggregates in water (a) and in $\left[\mathrm{C}_{4} \mathrm{mim}\right]\left[\mathrm{BF}_{4}\right]$ (b). Hollow ellipses and hollow circles represent the cations and anions in ILs, respectively. Reprinted from Li et al. (2008a).

ILs based on the 1-alkyl-3-methylimidazolium cation $\left(\mathrm{C}_{n} \mathrm{mim}^{+}\right)$possess an inherent amphiphilicity. In recent years, surfactant behaviors of such ILs received much attention. Miskolczy and his coworkers (Miskolczy et al., 2004) investigated the association of ILs possessing n-octyl moiety either in the cation or in the anion in aqueous solution. It was found that 1-butyl-3-methylimidazolium octyl sulfate acted as a surfactant above cmc $(0.031$ M). Whereas, 1-methyl-3-octylimidazolium chloride produced inhomogeneous solution of larger aggregates, which were dissolved on the addition of more than 2:1 molar excess of sodium dodecylsulfate (SDS) due to the formation of mixed micelle. The aggregation behavior of 1-alkyl-3-methylimidazolium ILs in aqueous solutions has been investigated (Bowers et al., 2004). It was proposed that the short-chain $\left[\mathrm{C}_{4} \mathrm{mim}\right]\left[\mathrm{BF}_{4}\right]$ formed polydisperse spherical aggregates, whereas the $\left[\mathrm{C}_{8} \mathrm{mim}\right] \mathrm{I}$ formed regularly sized micelles above the $\mathrm{cmc}$.

The micelle formation of surface active $\left[\mathrm{C}_{2 n} \mathrm{mim}\right]^{+}(\mathrm{n}=4 \sim 8)$ in aqueous solution was investigated by several methods, such as surface tension, electrical conductivity measurements and fluorescence techniques et al. (Blesic et al., 2007; Blesic et al., 2008; Dong et al., 2007; Dong et al., 2008a; Dong et al., 2008b; El Seoud et al., 2007; Inoue et al., 2007; Jungnickel et al., 2008; Luczak et al., 2008; Luczak et al., 2009; Modaressi et al., 2007b; Singh \& Kumar, 2007, 2008; Vanyur et al., 2007; Wang et al., 2008; Wang et al., 2007; Zhang et al., 2008b; Zhao et al., 2008a). Results showed that the long chain imidazolium ILs acted as ionic surfactants and stronger aggregation tendency of the ILs might be attributed to characteristic nature of imidazolium head group such as potency of H-bond formation, which is lacking in common ionic surfactants. The aggregation number of the ILs was found to increase with the increasing length of the alkyl chain and a possible microscopic aggregation structure such as stairs has been proposed (Zhao et al., 2008a). Aggregationinduced conformational changes in different ILs were shown to depend on the aromatic ring, alkyl chain, counterions, and their interactions with water. Fluorescence quenching 
method in which pyridinium ILs acted as quenchers was firstly used to detect the aggregation behavior of surfactant ILs (Blesic et al., 2008).

The influence of the anions on the aggregation of ILs was first reported by Wang et al., and explained by the hydrated radius or Gibbs energy of hydration of the anions (Wang et al., 2008). The ring type of the cations also had significant effect on the aggregation behavior of the ILs, which was controlled mainly by the balance among the factors of hydrophobicity of the cations, binding strength of the cations with a given anion, and the steric repulsion between the head groups of the cations. The former two factors promote but the latter factor weakens the aggregates formation. Zheng and his coworkers (Dong et al., 2008a) studied the aggregation of surface active $\left[\mathrm{C}_{16} \mathrm{mim}\right] \mathrm{Br}$ and reported the formation of wormlike micelles in the presence of salts, similar to the situation of some traditional ionic surfactants in aqueous solution. Also, $\left[\mathrm{C}_{16} \mathrm{mim}\right] \mathrm{Br}$ was used as a new cationic surfactant for separation of phenolic compounds by MEKC (Niu et al., 2009).

ILs based on imidazolium and ammonium salts with longer-substituent cations selfassemble on negatively charged polyimide substrates via electrostatic force. Whereas for shorter-substituent cations, no aggregates formed due to the less hydrophobic interaction than the electrostatic repulsive interaction between the cations and the counter anions (Zhao et al., 2008b). Dorbritz et al. (Dorbritz et al., 2005) found that the formation of aggregates of $\left[\mathrm{C}_{4} \mathrm{mim}\right]\left[\mathrm{BF}_{4}\right]$ and $\left[\mathrm{C}_{4} \mathrm{mim}\right]\left[\mathrm{Tf}_{2} \mathrm{~N}\right]$ in aqueous solution depended on the solvent, the IL concentration and the anion structure of the ILs. They also mentioned that ILs can be used to improve the solubility of hydrophobic compounds.

Anderson's group (Pino et al., 2009) studied the micellar properties of aqueous solutions of two ILs, 1-hexadecyl-3-butylimidazolium bromide and 1,3-didodecylimidazolium bromide, in the presence of several organic solvents (methanol, 1-propanol, 1-butanol, 1-pentanol, and acetonitrile) by surface tensiometry. For both ILs, increases in the $\mathrm{cmc}$ values and minimum surface area per surfactant molecule, decreases in the maximum surface excess concentration, adsorption efficiency and effectiveness of surface tension reduction were obtained when increasing the organic solvent content.

The aggregation behavior and thermodynamic properties of micellization for the IL-type Gemini imidazolium surfactants with different spacer length $\left(\left[\mathrm{C}_{12}-\mathrm{s}-\mathrm{C}_{12} \mathrm{im}\right] \mathrm{Br}{ }_{2}, \mathrm{~s}=2,4,6\right)$ have been investigated. Results showed that the surface activity of $\left[\mathrm{C}_{12}-\mathrm{s}-\mathrm{C}_{12} \mathrm{im}\right] \mathrm{Br}_{2}$ decreased with increasing spacer length, and the micellization was entropy-driven when $\mathrm{s}=2$ and 4 , whereas aggregation of $\left[\mathrm{C}_{12}-6-\mathrm{C}_{12} \mathrm{im}\right] \mathrm{Br}_{2}$ is enthalpy-driven at lower temperature but entropy-driven at higher temperature (Ao et al., 2009).

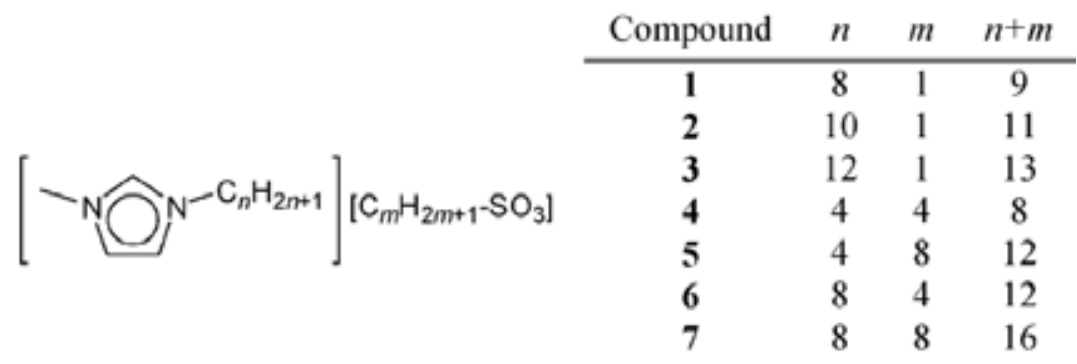

Fig. 8. General structure of 1-alkyl-3-methylimidazolium alkylsulfonate ILs $\left(\left[\mathrm{C}_{\mathrm{n}} \mathrm{H}_{2 \mathrm{n}+1} \mathrm{mim}\right]\left[\mathrm{C}_{\mathrm{m}} \mathrm{H}_{2 \mathrm{~m}+1} \mathrm{SO}_{3}\right]\right) ; \mathrm{m}+\mathrm{n}$ is the sum of the number of carbon atoms in the two alkyl-substituents. Reprinted from Blesic et al. (2009b). 
Anionic and cationic alkyl-chain effects on the self-aggregation of both neat and aqueous solutions of 1-alkyl-3-methylimidazolium alkylsulfonate salts, $\left[\mathrm{C}_{n} \mathrm{H}_{2 \mathrm{n}+1} \mathrm{mim}\right]\left[\mathrm{C}_{\mathrm{m}} \mathrm{H}_{2 \mathrm{~m}+1} \mathrm{SO}_{3}\right]$ (Figure 8), have been investigated for the first time by Blesic et al. (Blesic et al., 2009b). They compared the effects of the alkyl-substitution patterns in both the cation and anion on the surfactant properties of these salts. It was found that the ILs with methylsulfonate anions ( $n$ $=8,10$, and 12) behaved as conventional cationic surfactants, showing a decrease of the cmc with the increase of the alkyl chain length in the cation. When the amphiphilic character is present in both the cation and anion $(n=4$ and $8, m=4$ and 8), a synergistic packing effect appears to lead to the formation of novel catanionic surfactants with both cmc values lower than anticipated, and enhanced surface activity. Bhargava and his coworkers (Bhargava \& Klein, 2009) applied molecular dynamics (MD) to study the cation aggregation of $\left[\mathrm{C}_{10} \mathrm{mim}\right] \mathrm{Br}$ in aqueous solution and found that the chains were buried inside the micelle to avoid unfavorable interactions with water, leaving the polar headgroups exposed to water.

Recently, Kunz et al. (Thomaier \& Kunz, 2007) have reported the aggregation behavior of surfactant-like ILs, $\left[\mathrm{C}_{16} \mathrm{mim}\right] \mathrm{Cl}$ and $\left[\mathrm{C}_{16} \mathrm{mim}\right]\left[\mathrm{BF}_{4}\right]$, in another IL ethylammonium nitrate (EAN), where the structures due to electrostatic interactions can persist at such high temperatures. The aggregation behavior of a series of long-chain ILs, $\left[\mathrm{C}_{2 n} \mathrm{mim}\right] \mathrm{Br}(n=5 \sim 8)$, in $\left[\mathrm{C}_{4} \mathrm{mim}\right]\left[\mathrm{BF}_{4}\right]$ was studied by $\mathrm{Li}$ et al. ( $\mathrm{Li}$ et al., 2008a) for the first time. The results indicated that the $\mathrm{cmc}$ for the long-chain ILs in $\left[\mathrm{C}_{4} \mathrm{mim}\right]\left[\mathrm{BF}_{4}\right]$ are much larger than that in water and diameters of the spherical aggregates obtained by freeze-fracturing electron microscopy (FFEM) and dynamic light scattering (DLS) measurements were 70 100 nm. Davis and his coworkers (Merrigan et al., 2000) synthesized four new surfactant fluorinated ILs (Figure 9) and reported the formation and stabilization of dispersions of perfluorocarbons in $\left[\mathrm{C}_{6} \mathrm{mim}\right]\left[\mathrm{PF}_{6}\right]$ for the first time.

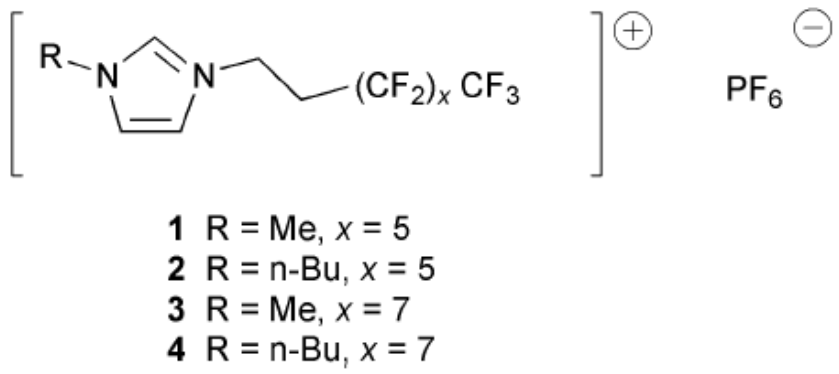

Fig. 9. General structures of the new fluorous ILs. Reprinted from Merrigan et al. (2000).

\section{2 lonic liquid based microemulsions}

IL based microemulsions, which utilize ILs to replace one or more components of classical microemulsions, are so attractive that lots of papers have been published to characterize these kinds of IL based microemulsions.

First of all, IL based microemulsions, in which ILs replaced water of traditional microemulsions, have been extensively characterized by a number of techniques. Microregion of phase diagram of IL based microemulsions was detected by cyclic voltammetric technique (Gao et al., 2006a), electrical conductivity (Gao et al., 2004; Gao et al., 2006b; Gao et al., 2007b; Gao et al., 2006d; Li et al., 2007b), and direct observation, where the phase boundaries were determined by observing the transition from transparency to 
turbidity (Cheng et al., 2007a; Cheng et al., 2007b; Cheng et al., 2008; Gao et al., 2005b; Li et al., 2005a). Based on the phase diagram, DLS (Cheng et al., 2007a; Gao et al., 2004; Gao et al., 2006b; Gao et al., 2008b; Gao et al., 2005b; Li et al., 2007b), FFEM (Cheng et al., 2007a; Gao et al., 2004; Gao et al., 2008b), small-angle X-ray scattering (SAXS) (Li et al., 2005a) and smallangle neutron scattering (SANS) (Eastoe et al., 2005) have been applied to characterize the microemulsions with polar IL cores. These techniques proved the swollen of reversed micelle with the addition of IL, which indicated the formation of reversed microemulsion. More detailed information was gained through FTIR (Gao et al., 2006b), ${ }^{1} \mathrm{H}$ NMR (Gao et al., 2006b; Gao et al., 2008b), UV-vis spectroscopy (Gao et al., 2006b; Gao et al., 2008b; Gao et al., 2005b; Li et al., 2007b) and conductivity measurements (Gao et al., 2006b; Gao et al., 2008b; Li et al., 2005a). Sarkar and his coworkers (Adhikari et al., 2007; Chakrabarty et al., 2005; Seth et al., 2006, 2007a; Seth et al., 2007b) initiated the work of applying steady-state and time-resolved fluorescence spectroscopy to investigate IL based microemulsions. Coumarin 151, 153 and 490 were adopted as the probes. The results showed the solvation time inside the polar cores of the microemulsions was retarded compared to that in neat IL because of restrictions in the ionic motions imposed by the microemulsions. $\mathrm{Li}$ et al. ( $\mathrm{Li}$ et al., 2007b) studied the reversed microemulsion of $\mathrm{TX}-100$ in toluene with $\left[\mathrm{C}_{4} \mathrm{mim}\right]\left[\mathrm{BF}_{4}\right]$ cores, using methyl orange and methylene blue as probes. With the addition of $\left[\mathrm{C}_{4} \mathrm{mim}\right]\left[\mathrm{BF}_{4}\right]$ into TX$100 /$ toluene micelle, the polarity of the microemulsion increased firstly, and then became constant, indicating the formation of "IL pool". [ $\left.\mathrm{C}_{4} \mathrm{mim}\right]\left[\mathrm{BF}_{4}\right] / \mathrm{TX}-100 / p$-xylene reversed microemulsion was investigated and a plausible structure with "IL pool" was presented (Gao et al., 2006b). It was proposed that the electropositive imidazolium ring of IL destroyed the hydrogen-bonding between TX-100 molecules. Successive addition of $\left[\mathrm{C}_{4} \mathrm{mim}\right]\left[\mathrm{BF}_{4}\right]$ led to the appearance of large-sized microemulsion droplet clusters (Gao et al., 2008b).

Additionally, ILs may also replace the other components of traditional microemulsions. In this field, Cheng et al. (Cheng et al., 2007b) reported the first microemulsion formed by two ILs, i.e., hydrophobic $\left[\mathrm{C}_{4} \mathrm{mim}\right]\left[\mathrm{PF}_{6}\right]$ and hydrophilic propylammonium formate (PAF). The formation of IL based microemulsion in supercritical carbon dioxide with N-ethyl perfluorooctylsulfonamide was reported (Liu et al., 2007). The first microemulsion comprising an IL $\left(\left[\mathrm{C}_{16} \mathrm{mim}\right] \mathrm{Cl}\right)$ as surfactant and another IL (EAN and $\left[\mathrm{C}_{4} \mathrm{mim}\right]\left[\mathrm{BF}_{4}\right]$, respectively) as polar pseudo-phase was presented (Zech et al., 2009). Zheng and his coworkers ( $\mathrm{Li}$ et al., 2009c) reported the phase diagram of $p$-xylene-[ $\left.\mathrm{C}_{14} \mathrm{mim}\right] \mathrm{Br}$-water ternary system, where hexagonal, lamellar lyotropic liquid crystals or microemulsions formed depending on the composition. They confirmed the formation of oil-in-water $(\mathrm{O} / \mathrm{W})$ microemulsion through the linear increasing volume of the droplets with added p-xylene. Gao et al. (Gao et al., 2009a) considered the hydrophobic interaction between the added organic solvents and hydrophobic groups of surfactant molecules to be the driving force in the formation of oil-in-IL (O/IL) microemulsions (Figure 10). They observed a bicontinuous microstructure by FFEM for the first time with successive addition of organic solvents.

The effect of additional water on the microstructure and properties of IL based microemulsions has been studied. In the $\left[\mathrm{C}_{4} \mathrm{mim}\right]\left[\mathrm{BF}_{4}\right] / \mathrm{TX}-100 /$ thriethylamine microemulsion, water located in the palisade layers and made a base environment which might be used to prepare metal hydroxides and metal oxides ( $\mathrm{Li}$ et al., 2007a). For the $\left[\mathrm{C}_{4} \mathrm{mim}\right]\left[\mathrm{BF}_{4}\right] / \mathrm{TX}-100 /$ benzene microemulsion, water molecules interacted with oxyethylene (OE) units of TX-100 through hydrogen-bonding and attracted electropositive imidazolium ring of IL with electronegative oxygen (Gao et al., 2007a; Gao et al., 2007b). Hence, the amount of solubilized $\left[\mathrm{C}_{4} \mathrm{mim}\right]\left[\mathrm{BF}_{4}\right]$ enhanced with the increase of water content 


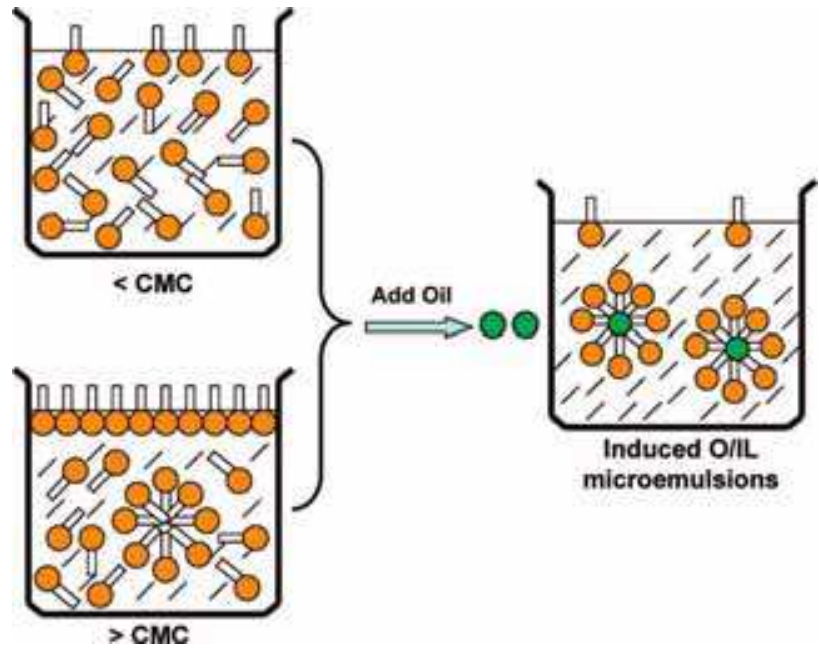

Fig. 10. Schematic diagrams of solution environments before (left) and after (right) adding organic solvents to the mixture of TX-100 and $\left[\mathrm{C}_{4} \mathrm{mim}\right]\left[\mathrm{BF}_{4}\right]$. Reprinted from Gao et al. (2009a).

because the water molecules were like "glue" that stuck the IL and OE units more tightly together. However, an increase in the amount of water in $\left[\mathrm{C}_{4} \mathrm{mim}\right]\left[\mathrm{BF}_{4}\right] / \mathrm{TX}-$ $100 /$ cyclohexane microemulsions led to the phase separation and a remarkable decrease in the size of droplets (Gao et al., 2008a). Therefore, the number of droplets increased, which was further confirmed by conductivity measurements. The opposite effects caused by the water added on IL based microemulsions with same composition except continuous oil attracted us to study the role of the water.

\subsection{Ionic liquid based lyotropic liquid crystal systems}

Liquid crystals are liquid anisotropic compounds, whose properties are intermediate between that of the crystalline solid state and that of the liquid state. The refractive index, the electric permittivity, the magnetic susceptibility, and the mechanical properties of a liquid crystal depend on the direction in which these quantities are measured (Binnemans, 2005). The investigations of the lyotropic liquid crystalline phase formation containing ILs are also of great interest.

Davis and his coworkers (Davis et al., 1998) obtained a novel IL by anion metathesis with $\mathrm{NaPF}_{6}$ after the imidazole-ring miconazole reacting with alkyl iodides to form imidazolium cations, which exhibited lyotropic liquid crystalline behavior while inducing the gelation of benzene. Firestone's group reported that lyotropic liquid crystalline formed in $\left[\mathrm{C}_{10} \mathrm{mim}\right] \mathrm{Br}-$ water (5-40\% wt \%) system (Firestone et al., 2002). They also obtained anisotropic gold nanoparticles with a variety of sizes and morphologies in the nanostructured $\left[\mathrm{C}_{10} \mathrm{mim}\right] \mathrm{Cl}-$ water ionogel template by photochemical reduction of $\mathrm{HAuCl}_{4}$ (Firestone et al., 2005).

Chen and his coworkers (Zhang et al., 2007) reported the formation of two lyotropic liquid crystals formed in a ternary system of $\left[\mathrm{C}_{16} \mathrm{mim}\right] \mathrm{Cl}, 1$-decanol, and water at $298 \mathrm{~K}$, where one was the hexagonal phase connected to the $\left[\mathrm{C}_{16} \mathrm{mim}\right] \mathrm{Cl}$-water axis and the other was the lamellar phase in the center in the phase diagram (Figure 11). The formation of liquid 


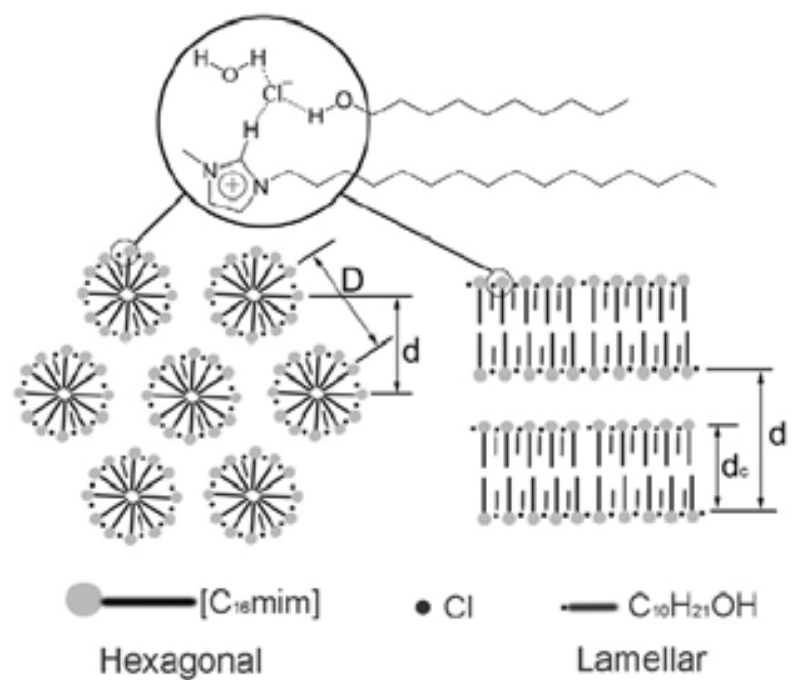

Fig. 11. Sectional schematic graph of possible structures formed in the hexagonal and lamellar phases. H-bonded network comprising $\mathrm{H}_{2} \mathrm{O}, \mathrm{Cl}^{-}$, the imidazolium cation, and $\mathrm{C}_{10} \mathrm{H}_{21} \mathrm{OH}$ (top). Reprinted from Zhang et al. (2007).

crystalline phases is believed to arise from a hydrogen-bonded network comprised of an imidazolium ring, anion, 1-decanol, and water. Two types of lyotropic liquid crystalline phases, hexagonal and lamellar, formed in the ternary mixtures of $\left[\mathrm{C}_{16} \mathrm{mim}\right] \mathrm{Br} / \mathrm{p}$ xylene/water, where the lattice parameters depended on the content of surfactant and water (Zhang et al., 2007). Phase behaviors of three long-chained imidazolium ILs, i.e., $\left[\mathrm{C}_{12} \mathrm{mim}\right] \mathrm{Br}$, $\left[\mathrm{C}_{14} \mathrm{mim}\right] \mathrm{Br}$ and $\left[\mathrm{C}_{16} \mathrm{mim}\right] \mathrm{Br}$, with $p$-xylene and water were studied by $\mathrm{Li}$ et al. For the first time, the formation of a lyotropic bicontinuous cubic phase in imidazolium-type IL system was reported ( $\mathrm{Li}$ et al., 2009b). The hexagonal lyotropic liquid crystalline phase formed in the ternary system of the $\left[\mathrm{C}_{12} \mathrm{mim}\right] \mathrm{Br}$ in aqueous solution of $\left[\mathrm{C}_{4} \mathrm{mim}\right]\left[\mathrm{BF}_{4}\right](\mathrm{Wu}$ et al., 2009b). In addition, it was found that the cylindrical units compacted much denser for the hexagonal phases formed by $\left[\mathrm{C}_{12} \mathrm{mim}\right] \mathrm{Br}$ in comparison with that formed by dodecyltrimethylammonium bromide (DTAB).

It was reported that a lamellar phase could be formed in aqueous solutions of Brij-97 by solubilizing $\left[\mathrm{C}_{4} \mathrm{mim}\right]\left[\mathrm{PF}_{6}\right]$ and $\left[\mathrm{C}_{4} \mathrm{mim}\right]\left[\mathrm{BF}_{4}\right]$ (Wang \& Zhou, 2009). [ $\left.\mathrm{C}_{4} \mathrm{mim}\right]\left[\mathrm{PF}_{6}\right]$ was dominantly penetrated between the $\mathrm{OE}$ chains of surfactant molecules, whereas $\left[\mathrm{C}_{4} \mathrm{mim}\right]\left[\mathrm{BF}_{4}\right]$ was mainly located in the water layer of hexagonal phases and therefore, the strength of the network of hexagonal phase formed in the Brij-97/water/[C $\left.\mathrm{C}_{4} \mathrm{mim}\right]\left[\mathrm{BF}_{4}\right]$ system was stronger than that of the Brij-97/water/[ $\left.\mathrm{C}_{4} \mathrm{mim}\right]\left[\mathrm{PF}_{6}\right]$ system.

However, the reports on the molecular aggregations using IL as co-surfactants are still scarce in the literature. As a kind of co-surfactant, ILs are superior to alcohol because of its negligible vapor pressure, high stability and viscosity. Friberg et al. (Friberg et al., 2000) studied the solubilization of $\left[\mathrm{C}_{4} \mathrm{mim}\right]\left[\mathrm{PF}_{6}\right]$ in the lamellar phase of Brij-30/water system, and the results showed that IL can be solubilized into the lamellar phase without changing the dimensions of the amphiphilic layer. Wang et al. (Wang et al., 2005) determined the phase diagram of ternary system of Brij-97/IL $\left(\left[\mathrm{C}_{4} \mathrm{mim}\right]\left[\mathrm{PF}_{6}\right]\right.$ or $\left.\left[\mathrm{C}_{4} \mathrm{mim}\right]\left[\mathrm{BF}_{4}\right]\right) /$ water and investigated the location of IL in the hexagonal liquid crystal. Ge et al. (Ge et al., 2007) 

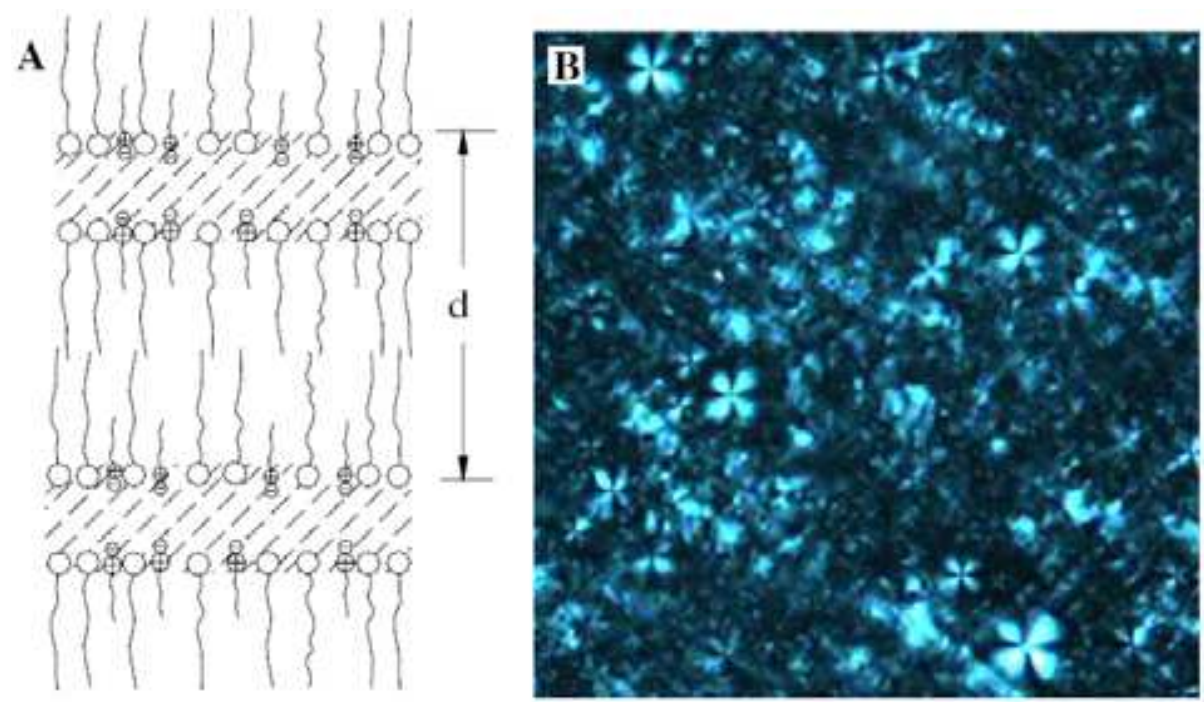

Fig. 12. Structure illustration (A) and typical micrograph (B) of lamellar phase in Brij$30 /\left[\mathrm{C}_{4} \mathrm{mim}\right]\left[\mathrm{PF}_{6}\right] / \mathrm{H}_{2} \mathrm{O}$ system. The weight ratio of $\mathrm{B}$ is Brij-30: $\left[\mathrm{C}_{4} \mathrm{mim}\right]\left[\mathrm{PF}_{6}\right]: \mathrm{H}_{2} \mathrm{O}=54: 6: 40$. Reprinted from Ge et al. (2007).

reported the microstructure of lamellar liquid crystal composed of Brij-30, $\left[\mathrm{C}_{4} \mathrm{mim}\right]\left[\mathrm{PF}_{6}\right]$ and water (Figure 12), where the structure strength was enhanced by increasing the amount of Brij-30 and $\left[\mathrm{C}_{4} \mathrm{mim}\right]\left[\mathrm{PF}_{6}\right]$ and impaired with the increase of water content. The lubrication properties of the ternary system were investigated and the effect of IL on the lubrication properties of traditional lamellar phase was confirmed.

$\mathrm{Su}$ et al. (Xiao et al., 2008) fabricated a new type of thermotropic liquid-crystalline photosensitive supramolecular ionic self-assembly of polyelectrolyte and functional unit azobenzene IL crystal (azo-ILC), where the thermal and phase behaviors can be modulated by changing the spacer length (methylene units in azo). Ma et al. (Ma et al., 2008) found that the addition of very small amounts of an alcohol or water into tri-ndecylmethylphosphonium chloride and bromide salts (1P10X) induced the formation of liquid crystalline, where strong association between the hydroxyl groups of alcohol or water and the head groups of 1P10X is indicated.

However, little attention has been given to the protein crystallization system where IL is added. $\mathrm{Li}$ et al. found that the addition of $\left[\mathrm{C}_{4} \mathrm{mim}\right]\left[\mathrm{BF}_{4}\right]$ could promote the crystallization of lysozyme, which was probably resulted from the influence of the ionic polarization and kinetics in the lysozyme crystallization (Li et al., 2008c).

\section{4 lonic liquid based Vesicles and gels}

Vesicles represent one class of self-assembly formed by phospholipids and synthetic surfactants. Generation of vesicles from single surfactants or from mixtures of anionic and cationic surfactants has been reported over the last several years.

Diakyldimethylammonium bromide formed bilayer membranes in the designed IL systems and ionophilic ether groups of ILs were found to be indispensable for the stable solvation of ammonium bilayers (Nakashima \& Kimizuka, 2002). This is the first report which supported 
that IL is in favor of the formation of surfactant vesicle phase. Kimizuka and his coworkers (Kimizuka \& Nakashima, 2001) reported that stable bilayer membranes formed when glycolipids were dispersed in sugar-philic ether-containing ILs, which displayed reversible thermal transformation from fibrous assemblies to vesicles. Marangoni and his coworkers (Singh et al., 2009) reported the formation of spontaneous vesicle in the binary mixture of SDS and an IL amphiphile, hexylpyridinium tetrafluoroborate. Strong electrostatic interactions between bulky organic ions are the main force of the formation of vesicle aggregates.

Tang et al. (Tang et al., 2006) reported that Brij-76 were temperature dependant on the selfassembly processes in $\left[\mathrm{C}_{4} \mathrm{mim}\right]\left[\mathrm{BF}_{4}\right]$, where passed gel, clear solution, vesicles and emulsion transformations at 30, 85, 90 and $110{ }^{\circ} \mathrm{C}$, respectively. Zhao et al. (Zhao et al., 2009a) investigated the phase behavior of ternary system which was composed of $\left[\mathrm{C}_{16} \mathrm{mim}\right] \mathrm{Cl}$, SDS and water. It was found that a novel gel phase with quite high water content could be fabricated and the lamellar structure was obtained in SDS-rich region. Both the hydrophobic interaction of alkyl chains and interactions between oppositely charged head groups played important roles for the gel formation.

The self-assembled surfactant vesicles formed by the fluorous surfactant $\mathrm{Zn}\left(\mathrm{OOCCH}_{2} \mathrm{C}_{6} \mathrm{~F}_{13}\right)_{2}$ or by mixtures of tetradecyldimethylamine oxide $\left(\mathrm{C}_{14} \mathrm{DMAO}\right)$ and $\mathrm{Zn}\left(\mathrm{OOCCH} \mathrm{C}_{6} \mathrm{~F}_{13}\right)_{2}$ were reported by Hao's group (Hao et al., 2005). Tan et al. (Tan et al., 2009) reported that the gelation of $\left[\mathrm{C}_{4} \mathrm{mim}\right]\left[\mathrm{PF}_{6}\right]$ were induced by the self-assembly of gelators, where the mean minimum concentrations were found to be less than $2 \mathrm{wt} \%$ (Figure 13). The similar ion conductivities of $\left[\mathrm{C}_{4} \mathrm{mim}\right]\left[\mathrm{PF}_{6}\right]$ gels to those of the pure $\left[\mathrm{C}_{4} \mathrm{mim}\right]\left[\mathrm{PF}_{6}\right]$ indicated that the supramolecular structures in the $\left[\mathrm{C}_{4} \mathrm{mim}\right]\left[\mathrm{PF}_{6}\right]$ gels had apparently no effect on the mobility of the ions. Thus, the $\left[\mathrm{C}_{4} \mathrm{mim}\right]\left[\mathrm{PF}_{6}\right]$ gels formed by the gelators may be used as electrolytes in electrochemical devices.

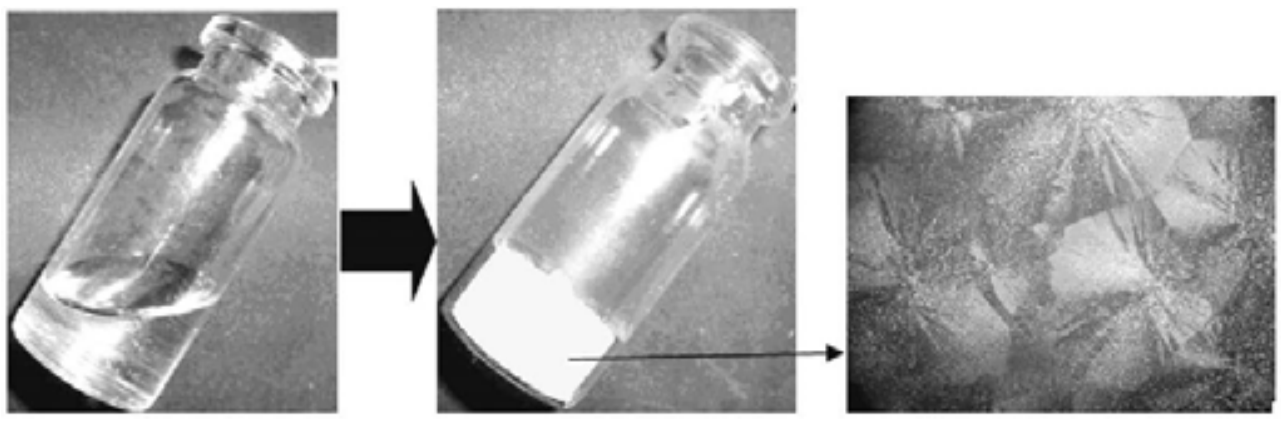

Fig. 13. Schematic illustration of gelation of $\left[\mathrm{C}_{4} \mathrm{mim}\right]\left[\mathrm{PF}_{6}\right]$ and the POM image of a $\left[\mathrm{C}_{4} \mathrm{mim}\right]\left[\mathrm{PF}_{6}\right]$ gel formed in the presence of $2 \mathrm{wt} \%$ of BODM (magnification: 1000). Reprinted from Tan et al. (2009).

\section{Supramolecular structures based on the host networks in ionic liquids}

Generally, ILs are considered as homogeneous solvents, similar to the normal molecular solvents. However, it has been found that supramolecular networks exist in pure ILs, especially in imidazolium ILs, which have already been extensively reviewed in the literature (Dupont, 2004; Leclercq \& Schmitzer, 2009a). Here, we illustrate the self- 
organisation of ILs and some of the organisations observed in pure ILs in order to raise the interesting in exploring how the supramolecular structure of ILs affect the formation of supermolecules and supramolecular assemblies.

\subsection{Supramolecular networks in ionic liquids}

\subsubsection{Supramolecular structures in solid state}

A typical supramolecular model for imidazolium ILs in solid state (Dupont, 2004; Leclercq \& Schmitzer, 2009a), suitable to small and spherical anions with symmetric cations, came from an overview of X-ray analyses results (Choudhury et al., 2005, 2006; Dupont et al., 2000; Fuller et al., 1994; Golovanov et al., 2005; Gordon et al., 1998; Holbrey et al., 2004; Saha et al., 2003), which indicates the existence of an extended network of cations and anions connected together by hydrogen bonding (Figure 14A) (Dupont, 2004; Leclercq \& Schmitzer, 2009a). The unimeric unit is always constituted by one imidazolium cation surrounded by at least three anions and each anion is surrounded by at least three imidazolium cations. With respect to the specific number of anions/cations that surround the cation/anion, it depends on the geometry of anion and the nature of the imidazolium residues. The strongest hydrogen bond always involves the most acidic $\mathrm{H}(2)$ of imidazolium ring, followed by $\mathrm{H}(4)$ and $\mathrm{H}(5)$ of the imidazolium cation and sometimes by the proton of the $\alpha$-carbon on nitrogen. These hydrogen bonds, which are mostly electrostatic in nature, are weak to moderate $\left(\mathrm{H} \cdots \mathrm{X}\right.$ bond lengths $>2.2$ angstrom, $\mathrm{C}-\mathrm{H} \cdots \mathrm{X}$ bond angles between $100^{\circ}$ and $\left.180^{\circ}\right)$. Besides hydrogen bonding, other interactions (such as electrostatic interactions, $\pi-\pi$ stacking, C-H $\cdots \pi$ interactions and combination of these interactions) between the cations and the anions can also lead to the formation of the supramolecular network. For example, anions with phenyl residues (such as $\mathrm{TPhB}^{-}$) can interact with imidazolium cations via C$\mathrm{H} \cdots \pi$ interactions and form a supramolecular framework (Dupont et al., 2000). Recently, Leclercq et al. (Leclercq et al., 2009b) synthesized $N, N^{\prime}$-diaromatic diimidazolium cations, which include electron-rich (aromatic) and electron-poor (imidazolium) rings, and found that a perfect alternation of electron-rich and electron-poor ring can maximize the $\pi-\pi$ stacking.

Furthermore, the above two-dimensional organization may evolve to three-dimensional structures through the chains of imidazolium rings (Figure 14B). In some cases, $\pi$ - $\pi$ stacking interactions among imidazolium rings, and a relatively weak $\mathrm{C}-\mathrm{H} \cdots \pi$ interactions through the methyl group and the $\pi$ system of the imidazolium ring can also be found in 1-alkyl-3-
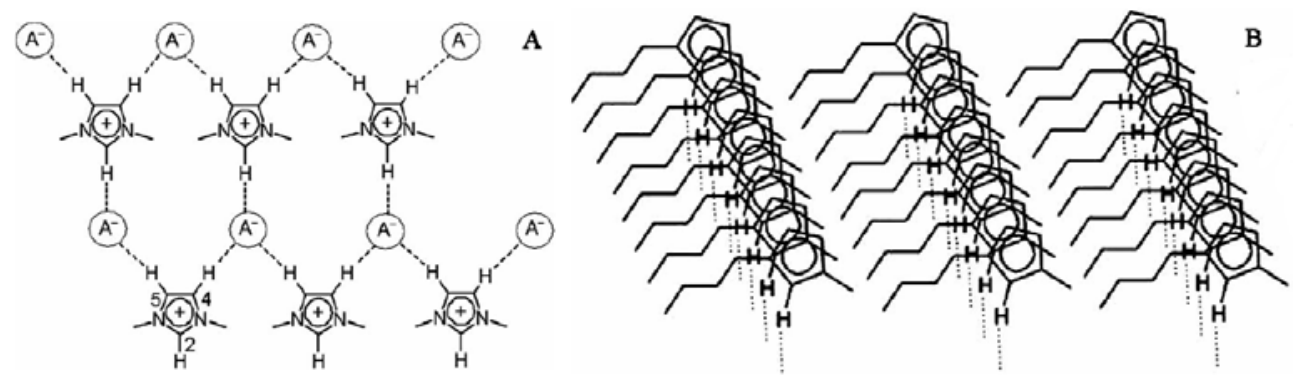

Fig. 14. Simplified two- (A) and three-dimensional (B) supramolecular structures of imidazolium ILs. Reprinted from Leclercq \& Schmitzer (2009a). 
methylimidazolium salts. Particularly, in some special confined circumstances, such as the hollow interiors in multi-walled carbon nanotubs and the nanospace between graphite walls, these weak interactions may be strengthened, resulting in high-melting-point crystals of imidazolium ILs (Chen et al., 2007; Sha et al., 2009). This molecular arrangement can form channels, where the spherical anions are accommodated as one-dimentional chains. This structural pattern also rests with the geometry of anion and the nature of the imidazolium residues.

Therefore, Dupont (Dupont, 2004) proposed that the best description for the imidazolium salts in the solid state is $\left[\mathrm{I}_{\mathrm{x}} \mathrm{X}_{\mathrm{x}-\mathrm{n}}\right]^{\mathrm{n}+}\left[\mathrm{I}_{\mathrm{x}-\mathrm{n}} \mathrm{X}_{\mathrm{x}}\right]^{\mathrm{n}^{-}}$, where I represents the imidazolium cation and $\mathrm{X}$ represents anion.

As for other ILs, such as tetrabutylammonium trifluoromethanesulfonate, who is short of hydrogen band, $\pi-\pi$ stacking interactions and $\mathrm{C}-\mathrm{H} \cdots \pi$ interactions, electrostatic interactions are important in the construction of the extended networks (Leclercq et al., 2008). Recently,

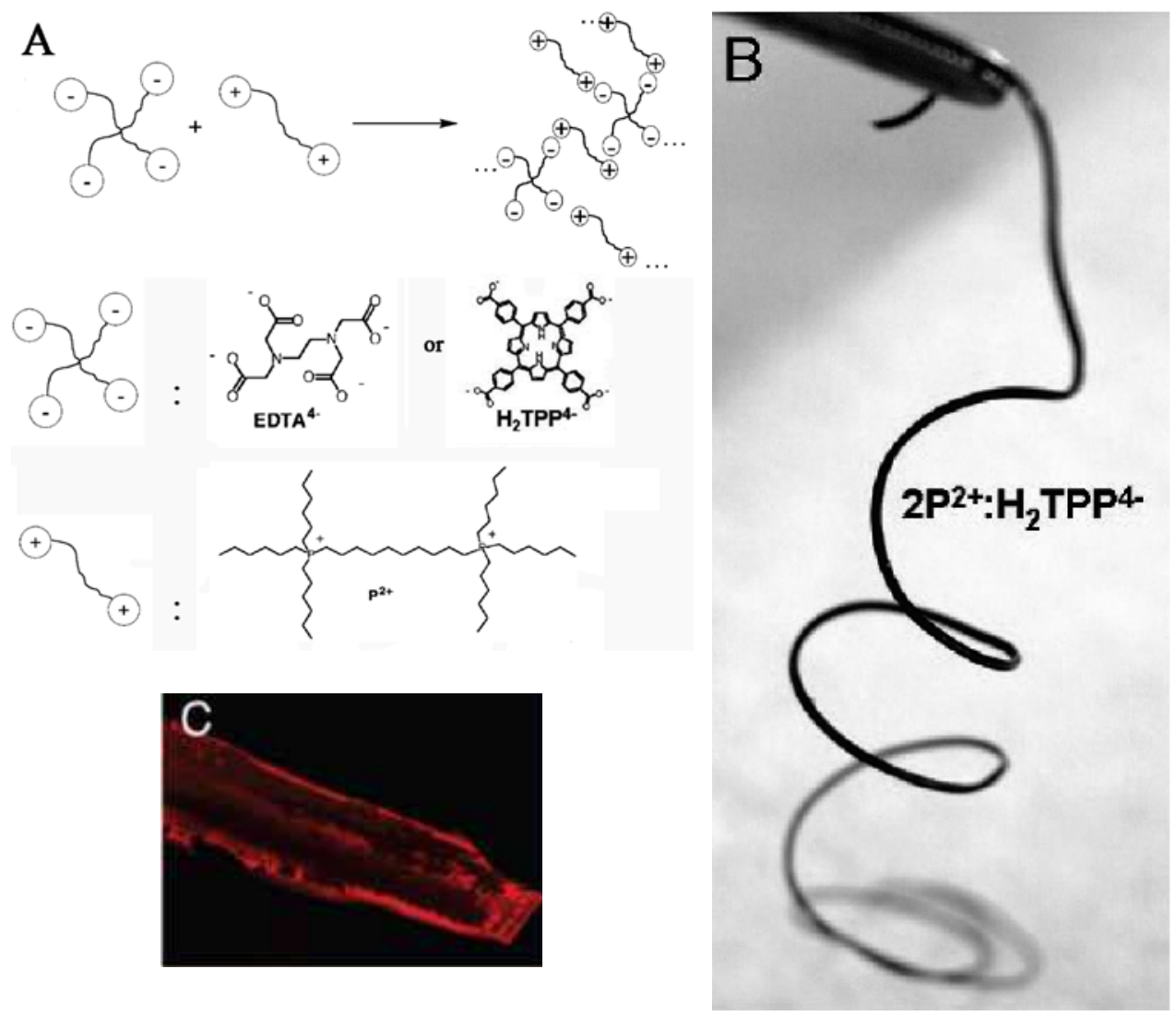

Fig. 15. (A) Schematic diagram of the formation of a supramolecular ionic network and the molecular structures of the corresponding units. (B) Photograph and (C) fluorescent micrograph $\left(\lambda_{\text {ex }}=514 \mathrm{~nm}\right)$ of an ionic network fiber prepared from $2 \mathrm{P}^{2+}: \mathrm{H}_{2} \mathrm{TPP}^{4-}$. Reprinted from Wathier \& Grinstaff (2008) and Craig (2009). 
Wathier and Grinstaff (Wathier \& Grinstaff, 2008) prepared an IL with ionic networks using a phosphonium dication $\left(\mathrm{P}^{2+}\right)$ and a tetraanion, ethylenediaminetetraacetate (EDTA $\left.{ }^{-}\right)$ (Figure 15A), which has a viscosity of about $1.2 \times 10^{4} \mathrm{~Pa} \cdot \mathrm{s}$. When EDTA ${ }^{-}$was replaced by para-tetracarboxy-5,10,15,20-tetraphenyl-21H,23H-porphine, $\mathrm{H}_{2} \mathrm{TPP}^{-}$(Figure 15A), an IL with a viscosity of ca. $10^{6} \mathrm{~Pa}$ s at $25^{\circ} \mathrm{C}$ was obtained. While the $2 \mathrm{P}^{2+}: \mathrm{H}_{2} \mathrm{TPP}^{4-}$ IL was heated to $160{ }^{\circ} \mathrm{C}$, a fiber could be hand-pulled from the liquid (Figure 15B). Within the fiber, the porphyrins retained their fluorescence properties (Figure 15C), thus suggesting the potential utility in sensors, etc. Furthermore, the above work suggests that ionic networks formed from effective noncoordinating ionic pairs, in particular those found in ILs, might provide an interesting, useful, and complementary strategy for the formation of supramolecular structures (Craig, 2009).

\subsubsection{Supramolecular structures in liquid phase}

When ILs are transformed from crystal to liquid state, the long-range order is lost, but longrange Coulomb interactions between cations and anions in ILs are maintained (Dupont, 2004; Leclercq \& Schmitzer, 2009a). This concept is supported by the results of IR (Dieter et al., 1988; Ozawa et al., 2003; Talaty et al., 2004), Raman (Katayanagi et al., 2004; Talaty et al., 2004), neutron diffraction analysis (Deetlefs et al., 2006; Hardacre et al., 2003), X-ray reflectivity experiment (Carmichael et al., 2001), small-angle X-ray diffraction analysis (Bradley et al., 2002) and large-angle X-ray scattering experiment (Kanzaki et al., 2009), indicating that 1,3-dialkylimidazolium ILs have analogous structural patterns in the solid and liquid phases. It is the long-range Coulomb interactions in ILs that can lead to longer spatial correlations than those in comparable classic van der Waals organic liquids (Cang et al., 2003). In other words, the supramolecular structures observed in crystal are reserved in liquid state (Dupont, 2004; Leclercq \& Schmitzer, 2009a). Although Fujii et al. (Fujii et al., $2008 \mathrm{~b}$ ) found that the liquid structure of $\left[\mathrm{C}_{2} \mathrm{mim}\right]\left[\mathrm{Tf}_{2} \mathrm{~N}\right] \mathrm{IL}$ is significantly different from its layered crystal structure, the ordered structure still exists, where the charge-charge interaction rather than the hydrogen bonding plays an essential role. Besides imidazolium ILs, other ILs (such as N-alkyl-N-methylpyrrolidinium ILs (Fujii et al., 2008a; Fukuda et al., 2008)) have also order structures in liquid state.

Several MD simulations (Lopes \& Padua, 2006; Urahata \& Ribeiro, 2004; Wang \& Voth, 2005), especially the work of Lopes and Padua (Lopes \& Padua, 2006), suggested the presence of polar domains that are formed by the head groups of the cations and anions, and of nonpolar domains that are formed by the alkyl groups in 1-alkyl-3methylimidazolium ILs $\left(\mathrm{C}_{\mathrm{n}} \geq \mathrm{C}_{4}\right)$. As the length of the alkyl chain increases, the nonpolar domains become larger and more connected, and cause swelling of the ionic network, in a manner analogous to microphase separation (Lopes \& Padua, 2006). Recently, the results of X-ray diffraction (XRD) experiment (Triolo et al., 2007), fluorescent spectra (Hu \& Margulis, 2006), Raman spectra (Iwata et al., 2007; Shigeto \& Hamaguchi, 2006), NMR (Mele et al., 2006), femtosecond solvation dynamics study (Adhikari et al., 2007) and optical Kerr Effect spectra (Xiao et al., 2007) of 1-alkyl-3-methylimidazolium ILs also suggested the presence of heterogeneous structures. Furthermore, the result of the XRD experiment also reflected that the size of the inhomogeneous structures is proportional to the length of the alkyl chain (Triolo et al., 2007). Thus, this suggests that the above-mentioned nanodomains are built up by the aggregation of neutral alkyl chains surrounded by charges, whose uniform spatial distribution is determined by the strong electrostatic interactions (Triolo et al., 2007). Thus, 
there will be a competition between the interactions of a given solute with those two regions (Blesic et al., 2009a). Rebelo et al. (Rebelo et al., 2007) suggested that a nonpolar solute (e.g., n-hexane) will interact preferentially with the nonpolar domains, while a dipolar or associative solutes (e.g., water) will interact with the polar domains. Therefore, this kind of heterogeneous structure of ILs will make the solubility and reactivity of solutes in ILs obviously different from those in the normal molecular solvents.

\subsubsection{Thermotropic liquid crystal phase of ionic liquids}

As for imidazolium ILs with long alkyl chains $\left(C_{n} \geq C_{12}\right)$, liquid crystal (LC) phase often appears in the course of increasing temperature (Bowlas et al., 1996; Bradley et al., 2002; De Roche et al., 2003; Getsis \& Mudring, 2008; Holbrey \& Seddon, 1999; Lee et al., 2000; Lee et al., 1997; Li et al., 2005b; Zhou \& Antonietti, 2004). If an anion has a long alkyl chain, the long alkyl chains on the imidazolium ring are not necessary for the formation of LC (Mukai et al., 2004). In addition, some metal complex anion, such as $\mathrm{PdCl}_{4}{ }^{-}$and $\mathrm{CuCl}_{4}{ }^{-}$, can be applied (Bowlas et al., 1996; Hardacre et al., 2001; Lee et al., 2004; Lin \& Vasam, 2005). Generally, the temperature range for LCs can be adjusted by altering counter anion and the length of alkyl chain.

Up to now, most of the found LC structures of imidazolium ILs are smectic A phase, consisting of interdigitated bilayers. This supramolecular structure can be considered as the result of the alternate assembling of ionic layers and van der Waals layers. In the former, the ionic head groups interact with the counterions through Coulomb force, while the latter build from (anti)parallel stacking of the alkyl chains through van der Waals force. Moreover, the

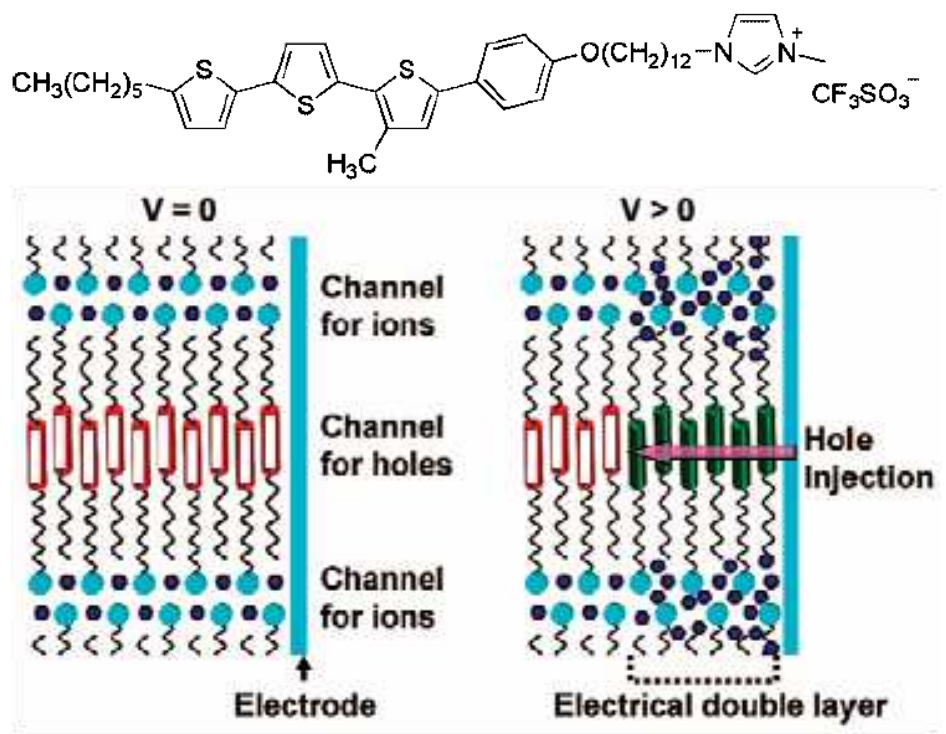

Fig. 16. Molecular structure of 1-methylimidazolium ILs containing phenylterthiophene moiety (up), and schematic image of a nanostructured liquid crystal consisting of ionic and $\pi$-conjugated moieties (bottom): blank cylinders are neutral phenylterthiophene moieties; dark cylinders are the oxidized ones; smaller spheres and larger plates are triflate anions and imidazolium moieties, respectively. Reprinted from Yazaki et al. (2008a). 
hydrogen bonds between the $\mathrm{H}$-atoms of imidazolium cations and anions are important in the formation and stabilization of ionic layers (Lee et al., 2000; Lee et al., 2004; Lee et al., 1997).

The functionalization of imidazolium is a useful method for the application of imidazolium ionic LCs. Recently, Kato and collaborators (Yazaki et al., 2008a) synthesized a new ILs with a 1-methylimidazolium group as an ion-conductive part and $\pi$-conjugated phenylterthiophene moiety related to the electronic charge transport (Figure 16). In its smectic A phase, the ionic and the $\pi$-conjugated moieties were nanosegregated, leading to the formation of twodimensional ion-conductive channels between hole transport layers (Figure 16) (Yazaki et al., 2008a). Consequently, the holes were injected from the anode and transported into the hole transport layers consisting of phenylterthiophene moieties (Figure 16), resulting in the oxidation of the $\pi$-conjugated moieties (Yazaki et al., 2008a). In experiment, the IL exhibited electrochromism in the LC state without a liquid electrolyte layer, unlike conventional redox-active conjugated polymers and liquid crystals (Yazaki et al., 2008a). This LC would be applied to various electronic devices such as light-emitting electrochemical cells as well as the electrochromic devices.

The structure of imidazolium ionic LCs is much simplex, which makes its application in many fields confined. In order to resolve this problem, much effective effort has been made (Goossens et al., 2008; Kumar \& Pal, 2005; Pal \& Kumar, 2006; Seo et al., 2007; Yasuda et al., 2010; Yazaki et al., 2008b; Yazaki et al., 2010; Yoshio et al., 2004; Yoshio et al., 2006; Yoshio et al., 2007; Yoshizawa et al., 2004; Zhang et al., 2008d), especially the work of Kato and collaborators (Yasuda et al., 2010; Yazaki et al., 2008b; Yazaki et al., 2010; Yoshio et al., 2004; Yoshio et al., 2006; Yoshio et al., 2007). They observed the appearance of a hexagonal columnar LC structure in 1-methylimidazolium ILs with tri-alkoxy substituted phenyl groups, a class of LC mesogers, attached to the nitrogen atom (Yoshio et al., 2004; Yoshio et al., 2006; Yoshio et al., 2007). Besides a wide temperature range of LC phase (Yoshio et al., 2004; Yoshio et al., 2006; Yoshio et al., 2007) and tunable feasible adjustment of LC properties by altering counter anions (Yoshio et al., 2007), the synthesized compounds in columnar LC state were highly anisotropic ion-conductive in one-dimension (Yoshio et al., 2004; Yoshio et al., 2006; Yoshio et al., 2007), which would be useful for transportation of ions, energy, and information at the nanometer level. Recently, Kato et al. (Yazaki et al., 2008b) prepared two new 1methylimidazolium-based ionic LCs, containing an L-glutamic acid moiety and bis(alkyloxy)phenyl groups (Figure 17). The ionic conductivities and LC structures of the obtained 1-methylimidazolium ILs could be conveniently adjusted by anions, which would potentially be used as an on-off switch of ions (Figure 17) (Yazaki et al., 2008b).
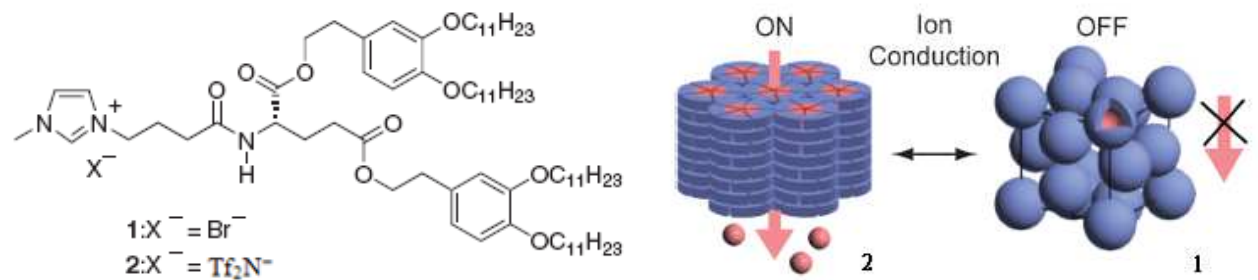

Fig. 17. Molecular structures of 1-methylimidazolium ILs containing an L-glutamic acid moiety and bis(alkyloxy)phenyl groups (left), and schematic illustration of an ideal on-off switch of ion conduction using the structural change from columnar to micellar cubic LC structures (right). Reprinted from Yazaki et al. (2008b). 
Besides imidazolium ionic LCs, other thermotropic ionic LCs based on pyridinium (Bowlas et al., 1996; Cruz et al., 2000; Cui et al., 2002; Gordon et al., 1998; Neve et al., 2000; Neve et al., 2001; Taubert, 2004), quaternary ammonium (Alami et al., 1993; Arkas et al., 1999; Lu et al., 1997; Pott \& Meleard, 2009; Tittarelli et al., 1997), quaternary phosphonium (Abdallah et al., 2000; Chen et al., 2002; Gowda et al., 2004), pyrrolidinium (Goossens et al., 2009), dithiolium (Artzner et al., 1997) and guanidinium ILs (Kim et al., 2005; Mathevet et al., 2005; Sauer et al., 2008) have also been explored. Two important phenomena should be especially noticed. Firstly, some of them have several kinds of liquid-crystalline structures. For example, with the change of alkyl chain length and counter anions, highly ordered smectic phases (the smectic E phase and the uncommon smectic T phase), smectic A phases, and hexagonal columnar phases were observed in the pyrrolidinium ILs (Goossens et al., 2009). Secondly, the behaviors of tri-alkyl-methyl-ammonium ionic LCs may be fine-tuned further to well defined hydrophobic thickness corresponding to uneven numbers of mean alkyl carbons, by the use of simple binary liquid mixtures (Pott \& Meleard, 2009).

\subsection{Inclusion phenomenon of guest compounds in the ionic liquid network}

As the above description, neat imidazolium ILs have supramolecular framework. Furthermore, up to now, much evidence indicated that some of the supramolecular networks can be reserved when ILs are mixed with other materials and inclusion-type structures are formed.

\subsubsection{Inclusion of water in ionic liquids}

Because ILs can absorbed significant amount of water from the atmosphere and trivial water is difficult to be removed, water becomes the most common impurity in ILs (Huddleston et al., 2001; Seddon et al., 2000; Takamuku et al., 2009). The existence of water in ILs may affect many of their physical and chemical properties, such as polarity, viscosity, conductivity, and reactivity as well as solvation and solubility properties (Brown et al., 2001; Cammarata et al., 2001; Najdanovic-Visak et al., 2003; Schroder et al., 2000; Widegren et al., 2005).

In order to explain the large differences in the effect of water on the diffusion coefficient for neutral and for ionic species in imidazolium IL media, Compton et al. (Schroder et al., 2000) postulated that "wet" ILs may not be regarded as homogeneous solvents, but have to be considered as "nano-structured" with polar and non-polar regions.

Through the research based on attenuated total reflectance IR spectroscopy, Cammarata et al. (Cammarata et al., 2001) considered that water molecules absorbed from the air by 1alkyl-3-methylimidazolium ILs are mostly in the "free" (not self-associated) state, most of which act as bridge between anions $\left(\mathrm{X}^{-}\right)$, such as $\mathrm{BF}_{4}^{-}$and $\mathrm{PF}_{6}^{-}$, via hydrogen bond of type $\mathrm{X}^{-} \cdots \mathrm{HOH} \cdots \mathrm{X}^{-}$. Later, Mele et al. (Mele et al., 2003) found that the $\mathrm{H}(2), \mathrm{H}(4)$ and $\mathrm{H}(5)$ within the imidazolium ring could interact with water molecules via hydrogen bond of type $\mathrm{C}-\mathrm{H} \cdots \mathrm{O}$ at very low water content by NMR spectroscopy through intermolecular nuclear Overhauser enhancements on $\left[\mathrm{C}_{4} \mathrm{mim}\right]\left[\mathrm{BF}_{4}\right]$ IL. Based on the MD simulations and NMR experiment, Mele et al. (Moreno et al., 2008) further indicated that the ions of $\left[\mathrm{C}_{4} \mathrm{mim}\right]\left[\mathrm{BF}_{4}\right]$ IL are selectively coordinated by individual water molecules, but the ionic network is largely unperturbed at low water content. Recently, Zhang et al. (Zhang et al., 2008c) found that water molecules tend to interact with the anion moiety of ILs first, via hydrogen bond, rather than with hydrogen atoms within the imidazolium, which is further confirmed by the most recent work of Takamuku et al. (Takamuku et al., 2009). It is also found that water is not homogenously mixed with $\left[\mathrm{C}_{2} \mathrm{mim}\right]\left[\mathrm{BF}_{4}\right]$ IL at low water content (Zhang et al., 2008c). 
In addition, no direct hydrogen bonds between cations and anions were observed in the crystal structure of [1,3-dibenzylimidazolium] $\mathrm{Br} \cdot \mathrm{H}_{2} \mathrm{O}$, but water molecules connected anions and cations in the supramolecular framework (Leclercq et al., 2009c). In other words, water molecules were included in the crystal lattice.

Thus, the existing states of water molecules in the liquid and crystal phases support the hypothesis of polar and non-polar regions of the supramolecular network. From another point of view, at low water content, the water could be regarded as guest included in the supramolecular framework of imidazolium ILs.

\subsubsection{Inclusion of aromatic compounds in ionic liquids}

After mixing of some imidazolium ILs with excess of aromatic hydrocarbons, biphasic mixtures are obtained. The lower layer is IL-rich phase, which exhibits the characteristics of typical liquid clathrates, i.e., low viscosity (relative to the initial neat ILs), immiscibility with excess aromatic solvents, and non-stoichiometric (but reproducible) compositions, while the concentration of IL is too low to be detected in the upper layer. Recently, it was found that the immiscibility gap became smaller when the polarity of substituted benzenes increased and their molecular size decreased (Shiflett \& Yokozeki, 2008; Shiflett et al., 2009; Shiflett \& Niehaus, 2010). However, when both dipole and quadrupole moments are present in an aromatic compound, they have an antagonistic effect, reducing the solubility in the IL (Shimizu et al., 2009). Up to now, such liquid clathrates or IL-biphases have been used in the fields of organic syntheses (Boxwell et al., 2002; Clavier et al., 2008; DeCastro et al., 2000; Surette et al., 1996), polymerization (Csihony et al., 2002), separations of aromatics from hydrocarbons (Arce et al., 2007; Selvan et al., 2000) and so on.

Holbrey et al. (Holbrey et al., 2003) obtained crystalline $\left[\mathrm{C}_{1} \mathrm{mim}\right]\left[\mathrm{PF}_{6}\right] \cdot 0.5 \mathrm{C}_{6} \mathrm{H}_{6}$ by cooling the lower phase of the $\left[\mathrm{C}_{1} \mathrm{mim}\right]\left[\mathrm{PF}_{6}\right]-\mathrm{C}_{6} \mathrm{H}_{6}$ system to room temperature. The crystal structure of the clathrate (Figure 18A) shows that there is a three-dimensional array of hydrogen-bonded cations and anions, a typical supramolecular structure for imidazolium ILs in solid state. This three-dimensional framework results in the formation of "channels" along the (001) direction of the crystal lattice in which benzene molecules are included by a staggered $\pi-\pi$ "sandwich" between two imidazolium cations. Later, Lachwa et al. (Lachwa et al., 2006) draw the similar conclusion from the crystal structure of $\left[\mathrm{C}_{2} \operatorname{mim}\right]\left[\mathrm{NTf}_{2}\right] \cdot \mathrm{C}_{6} \mathrm{H}_{6}$ (Figure 18B). However, the formed structure has to allow for a higher proportion of benzene molecules, forming a tube-like structure with a rectangular cross-section around the cations of ILs. The formation of clathrate phases could be regarded as an example of the organization of guest molecules in the pre-organised host network.

Deetlefs et al. (Deetlefs et al., 2005) further indicated that the addition of benzene to $\left[\mathrm{C}_{1} \mathrm{mim}\right]\left[\mathrm{PF}_{6}\right]$ leads to an expansion of the cation-cation contacts through the neutron diffraction study on the $\left[\mathrm{C}_{1} \mathrm{mim}\right]\left[\mathrm{PF}_{6}\right]-\mathrm{C}_{6} \mathrm{H}_{6}$ mixtures. Moreover, around the benzene molecule, alternating cation-anion layers are observed with the first-shell anions interacting with the ring hydrogens while the cations interact with the ring electrons. The incorporation of benzene is found to displace the anions with approximate three benzenes replacing each anion, suggesting benzene intercalation into the structure as found in the solid. Benzene is also found to be homogeneously distributed throughout the IL with no evidence of micellar formation.

With respect to the inclusion crystal $\left[\mathrm{C}_{2} \mathrm{mim}\right]\left[\mathrm{NTf}_{2}\right] \cdot \mathrm{C}_{6} \mathrm{H}_{6}$, through the MD study of its congruent melting, Alavi et al. (Kowsari et al., 2010) further found that the presence of a 

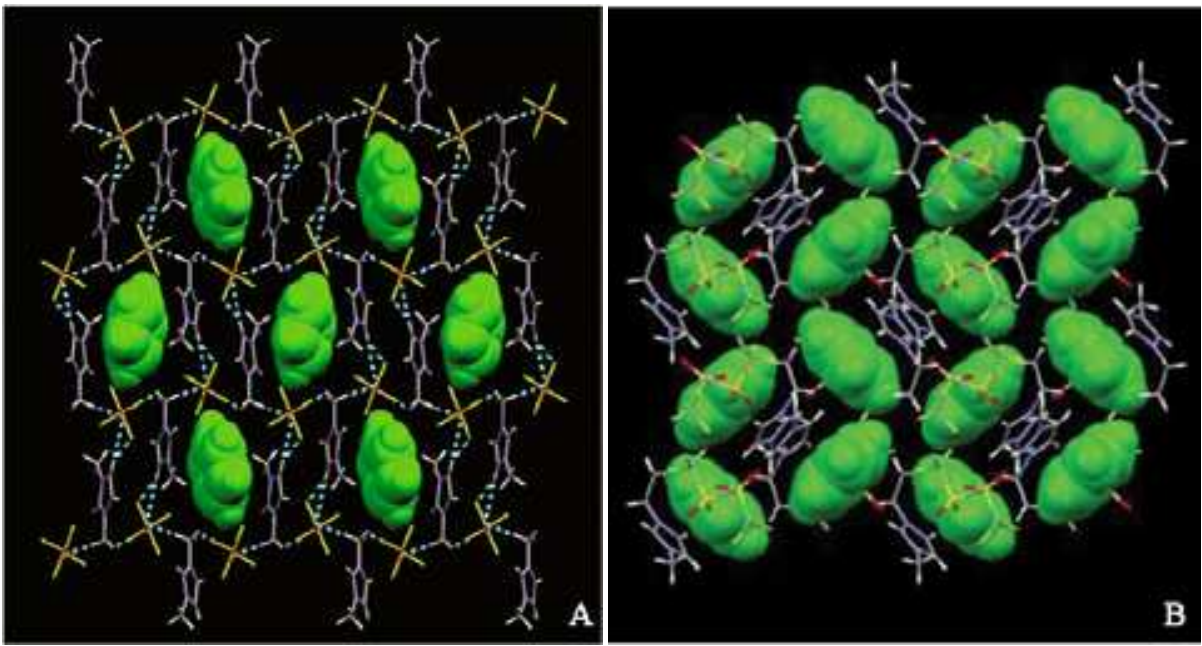

Fig. 18. Packing patterns in the crystal structures of $\left[\mathrm{C}_{1} \mathrm{mim}\right]\left[\mathrm{PF}_{6}\right] \cdot 0.5 \mathrm{C}_{6} \mathrm{H}_{6}(\mathrm{~A})$ and [ $\left.\mathrm{C}_{2} \mathrm{mim}\right]\left[\mathrm{NTf}_{2}\right] \cdot \mathrm{C}_{6} \mathrm{H}_{6}$ (B). Reprinted from Holbrey et al. (2003) and Lachwa et al. (2006).

stoichiometric number of benzene molecules does not affect the nearest neighbor ionic association between $\left[\mathrm{C}_{2} \mathrm{mim}\right]^{+}$and $\left[\mathrm{NTf}_{2}\right]^{-}$, but increases the mean-square displacements of both cations and anions compared to pure liquid $\left[\mathrm{C}_{2} \mathrm{mim}\right]\left[\mathrm{NTf}_{2}\right]$, showing that second shell ionic associations are weakened.

Besides imidazolium ILs, other ILs based on quaternary ammonium (Coleman et al., 1990; Pickett, 1985), pyridinium (Christie et al., 1991) and so forth (Gaudet et al., 1988) can also form liquid/solid clathrates with aromatic molecules, in which suitable anions are important.

\subsubsection{Co-crystals of ionic liquids}

It has been reported that imidazolium ILs are able to form co-crystals with quaternary ammonium ILs with same anions (Leclercq et al., 2007, 2008), e. g., [C 2 mim][TfO] with [tetrabutylammonium][TfO] ([Bu $4 \mathrm{~N}][\mathrm{TfO}]$ ) (Leclercq et al., 2008). The co-crystal structure of $\left[\mathrm{C}_{2} \mathrm{mim}\right][\mathrm{TfO}]$ and $\left[\mathrm{Bu}_{4} \mathrm{~N}\right][\mathrm{TfO}]$ (Figure 19) could be described as a supramolecular framework formed by $\mathrm{C}_{2} \mathrm{mim}^{+}$and $\mathrm{TfO}^{-}$through hydrogen bonding, in which all $\mathrm{Bu}_{4} \mathrm{~N}^{+}$are trapped (Leclercq et al., 2008). This phenomenon may be considered to be another example of the inclusion of guest molecules in the supramolecular host network.

Besides the above three kinds of molecules, gas molecules (such as $\mathrm{CO}_{2}$ ) (Costantini et al., 2005; Dupont, 2004; Gutowski \& Maginn, 2008; Huang et al., 2006; Weingartner, 2008) and (bio)macromolecules (Dupont, 2004; Feher et al., 2007; Leclercq \& Schmitzer, 2009a), even nanoparticles (Dupont, 2004; Leclercq \& Schmitzer, 2009a; Lee et al., 2009), may act as guests included in the supramolecular host framework of ILs.

\section{Effects of ionic liquids on the formation of supramolecular structures}

ILs can not only participate directly in the formation of supramolecular systems, but also influence the formation of various supramolecular structures. 


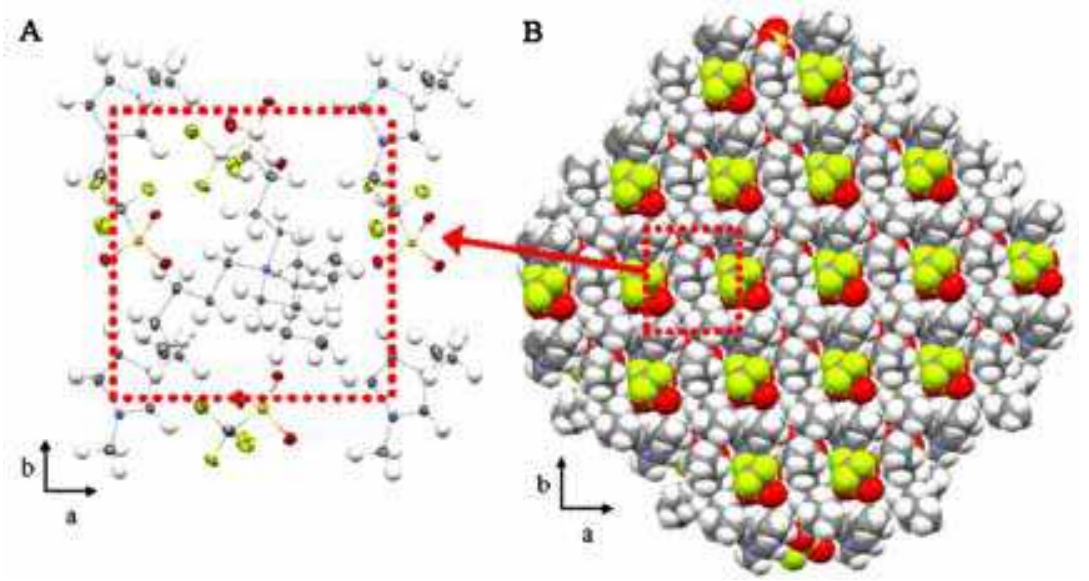

Fig. 19. (A) View of the local assembly around a tetrabutylammonium cation $\left(\mathrm{Bu}_{4} \mathrm{~N}^{+}\right)$and (B) space-filled view of the co-crystal of $\left[\mathrm{C}_{2} \mathrm{mim}\right][\mathrm{TfO}]$ and $\left[\mathrm{Bu}_{4} \mathrm{~N}\right][\mathrm{TfO}]$. Reprinted from Leclercq et al. (2008).

\subsection{Effects of ionic liquids on the formation of polyrotaxanes and polypseudorotaxanes}

Polyrotaxanes (PRs) and polypseudorotaxanes (PPRs) formed by CDs in the presence of ILs have been studied. Samitsu et al. (Samitsu et al., 2006) used ILs as new solvents for PR, consisting of a-CD and poly (ethylene glycol). They found that halogen-containing ILs, such as chlorides or bromides, were good solvents for PRs, regardless of their cations. This discovery was applied in the preparation of IL-containing slide-ring gels (SR gels), which are supramolecular networks of PR swollen with ILs, using a devised "non-drying" technique accompanied by solvent exchange. A kind of PPRs were prepared by supramolecular self-assembly of $\beta$-CDs threaded onto the triblock copolymers (Pluronic F127) in $\left[\mathrm{C}_{4} \mathrm{mim}\right]\left[\mathrm{PF}_{6}\right]$ with two different manners (Jing et al., 2007). It was found that not only the $\mathrm{PO}$ segments but also many EO segments are included by $\beta$-CD molecules in the PPRs. Interestingly, which one, $\mathrm{F} 127$ or $\left[\mathrm{C}_{4} \mathrm{mim}\right]\left[\mathrm{PF}_{6}\right]$, will finally be included inside $\beta-\mathrm{CD}$, can be controlled by ethanol amount around the initially $\beta-\mathrm{CD} /\left[\mathrm{C}_{4} \mathrm{mim}\right]\left[\mathrm{PF}_{6}\right] \mathrm{ICs}$. At higher ethanol concentration, F127 may squeeze $\left[\mathrm{C}_{4} \mathrm{mim}\right]\left[\mathrm{PF}_{6}\right]$ molecules out from $\beta-\mathrm{CD}$ and thread themselves instead into the cavity of $\beta-\mathrm{CD}$ and finally precipitate with more CDs being stacked (Figure 20).

\subsection{Effects of ionic liquids on the formation of the supramolecular structures in the extraction systems based on crown ethers}

No significant close contacts are observed between ILs and crown ethers based on the study of co-crystallisation of imidazolium based salts with 18-crown-6 (18C6), though coulomb interactions between the ionic (liquid) components and hydrogen bonding are important (Gjikaj et al., 2008). However, because of the influence of ILs to the system of crown ethers, they are being used in the extraction of metal ions, amino acid and so on.

For the first time, Dai et al. (Dai et al., 1999) used the system dicyclohexano-18-crown-6 (DCH18C6) $-\left[\mathrm{R}_{1} \mathrm{R}_{2} \mathrm{mim}\right]\left[\mathrm{NTf}_{2}\right] /\left[\mathrm{PF}_{6}\right]$ to extract $\mathrm{Sr}^{2+}$, obtaining the distribution coefficient as 


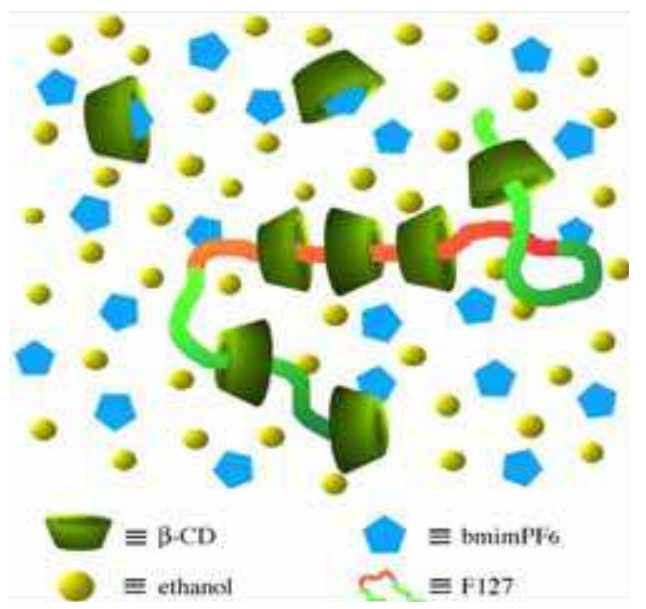

Fig. 20. Schematic representation of the inclusion choice between $\mathrm{F} 127$ and $\left[\mathrm{C}_{4} \mathrm{mim}\right]\left[\mathrm{PF}_{6}\right]$. Reprinted from Jing et al. (2007).

high as $10^{4}$. The extraction process can be easily tailored by varying the substituting groups in the imidazolium cation and the counter anions. In succession, more and more systems involved ILs and crown ethers were investigated (Chun et al., 2001; Langmaier et al., 2009; Nockemann et al., 2007; Okamura et al., 2010; Stepinski et al., 2010; Visser et al., 2000; Xu et al., 2009). These results discovered that as the alkyl group in the ILs was elongated, the extraction efficiency decreased, but the extraction selectivity increased. The distribution is not only related to the concentration and the hydrophobicity of crown ethers, but also to the composition of the aqueous phase. To increase the extraction efficiency of metal ions, the additives, such as TBP, were added into the system due to the formation of a synergistic adduct (Stepinski et al., 2005). The magnitude of the synergistic enhancement is shown to depend on the alkyl chain length of the ILs $\left[\mathrm{C}_{n} \operatorname{mim}\right]\left[\mathrm{Tf}_{2} \mathrm{~N}\right]$ cation, with the effect diminishing as the cation hydrophobicity increases until for $\left[\mathrm{C}_{10} \mathrm{mim}\right]\left[\mathrm{Tf}_{2} \mathrm{~N}\right]$.

The traditional crown ether, for example DCH18C6, can extract metal ions efficiently. However, metal ions are not easy to be stripped. In order to overcome this disadvantage, a series of $N$-alkyl aza-18-crown-6 ethers were synthesized (Luo et al., 2004a). These crown ethers in ILs were investigated as recyclable extractants for separation of $\mathrm{Sr}^{2+}$ and $\mathrm{Cs}^{+}$from aqueous solutions. They discovered a strong dependence of selectivity on the type of ILs. Recently, Shimojo et al. (Shimojo et al., 2009) reported the first study on the "intramolecular" synergistic extraction of a metal ion in an IL-based system. $\mathrm{Sr}^{2+}$ was extracted by a novel extractant $\beta$-diketone-substituted diaza-18-crown-6 (H2ßDA18C6). By compared with 1phenyl-3-methyl-4-benzoyl-5-pyrazolone (HPMBP) and N,N'-dibenzyl-4,13-diaza-18-crown6 (DBzDA18C6), they found that H2ßDA18C6 provides a remarkably high performance for $\mathrm{Sr}^{2+}$ extraction into $\left[\mathrm{C}_{2} \mathrm{mim}\right]\left[\mathrm{Tf}_{2} \mathrm{~N}\right]$ due to a cooperative "intramolecular" interaction when compared with the "intermolecular" synergy extraction system of the mixture of HPMBP and DBzDA18C6. The two protons from protonated H2ßDA18C6 were released to extract $\mathrm{Sr}^{2+}$, the transfer of $\mathrm{Sr}^{2+}$ into $\left[\mathrm{C}_{2} \mathrm{mim}\right]\left[\mathrm{Tf}_{2} \mathrm{~N}\right]$ proceeds via the proton exchange reaction.

Because ILs are usually used in the separation of radioactive nuclides and the radiation effect on ILs for the extraction of metal ions is important. The influence of $\gamma$-radiation on the IL $\left[\mathrm{C}_{4} \mathrm{mim}\right]\left[\mathrm{PF}_{6}\right]$ and $\left[\mathrm{C}_{4} \mathrm{mim}\right]\left[\mathrm{Tf}_{2} \mathrm{~N}\right]$ during extraction of $\mathrm{Sr}^{2+}$ by DCH18C6 was studied 
(Yuan et al., 2008, 2009). The irradiation of IL influences greatly on this system. The $\mathrm{Sr}^{2+}$ partitioning in irradiated $\left[\mathrm{C}_{4} \mathrm{mim}\right]\left[\mathrm{PF}_{6}\right]$ decreases as the absorption dose increases. This is the result of the formation of acid during the irradiation of $\left[\mathrm{C}_{4} \mathrm{mim}\right]\left[\mathrm{PF}_{6}\right]$. Due to the competition between $\mathrm{H}^{+}$and $\mathrm{Sr}^{2+}$, the extraction efficiency decreased and can be recovered by simple washing the irradiated $\left[\mathrm{C}_{4} \mathrm{mim}\right]\left[\mathrm{PF}_{6}\right]$ with water.

Besides, stability constants of metal ion complexes with crown ethers in IL aqueous solutions were obtained (Popov et al., 2007) and the solubilization of the ILs [ $\left.\mathrm{C}_{\mathrm{n}} \mathrm{mim}\right]\left[\mathrm{Tf}_{2} \mathrm{~N}\right]$ by the presence of crown ether was studied (Rickert et al., 2007). It is also reported that the stability of cesium complexed with 18C6 in ILs is affected by the nature of both cation and anion of ILs (Vendilo et al., 2009; Vendilo et al., 2010b). Moreover, the complex stability is important for the extraction process (Vendilo et al., 2010a).

In the conventional organic solvents extractions, limited solubility of ionic species in nonionic organic solvents is the main problem and the toxicity of free crown ethers makes them unsuitable for industrial use. Task Specific ILs (Bates et al., 2002; Visser et al., 2001) (TSILs) contain specific functionality covalently incorporated within one of the ionic components of the IL, typically within the cation. Therefore, the "crowned" IL-crown ether as a functional group to functionalized IL was performed for a liquid/liquid extraction of metal ions (Park et al., 2006) and molecular-recognition ability (Ishida et al., 2004; Liu et al., 2005). The "crowned" ILs obtain their selectivity through their ability to fine-tune and reorganize their crown ether structure changing their number and type of donor atoms, appending ionizable groups, and modifying their lipophilicity. Ishida et al. (Ishida et al., 2004) designed and synthesized novel imidazolium-based ILs with a pseudo crown-ether moiety. The oxygen lone pairs had a potential as Lewis-basic and/or hydrogen-accepting functionality. Owing to the molecular-recognition ability, the enantiometic imidazolium cations could differently sense the chirality of the europium complexes. A series of novel ILs comprising crown-ether functionalities in cations or anions (crowned ILs) were prepared and characterized (Liu et al., 2005).The physical properties of different functionalized ILs were different, for example the thermal decomposition temperatures ( $\mathrm{T}_{\mathrm{dec}}$ ) of the ILs containing crowned cations are generally $80-100{ }^{\circ} \mathrm{C}$ higher than those of the ILs having crowned anions. The ILs functionalized by the crown ether may display potential utility in catalytic application as well as in separation and electrochemical sensing. Luo et al. (Luo et al., 2006) synthesized a new class of TSILs based on the covalent attachment of imidazolium cations to a monoaza-crown ether fragment. These TSILs exhibited lower extraction efficiency than the IL extraction systems using DCH18C6 or N-octylaza-18-crown-6 as extractant. This can be attributed to the coulombic repulsion from the covalently attached imidazolium cation. The selectivity of these TSILs is dependent on the structure of substituents on the imidazolium ring.

The mechanism of ILs-crown ethers system for metal ions extraction has been studied extensively. There are several kinds of mechanisms: cation exchange (Dai et al., 1999; Dietz \& Dzielawa, 2001; Dietz et al., 2003; Hirayama et al., 2008; Park et al., 2006; Popov et al., 2007), anion exchange (Jensen et al., 2003), mechanism of multiple distribution (Dietz \& Stepinski, 2005). By changing the ILs, the hydrophobicity of the IL cation increase (from $n=5$ to $\mathrm{n}=10$ in $\left[\mathrm{C}_{\mathrm{n}} \operatorname{mim}\right]\left[\mathrm{Tf}_{2} \mathrm{~N}\right]$ ), the predominant mode of partitioning changes from ionexchange involving the cationic portion of the IL to conventional neutral nitrato complex extraction (Dietz et al., 2003). The stereochemistry of crown ethers can also affect the mechanism. Dietz et al. (Dietz et al., 2008) studied the DCH18C6 stereochemistry influence the mode of sodium ion transfer from acidic nitrate media into ILs. DCH18C6 have five 
isomers, i.e., cis-syn-cis (csc), cis-anti-cis (cac), trans-syn-trans (tst), trans-anti-trans (tat) and cis-trans (ct) (Figure 21). For the cis isomers, rising nitric acid concentration is eventually accompanied by steeply falling values of the sodium distribution ratio. This was originated the crown ether-mediated exchange of a sodium ion for a hydronium ion in a DCH18C6$\mathrm{H}_{3} \mathrm{O}^{+}$adduct. In contrast, for the trans isomers, rising aqueous acidity is accompanied by increasing sodium extraction, consistent with partitioning of a neutral sodium nitrato-crown ether complex. A change from a cis to a trans isomer of DCH18C6 alters the predominant mode of sodium ion portioning into $\left[\mathrm{C}_{10} \mathrm{mim}\right]\left[\mathrm{Tf}_{2} \mathrm{~N}\right]$ from ion-exchange to neutral complex extraction. As a result, the process of extracting can be controlled by the isomers of extractants.

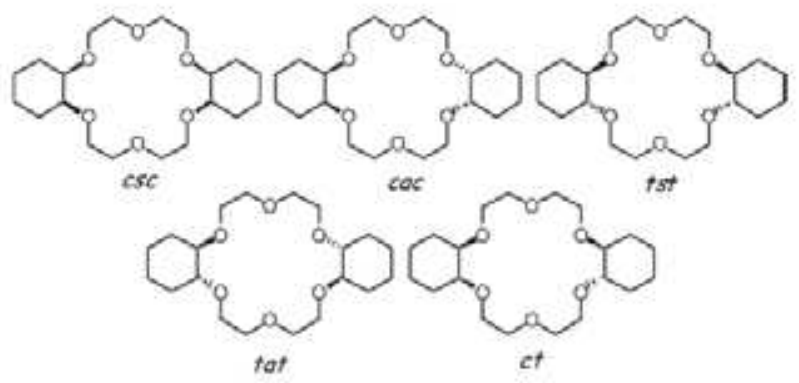

Fig. 21. Molecular structures of the cis-syn-cis (csc), cis-anti-cis (cac), trans-syntrans (tst), trans-anti-trans (tat), and cis-trans (ct) isomers of DCH18C6. Reprinted from Dietz et al. (2008).

ILs and crown ethers used in biochemistry have also been a field of increasing interest and importance (Kragl et al., 2002; van Rantwijk et al., 2003). Amino acids are hydrophilic and therefore difficult compounds for conventional solvent extraction. Amino acids were not soluble in IL, however, by adding a crown ether to the IL phase, the positive form of amino acids is complexed by the crown ether and the complex is extracted in the IL phase (CardaBroch et al., 2003). Amino acids Trp, Gly, Ala, Leu were efficiently extracted from aqueous solution as $\mathrm{pH}$ 1.5-4.0 (Lys and Arg at $\mathrm{pH}$ 1.5-5.5) into $\left[\mathrm{C}_{4} \mathrm{mim}\right]\left[\mathrm{PF}_{6}\right]$ with DCH18C6 (Smirnova et al., 2004). The most hydrophilic amino acids such as Gly were extracted as efficiently as the less hydrophilic ones. Compared to the conventional organic solvents, ILs enabled quantitative recovery of amino acids and eliminated emulsion formation, which usually occurs when cationic or anionic extractants are used.

Shimojo et al. (Shimojo et al., 2006a; Shimojo et al., 2006b) investigated a hydroxyl-groupcontaining IL with DCH18C6 was capable of quantitative partitioning of heme protein cytochrome c (Cyt-c) via supramolecular complexation and that the resulting Cyt-cDCH18C6 complex acts as a homogeneous biocatalyst in ILs. While using conventional organic solvents the protein transfer was negligibly small. The partitioning of a protein into ILs is controllable on the basis of hydrophobicity and type of the functional groups of ILs. This is the first report showing protein extraction into ILs.

Extractants comprised calixarene part in IL systems were also investigated (Shimojo \& Goto, 2004a; Sieffert \& Wipff, 2007). Shimojo et al. (Shimojo \& Goto, 2004b) studied the extraction of metal ions by a calix[4]arene-bearing pyridine in a typical IL, [C 8 mim] $\left[\mathrm{PF}_{6}\right]$. Pyridinocalix[4]arene showed a high extraction ability and selectivity for $\mathrm{Ag}^{+}$in five different metal ions $\left(\mathrm{Ag}^{+}, \mathrm{Cu}^{2+}, \mathrm{Zn}^{2+}, \mathrm{Co}^{2+}\right.$ and $\left.\mathrm{Ni}^{2+}\right)$. This compound transfers $\mathrm{Ag}^{+}$into IL 
phases via a cation-exchange mechanism and form a stable 1:1 complex with $\mathrm{Ag}^{+}$. Recently, calixarene comprising crown ethers have been extensively studied in the IL-extraction system (Chen \& Hussey, 2005; Chen, 2007; Luo et al., 2007; Rogers et al., 2004; Tsuda et al., 2006). Luo et al. (Luo et al., 2004b) extracted $\mathrm{Cs}^{2+}$ into $\left[\mathrm{C}_{\mathrm{n}} \operatorname{mim}\right]\left[\mathrm{Tf}_{2} \mathrm{~N}\right]$ using calix[4]arenebis(tert-octylbenzo-crown-6) (BOBCalixC6) as an extractant by an ion-exchange mechanism. The shorter alkyl chain of the ILs, the less solubilities of BOBCalixC6 in the corresponding ILs and the higher distribution coefficients because the less hydrophobic imidazolium cations have higher ion-exchange capability. The addition of $\mathrm{NaBPh}_{4}$, a sacrificial cation exchanger, can decrease the loss of ILs by $24 \%$, as a result, ion exchange take a partial role. MD study of the interfacial behavior in the $\mathrm{Cs}^{+}$and $\mathrm{Na}^{+}$extraction by a calix[4]arene-crown6 host (L) into ILs $\left[\mathrm{C}_{4} \mathrm{mim}\right]\left[\mathrm{Tf}_{2} \mathrm{~N}\right]$ and $\left[\mathrm{C}_{4} \mathrm{mim}\right]\left[\mathrm{PF}_{6}\right]$ demonstrated the IL forms a biphasic system with water (Sieffert \& Wipff, 2006a, b). Compared with the classical molecular solvent (chloroform), much longer times are needed to "equilibrate" IL systems. There is more intersolvent mixing with the IL than with chloroform especially the water-in-oil content. In the aqueous phase, there is some excess of $\mathrm{C}_{4} \mathrm{mim}{ }^{+}$over $\mathrm{Tf}_{2} \mathrm{~N}^{-}$. The $\mathrm{LCs}^{+}$ complex and L ligand behave differently and they are better solvated by the IL than by chloroform. They are adsorbed at the chloroform interface and adopt well-defined amphiphilic orientations. At the IL interface, they are poorly attracted. The comparison of $\left[\mathrm{C}_{4} \mathrm{mim}\right]\left[\mathrm{Tf}_{2} \mathrm{~N}\right]$ and $\left[\mathrm{C}_{4} \mathrm{mim}\right]\left[\mathrm{PF}_{6}\right]$ of the dry versus humid form of the latter one. They discovered that the importance of humidity. In the $\left[\mathrm{C}_{4} \mathrm{mim}\right]\left[\mathrm{PF}_{6}\right]-$ dry as in the $\left[\mathrm{C}_{4} \mathrm{mim}\right]\left[\mathrm{Tf}_{2} \mathrm{~N}\right]$ liquid, the first salvation shell of the "naked" $\mathrm{M}^{+}$ions is composed of solvent anions only, while in the $\left[\mathrm{C}_{4} \mathrm{mim}\right]\left[\mathrm{PF}_{6}\right]$-humid IL, it comprises from one to three solvent anions and about four $\mathrm{H}_{2} \mathrm{O}$ molecules. In the $\mathrm{LM}^{+}$complexes, the cation is shielded from solvent but still somewhat interacts with a solvent anion in the dry ILs and with water in the humid IL. These results provide a number of arguments explaining the specificity and efficiency of IL based extraction systems. Very recently, $\mathrm{Xu}$ et al. found that the bis(2propyloxy)calix[4]crown-6 (BPC6)/[ $\left.\mathrm{C}_{n} \mathrm{mim}\right]\left[\mathrm{Tf}_{2} \mathrm{~N}\right]$ system was highly efficient to remove $\mathrm{Cs}^{+}$from aqueous solution. A dual extraction mechanism, exchange of BPC6-Cs ${ }^{+}$complex and $\mathrm{Cs}^{+}$by $\mathrm{C}_{\mathrm{n}} \mathrm{mim}^{+}$was mentioned (shown in Figure 22) (Xu et al., 2010).

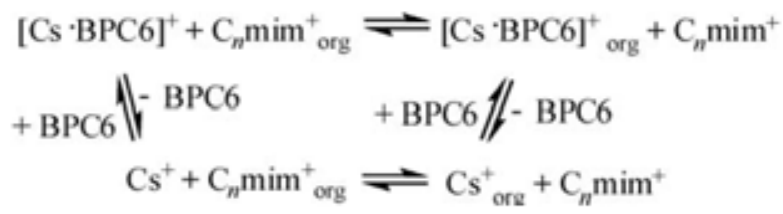

Fig. 22. A dual extraction mechanism for extraction $\mathrm{Cs}^{+}$by the BPC6/[C $\left.\mathrm{C}_{\mathrm{n}} \mathrm{mim}\right]\left[\mathrm{Tf}_{2} \mathrm{~N}\right]$ system. Reprinted from Xu et al. (2010).

\subsection{Effects of ionic liquids on other supermolecules}

The primary role of IL is to maintain good solvent conditions over a very wide temperature range for supramolecular ion gel (Mohmeyer et al., 2006; Noro et al., 2008, 2009). Supramolecular gelation in IL could be used in many fields, such as actuators, polymer electrolytes, membranes, or gate dielectrics for organic transistors. The structures and characteristics of nanohybrids or nanocomposites or self-organized nanotubes can be changed by the assistant of ILs (Gopalan et al., 2009; Li et al., 2009a; Paramasivam et al., 2008; Park et al., 2009b; Wu et al., 2009a). There are two aspects about effects of ILs on these supermolecules, 
which influence the system individually or jointly. One is that ILs affect the supermolecules because of the anions and cations of ILs and aromatic structures, which can result in electrostatic interactions, cation- $\Pi$ and/or $\pi-\pi$ stacking interactions (Gopalan et al., 2009; Li et al., 2009a; Park et al., 2009a; Park et al., 2009b; Wu et al., 2009a; Zhang et al., 2009). The other is that self-assemby of ILs influence the supermolecules (Gutel et al., 2007; Ma et al., 2009; Xu et al., 2009). The sensitivity of molecularly imprinted polymers (MIPs) can be improved by ILmediated method (Booker et al., 2006; He et al., 2008a; Wang et al., 2006; Wang et al., 2009). ILs are also used to synthesize other supramolecular host compounds (Scott et al., 2000) and can form different supramolecular networks from other solvents (Pedireddi et al., 2005).

\subsection{Effects of ionic liquids on the formation of supramolecular assemblies}

As mentioned above, ILs participated in the formation of micelles, microemulsions, liquid crystals and vesicles. In addition, IL also influenced the formation of the supramolecular assemblies as solvents and co-solvents.

The micelle formation of surfactants, such as SDS and Brij-35 in ILs ([C $\left.\mathrm{C}_{4} \mathrm{mim}\right] \mathrm{Cl}$ and $\left[\mathrm{C}_{4} \mathrm{mim}\right]\left[\mathrm{PF}_{6}\right]$ ) was first studied by Armstrong and his coworkers (Anderson et al., 2003). The micelle formation is caused by the solvophobic interactions between the hydrocarbon chains of the surfactant molecules just like hydrophobic interactions in aqueous medium. Relative studies on the aggregation of nonionic surfactants in ILs have been reported (Evans et al., 1982; Evans et al., 1983b; Fletcher \& Pandey, 2004; Gao et al., 2009b; Li et al., 2008b; Patrascu et al., 2006; Wu et al., 2008). Masahiro et al. (Moniruzzaman et al., 2008) reported the formation of reverse micelles in $\left[\mathrm{C}_{8} \mathrm{mim}\right]\left[\mathrm{Tf}_{2} \mathrm{~N}\right]$ comprising sodium bis(2-ethyl-1-hexyl) sulfosuccinate (AOT) as surfactant with 1-hexanol as a cosurfactant. This formation of aqueous droplets in the IL is attributed to the hydrophobic effects between the AOT tails and the long hydrocarbon chain of IL and the strong tendency of the AOT head group to interact with water. In addition, amphiphilic Pluronic polymers were found to be able to form well defined micelles in IL, the micellization was found to be entropy driving (He et al., 2006; Inoue \& Misono, 2008; Ueki et al., 2009; Zhang et al., 2008e).

ILs have also been found to influence the formation of micelles as co-surfactant. Behera et al. (Behera et al., 2007a; Behera et al., 2007b) reported that $\left[\mathrm{C}_{4} \mathrm{mim}\right]\left[\mathrm{PF}_{6}\right]$ and $\left[\mathrm{C}_{4} \mathrm{mim}\right]\left[\mathrm{BF}_{4}\right]$ participated in the TX-100 micellar phases. It was found that the addition of $30 \mathrm{wt} \%$ $\left[\mathrm{C}_{4} \mathrm{mim}\right]\left[\mathrm{BF}_{4}\right]$ resulted in decreased micellar size, increased $\mathrm{cmc}$, and decreased $N_{\text {agg, }}$ all of which were unchanged in aqueous $\left[\mathrm{C}_{4} \mathrm{mim}\right]\left[\mathrm{PF}_{6}\right]-\mathrm{TX}-100$ systems because of the low solubility of $\left[\mathrm{C}_{4} \mathrm{mim}\right]\left[\mathrm{PF}_{6}\right]$. These observations implied an overall unfavorable micellization process when the IL was present. Later, the concentration-dependent dual role of the ILs in altering physicochemical properties of ionic surfactant (SDS, CTAB) was demonstrated (Behera \& Pandey, 2007a, b; Beyaz et al., 2004; Lei et al., 2007; Modaressi et al., 2007a; Sifaoui et al., 2007). It is found that ILs acted as a metal salt at low concentrations and participated in the micellar phase with increasing $\left[\mathrm{C}_{4} \mathrm{mim}\right]\left[\mathrm{PF}_{6}\right]$ which led to a considerable decrease in the microfluidity of SDS micelles (Behera \& Pandey, 2007a, b). ILs also influence the aggregation behavior of Pluronic polymers (Dey et al., 2009; Zheng et al., 2007). Zheng et al. (Zheng et al., 2007) studied the effect of $\left[\mathrm{C}_{4} \mathrm{mim}\right] \mathrm{Br}$ on the aggregation behavior of PEOPPO-PEO P104 aqueous solution. It suggested that when the concentration of $\left[\mathrm{C}_{4} \mathrm{mim}\right] \mathrm{Br}$ was below $1.232 \mathrm{~mol} / \mathrm{L}$, there were P104 micelles in the aqueous solution with $\left[\mathrm{C}_{4} \mathrm{mim}\right] \mathrm{Br}$ embedding to the micellar core, while above this concentration, P104 micelles and $\left[\mathrm{C}_{4} \mathrm{mim}\right] \mathrm{Br}$ clusters coexisted in the system (Figure 23). 


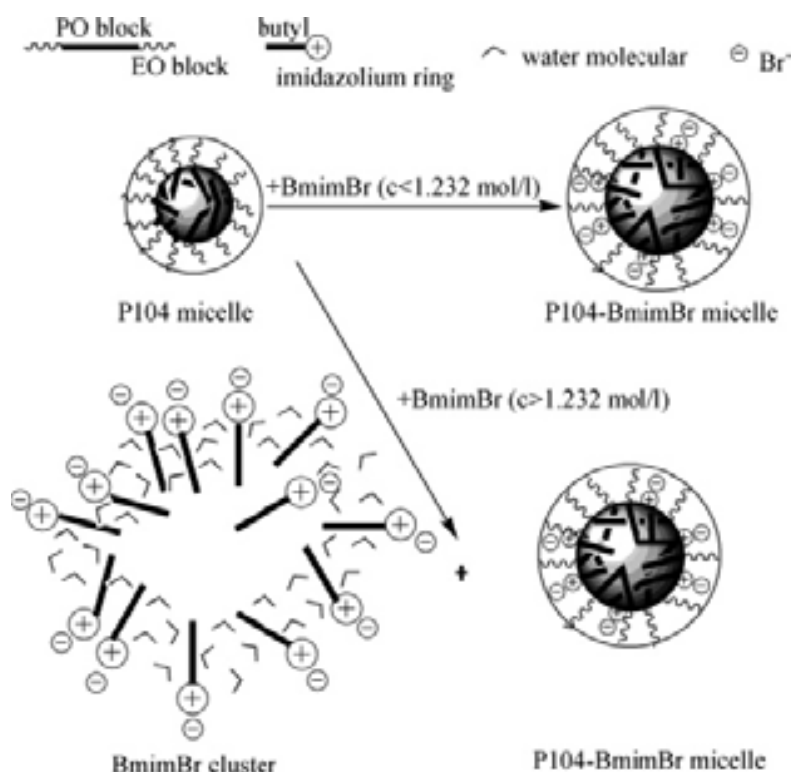

Fig. 23. Schematic illustration of the different types of complexes formed when $\left[\mathrm{C}_{4} \mathrm{mim}\right] \mathrm{Br}$ was added to 5\% Pluronic P104 aqueous solution. Reprinted from Zheng et al. (2007).

The formation of liquid crystal in ILs was firstly reported by Evans and co-workers (Evans et al., 1983a) in 1983, which was formed by $\beta_{.} \gamma$-distearoylphosphotidylcholine (DSPC) in EAN. Since then, many studies on the formation of liquid crystals in ILs are reported (Araos \& Warr, 2005; Atkin \& Warr, 2007; Greaves et al., 2007a, b; Tamuralis et al., 1987; Wang et al., 2004; Zhang et al., 2008a; Zhao et al., 2009b). Nonionic surfactants, $C_{n} E_{m}$, formed lyotropic liquid crystals in EAN and it was found that longer alkyl chains were necessary to drive the formation of liquid crystalline, suggesting that a rich pattern of "solvophobic" selfassembly (Araos \& Warr, 2005; Atkin \& Warr, 2007). The aggregation behavior of $\left[\mathrm{C}_{16} \mathrm{mim}\right] \mathrm{Cl}$ in EAN was also investigated and an additional $\mathrm{V}_{2}$ (reverse bicontinuous cubic) phase was identified when comparing such a phase behavior with that of the $\left[\mathrm{C}_{16} \mathrm{mim}\right] \mathrm{Cl} / \mathrm{H}_{2} \mathrm{O}$ binary system (Zhao et al., 2009b). Zhang et al. (Zhang et al., 2008a) reported the aggregation of Pluronic P123 in EAN, which was similar to those observed in $\mathrm{H}_{2} \mathrm{O}$ or $\left[\mathrm{C}_{4} \mathrm{mim}\right]\left[\mathrm{PF}_{6}\right]$ systems. They attributed the additional $\mathrm{V}_{2}$ phase in the P123-EAN system to the higher affinity for the hydrophobic PPO blocks to EAN than to water, which might reduce the effective area of the solvophilic headgroup and increase the volume of the solvophobic part.

\section{Conclusions}

In conclusion, ILs can act as guests to form supermolecules with several kinds of host molecules (i.e., cyclodextrins, cucurbit[n]urils and calixarenes), and can participate the constructing of supramolecular assemblies (i.e., micelles, microemulsions, lyotropic LCs, vesicles and gels). Besides, ILs can affect the formation of supramolecular structures, for example, the formation of polyrotaxanes and polypseudorotaxanes, the formation of the supramolecular structures in the extraction systems based on crown ethers, and so on. It is 
also noticed that imidazolium ILs have a three-dimensional supramolecular network with polar and non-polar regions, which can be used as powerful supramolecular receptors. However, the host-guest interaction usually takes place in aqueous solution. In ILs, how do the host molecules interact with guest molecules, and how do ILs affect the interaction? These are two interesting and challenging subjects.

In addition, when ILs are used as solvents, how will the supramolecular structures of ILs themselves affect the formation of supramolecular assemblies. For example, when the surfactant is added into the IL/oil mixture, two cases would happen. If the hydrophobic interactions between oil and surfactant are stronger than the interactions between IL and oils, liquid clathrate can be destroyed and O/IL microemulsions form. Otherwise, a new state would exist instead of O/IL microemulsions. However, in the reference, this field has not been mentioned. Moreover, because trivial water is difficult to be removed and could be included in the supramolecular framework of imidazolium ILs, ILs are not pure, which makes the system more complicated. This supramolecular structure may also affect the formation of supramolecular assemblies. Recently, we noticed that water plays the key role in the formation of IL based microemulsions. A small quantity of water can lead to great change in the phase diagram of IL/TX-100/oil ternary systems. Therefore, the effect of the supramolecular structures of ILs on the formation of supramolecular assemblies is another valuable subject.

Now, these fields of ILs are just beginning to be noticed. With the development of the exploration in these fields, more and more interesting phenomena and important results will be obtained. Thus, the investigation of ILs will encounter a new chance and challenge.

\section{Acknowledgements}

This work was supported by the National Natural Science Foundation of China (Grant No. 90206020 and 20871009).

\section{Abbreviations}

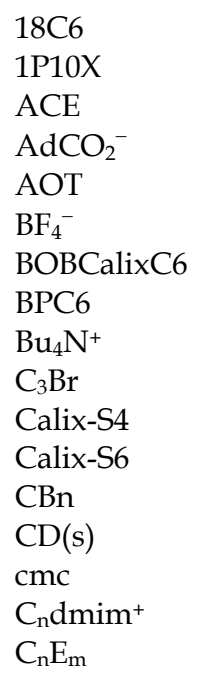

18-crown-6 tri-n-decylmethylphosphonium chloride and bromide affinity capillary electrophoresis adamantylcarboxylate anion sodium bis(2-ethyl-1-hexyl) sulfosuccinate tetrafluoroborate anion calix[4]arene-bis(tert-octylbenzo-crown-6) bis(2-propyloxy)calix[4]crown-6 tetrabutylammonium cation propyl-(2-hydroxyethyl)-dimethyl-ammonium bromide 4-sulfonatocalix[4]arene 4-sulfonatocalix[6]arene cucurbit[n]uril cyclodextrin(s) critical micelle concentration 1-alkyl-2,3-dimethylimidazolium cation alkyl poly-(oxyethyleneglycol) ethers 
$\left[\mathrm{C}_{\mathrm{n}} \mathrm{H}_{2 \mathrm{n}+1}\right.$ mim $]\left[\mathrm{C}_{\mathrm{m}} \mathrm{H}_{2 \mathrm{~m}+1} \mathrm{SO}_{3}\right]$ 1-alkyl-3-methylimidazolium alkylsulfonate

$\mathrm{C}_{\mathrm{n}} \mathrm{mim}^{+}$

$(\mathrm{CN})_{2} \mathrm{~N}^{-}$

$\mathrm{C}_{\mathrm{n}} \mathrm{OSO}_{3}^{-}$

$\mathrm{C}_{n} \mathrm{Py}^{+}$

$\mathrm{C}_{\mathrm{n} V i m}{ }^{+}$

DBzDA18C6

DCH18C6

$[\mathrm{DDA}]\left[\mathrm{NO}_{3}\right]$

DLS

DM- $\beta-C D$

DPPC

DSPC

DTAB

EAN

FFEM

H2 $\beta$ DA18C6

HP- $\beta-C D$

HPMBP

HP-a-CD

$\mathrm{HP}-\gamma-\mathrm{CD}$

IC

$\mathrm{IL}(\mathrm{s})$

ITC

$\mathrm{LC}(\mathrm{s})$

LCST

$\mathrm{MD}$

$\mathrm{NfO}^{-}$

$\mathrm{O} / \mathrm{IL}$

$\mathrm{O} / \mathrm{W}$

$\mathrm{OE}$

$\mathrm{OTos}^{-}$

PAF

$\mathrm{PF}_{6}^{-}$

PNCM

SANS

SAXS

SDS

tat

TBPFO

Tdec

$\mathrm{Tf}_{2} \mathrm{~N}^{-}$

$\mathrm{TfO}^{-}$

TM- $\beta-C D$

$\mathrm{TPhB}^{-}$

TSIL 1-alkyl-3-methylimidazolium cation

dicyanimide anion

alkylsulfate anion

1-alkylpyridinium cation

1-alkyl-3-vinylimidazolium cation

N, N'-dibenzyl-4, 13-diaza-18-crown-6

dicyclohexano-18-crown-6

didecyl-dimethylammonium nitrate

dynamic light scattering

heptakis-(2,6-di-O-methyl)- $\beta$-CD

L-dipalmitoylphosphatidylcholine

$\beta, \gamma$-distearoylphosphotidylcholine

dodecyltrimethylammonium bromide

ethylammonium nitrate

freeze-fracturing electron microscopy

$\beta$-diketone-substituted diaza-18-crown-6

hydroxypropyl- $\beta-C D$

1-phenyl-3-methyl-4-benzoyl-5-pyrazolone

hydroxypropyl-a-CD

hydroxypropyl- $\gamma-C D$

inclusion complex

ionic liquid(s)

isothermal titration calorimetry

liquid crystal(s)

lower critical solution temperature

molecular dynamics

nonafluorobutanesulfonate anion

oil-in-IL

oil-in-water

oxyethylene

tosylate anion

propylammonium formate

hexafluorophosphate anion

poly(NIPAAM-co- $\beta$-CD Methacrylate)

small-angle neutron scattering

small-angle $X$-ray scattering

sodium dodecylsulfate

trans-anti-trans

tetrabutylammonium perfluorooctanoate

thermal decomposition temperatures

bis(trifluoromethylsulfonyl)imide anion

trifluoromethanesulfonate anion

heptakis-(2,3,6-tri-O-methyl)- $\beta$-CD

tetraphenylborate anion

task specific ionic liquid 
tst

$\mathrm{V}_{2}$

XRD trans-syn-trans

reverse bicontinuous cubic phase

X-ray diffraction

\section{References}

Abdallah, D. J.; Robertson, A.; Hsu, H. F. \& Weiss, R. G. (2000). Smectic liquid-crystalline phases of quaternary group VA (especially phosphonium) salts with three equivalent long n-alkyl chains. How do layered assemblies form in liquidcrystalline and crystalline phases? J. Am. Chem. Soc., 122, 3053-3062.

Adhikari, A.; Sahu, K.; Dey, S.; Ghosh, S.; Mandal, U. \& Bhattacharyya, K. (2007). Femtosecond solvation dynamics in a neat ionic liquid and ionic liquid microemulsion: Excitation wavelength dependence. J. Phys. Chem. B, 111, 1280912816.

Alami, E.; Levy, H.; Zana, R.; Weber, P. \& Skoulios, A. (1993). A new smectic mesophase with 2-dimensional tetragonal symmetry from dialkyldimethylammonium bromides-ST. Liq. Cryst., 13, 201-212.

Amajjahe, S.; Choi, S.; Munteanu, M. \& Ritter, H. (2008). Pseudopolyanions based on poly(NIPAAM-co- $\beta$-cyclodextrin methacrylate) and ionic liquids. Angew. Chem.-Int. Edit., 47, 3435-3437.

Amajjahe, S. \& Ritter, H. (2008a). Supramolecular controlled pseudo-LCST effects of cyclodextrin-complexed poly(ionic liquids). Macromolecules, 41, 3250-3253.

Amajjahe, S. \& Ritter, H. (2008b). Anion complexation of vinylimidazolium salts and its influence on polymerization. Macromolecules, 41, 716-718.

Anderson, J. L.; Pino, V.; Hagberg, E. C.; Sheares, V. V. \& Armstrong, D. W. (2003). Surfactant solvation effects and micelle formation in ionic liquids. Chem. Commun., 2444-2445.

Ao, M. Q.; Huang, P. P.; Xu, G. Y.; Yang, X. D. \& Wang, Y. J. (2009). Aggregation and thermodynamic properties of ionic liquid-type gemini imidazolium surfactants with different spacer length. Colloid Polym. Sci., 287, 395-402.

Araos, M. U. \& Warr, G. G. (2005). Self-assembly of nonionic surfactants into lyotropic liquid crystals in ethylammonium nitrate, a room-temperature ionic liquid. J. Phys. Chem. $B, 109,14275-14277$.

Arce, A.; Earle, M. J.; Rodriguez, H. \& Seddon, K. R. (2007). Separation of aromatic hydrocarbons from alkanes using the ionic liquid 1-ethyl-3-methylimidazolium bis $\{$ (trifluoromethyl) sulfonyl $\}$ amide. Green Chem., 9, 70-74.

Arkas, M.; Tsiourvas, D.; Paleos, C. M. \& Skoulios, A. (1999). Smectic mesophases from dihydroxy derivatives of quaternary alkylammonium salts. Chem.-Eur. J., 5, 32023207.

Artzner, F.; Veber, M.; Clerc, M. \& Levelut, A. M. (1997). Evidence of nematic, hexagonal and rectangular columnar phases in thermotropic ionic liquid crystals. Liq. Cryst., 23, 27-33.

Atkin, R. \& Warr, G. G. (2007). Phase behavior and microstructure of microemulsions with a room-temperature ionic liquid as the polar phase. J. Phys. Chem. B, 111, 9309-9316.

Bates, E. D.; Mayton, R. D.; Ntai, I. \& Davis, J. H. (2002). $\mathrm{CO}_{2}$ capture by a task-specific ionic liquid. J. Am. Chem. Soc., 124, 926-927. 
Behera, K.; Dahiya, P. \& Pandey, S. (2007a). Effect of added ionic liquid on aqueous Triton X-100 micelles. J. Colloid Interface Sci., 307, 235-245.

Behera, K.; Pandey, M. D.; Porel, M. \& Pandey, S. (2007b). Unique role of hydrophilic ionic liquid in modifying properties of aqueous Triton X-100. J. Chem. Phys., 127, 184501.

Behera, K. \& Pandey, S. (2007a). Modulating properties of aqueous sodium dodecyl sulfate by adding hydrophobic ionic liquid. J. Colloid Interface Sci., 316, 803-814.

Behera, K. \& Pandey, S. (2007b). Concentration-dependent dual behavior of hydrophilic ionic liquid in changing properties of aqueous sodium dodecyl sulfate. J. Phys. Chem. B, 111, 13307-13315.

Beletskaya, I.; Tyurin, V. S.; Tsivadze, A. Y.; Guilard, R. \& Stern, C. (2009). Supramolecular chemistry of metalloporphyrins. Chem. Rev., 109, 1659-1713.

Beyaz, A.; Oh, W. S. \& Reddy, V. P. (2004). Ionic liquids as modulators of the critical micelle concentration of sodium dodecyl sulfate. Colloid Surf. B-Biointerfaces, 35, 119-124.

Bhargava, B. L. \& Klein, M. L. (2009). Molecular dynamics studies of cation aggregation in the room temperature ionic liquid $\left[\mathrm{C}_{10} \mathrm{mim}\right] \mathrm{Br}$ in aqueous solution. J. Phys. Chem. A, $113,1898-1904$.

Binnemans, K. (2005). Ionic liquid crystals. Chem. Rev., 105, 4148-4204.

Blesic, M.; Marques, M. H.; Plechkova, N. V.; Seddon, K. R.; Rebelo, L. P. N. \& Lopes, A. (2007). Self-aggregation of ionic liquids: micelle formation in aqueous solution. Green Chem., 9, 481-490.

Blesic, M.; Lopes, A.; Melo, E.; Petrovski, Z.; Plechkova, N. V.; Lopes, J. N. C.; Seddon, K. R. \& Rebelo, L. P. N. (2008). On the self-aggregation and fluorescence quenching aptitude of surfactant ionic liquids. J. Phys. Chem. B, 112, 8645-8650.

Blesic, M.; Lopes, J. N. C.; Padua, A. A. H.; Shimizu, K.; Gomes, M. F. C. \& Rebelo, L. P. N. (2009a). Phase equilibria in ionic liquid-aromatic compound mixtures, including benzene fluorination effects. J. Phys. Chem. B, 113, 7631-7636.

Blesic, M.; Swadzba-Kwasny, M.; Holbrey, J. D.; Lopes, J. N. C.; Seddon, K. R. \& Rebelo, L. P. N. (2009b). New catanionic surfactants based on 1-alkyl-3-methylimidazolium alkylsulfonates, $\left[\mathrm{C}_{\mathrm{n}} \mathrm{H}_{2 \mathrm{n}+1} \mathrm{mim}\right]\left[\mathrm{C}_{\mathrm{m}} \mathrm{H}_{2 \mathrm{~m}+1} \mathrm{SO}_{3}\right]$ : mesomorphism and aggregation. Phys. Chem. Chem. Phys., 11, 4260-4268.

Booker, K.; Bowyer, M. C.; Holdsworth, C. I. \& McCluskey, A. (2006). Efficient preparation and improved sensitivity of molecularly imprinted polymers using room temperature ionic liquids. Chem. Commun., 1730-1732.

Bowers, J.; Butts, C. P.; Martin, P. J.; Vergara-Gutierrez, M. C. \& Heenan, R. K. (2004). Aggregation behavior of aqueous solutions of ionic liquids. Langmuir, 20, 21912198.

Bowlas, C. J.; Bruce, D. W. \& Seddon, K. R. (1996). Liquid-crystalline ionic liquids. Chem. Commun., 1625-1626.

Boxwell, C. J.; Dyson, P. J.; Ellis, D. J. \& Welton, T. (2002). A highly selective arene hydrogenation catalyst that operates in ionic liquid. J. Am. Chem. Soc., 124, 93349335.

Bradley, A. E.; Hardacre, C.; Holbrey, J. D.; Johnston, S.; McMath, S. E. J. \& Nieuwenhuyzen, M. (2002). Small-angle X-ray scattering studies of liquid crystalline 1-alkyl-3methylimidazolium salts. Chem. Mater., 14, 629-635. 
Brown, R. A.; Pollet, P.; McKoon, E.; Eckert, C. A.; Liotta, C. L. \& Jessop, P. G. (2001). Asymmetric hydrogenation and catalyst recycling using ionic liquid and supercritical carbon dioxide. J. Am. Chem. Soc., 123, 1254-1255.

Cammarata, L.; Kazarian, S. G.; Salter, P. A. \& Welton, T. (2001). Molecular states of water in room temperature ionic liquids. Phys. Chem. Chem. Phys., 3, 5192-5200.

Cang, H.; Li, J. \& Fayer, M. D. (2003). Orientational dynamics of the ionic organic liquid 1ethyl-3-methylimidazolium nitrate. J. Chem. Phys., 119, 13017-13023.

Carda-Broch, S.; Berthod, A. \& Armstrong, D. W. (2003). Solvent properties of the 1-butyl-3methylimidazolium hexafluorophosphate ionic liquid. Anal. Bioanal. Chem., 375, 191-199.

Carmichael, A. J.; Hardacre, C.; Holbrey, J. D.; Nieuwenhuyzen, M. \& Seddon, K. R. (2001). Molecular layering and local order in thin films of 1-alkyl-3-methylimidazolium ionic liquids using X-ray reflectivity. Mol. Phys., 99, 795-800.

Chakrabarty, D.; Seth, D.; Chakraborty, A. \& Sarkar, N. (2005). Dynamics of solvation and rotational relaxation of coumarin 153 in ionic liquid confined nanometer-sized microemulsions. J. Phys. Chem. B, 109, 5753-5758.

Chen, H.; Kwait, D. C.; Gonen, Z. S.; Weslowski, B. T.; Abdallah, D. J. \& Weiss, R. G. (2002). Phase characterization and properties of completely saturated quaternary phosphonium salts. Ordered, room-temperature ionic liquids. Chem. Mater., 14, 4063-4072.

Chen, P. Y. \& Hussey, C. L. (2005). Electrochemistry of ionophore-coordinated Cs and Sr ions in the tri-1-butylmethylammonium bis((trifluoromethyl)sulfonyl)imide ionic liquid. Electrochim. Acta, 50, 2533-2540.

Chen, P. Y. (2007). The assessment of removing strontium and cesium cations from aqueous solutions based on the combined methods of ionic liquid extraction and electrodeposition. Electrochim. Acta, 52, 5484-5492.

Chen, S. M.; Wu, G. Z.; Sha, M. L. \& Huang, S. R. (2007). Transition of ionic liquid [bmim] $\left[\mathrm{PF}_{6}\right]$ from liquid to high-melting-point crystal when confined in multiwalled carbon nanotubes. J. Am. Chem. Soc., 129, 2416-2417.

Cheng, S. Q.; Fu, X. G.; Liu, J. H.; Zhang, J. L.; Zhang, Z. F.; Wei, Y. L. \& Han, B. X. (2007a). Study of ethylene glycol/TX-100/ionic liquid microemulsions. Colloid Surf. APhysicochem. Eng. Asp., 302, 211-215.

Cheng, S. Q.; Zhang, J. L.; Zhang, Z. F. \& Han, B. X. (2007b). Novel microemulsions: ionic liquid-in-ionic liquid. Chem. Commun., 2497-2499.

Cheng, S. Q.; Han, F.; Wang, Y. R. \& Yan, H. F. (2008). Effect of cosurfactant on ionic liquid solubilization capacity in cyclolhexane/TX-100/1-butyl-3-methylimidazolium tetrafluoroborate microemulsions. Colloid Surf. A-Physicochem. Eng. Asp., 317, 457461.

Chiappe, C. \& Pieraccini, D. (2005). Ionic liquids: solvent properties and organic reactivity. J. Phys. Org. Chem., 18, 275-297.

Choudhury, A. R.; Winterton, N.; Steiner, A.; Cooper, A. I. \& Johnson, K. A. (2005). In situ crystallization of low-melting ionic liquids. J. Am. Chem. Soc., 127, 16792-16793.

Choudhury, A. R.; Winterton, N.; Steiner, A.; Cooper, A. I. \& Johnson, K. A. (2006). In situ crystallization of ionic liquids with melting points below $-25{ }^{\circ} \mathrm{C}$. Crystengcomm, 8 , 742-745. 
Christie, S.; Dubois, R. H.; Rogers, R. D.; White, P. S. \& Zaworotko, M. J. (1991). Air stable liquid clathrates - solid-state structure and hydrocarbon solubility of organic cation triiodide salts. J. Incl. Phenom. Mol. Recogn. Chem., 11, 103-114.

Chun, S.; Dzyuba, S. V. \& Bartsch, R. A. (2001). Influence of structural variation in roomtemperature ionic liquids on the selectivity and efficiency of competitive alkali metal salt extraction by a crown ether. Anal. Chem., 73, 3737-3741.

Clavier, H.; Nolan, S. P. \& Mauduit, M. (2008). Ionic liquid anchored "Boomerang" catalysts bearing saturated and unsaturated NHCs: Recyclability in biphasic media for crossmetathesis. Organometallics, 27, 2287-2292.

Coleman, A. W.; Means, C. M.; Bott, S. G. \& Atwood, J. L. (1990). Air-stable liquid clathrates. 1. crystal-structure of $\left[\mathrm{NBu}_{4}\right]\left[\mathrm{Br}_{3}\right]$ and reactivity of the $\left[\mathrm{NBu}_{4}\right]\left[\mathrm{Br}_{3}\right] \cdot 5 \mathrm{C}_{6} \mathrm{H}_{6}$ liquid clathrate. J. Cryst. Spectrosc. Res., 20, 199-201.

Constable, E. C. (2008). Expanded ligands - An assembly principle for supramolecular chemistry. Coord. Chem. Rev., 252, 842-855.

Costantini, M.; Toussaint, V. A.; Shariati, A.; Peters, C. J. \& Kikic, I. (2005). High-pressure phase Behavior of systems with ionic liquids: Part IV. Binary system carbon dioxide+1-hexyl-3-methylimidazolium tetrafluoroborate. J. Chem. Eng. Data, 50, 5255.

Craig, S. L. (2009). From ionic liquids to supramolecular polymers. Angew. Chem.-Int. Edit., 48, 2645-2647.

Cruz, C.; Heinrich, B.; Ribeiro, A. C.; Bruce, D. W. \& Guillon, D. (2000). Structural study of smectic A phases in homologous series of $\mathrm{N}$-alkylpyridinium alkylsulphates. Liq. Cryst., 27, 1625-1631.

Csihony, S.; Fischmeister, C.; Bruneau, C.; Horvath, I. T. \& Dixneuf, P. H. (2002). First ringopening metathesis polymerization in an ionic liquid. Efficient recycling of a catalyst generated from a cationic ruthenium allenylidene complex. New J. Chem., $26,1667-1670$.

Cui, L.; Sapagovas, V. \& Lattermann, G. (2002). Synthesis and thermal behaviour of liquid crystalline pyridinium bromides containing a biphenyl core. Liq. Cryst., 29, 11211132.

Dai, S.; Ju, Y. H. \& Barnes, C. E. (1999). Solvent extraction of strontium nitrate by a crown ether using room-temperature ionic liquids. J. Chem. Soc. -Dalton Trans., 1201-1202.

Davis, J. H.; Forrester, K. J. \& Merrigan, T. (1998). Novel organic ionic liquids (OILs) incorporating cations derived from the antifungal drug miconazole. Tetrahedron Lett., 39, 8955-8958.

De Roche, J.; Gordon, C. M.; Imrie, C. T.; Ingram, M. D.; Kennedy, A. R.; Lo Celso, F. \& Triolo, A. (2003). Application of complementary experimental techniques to characterization of the phase behavior of $\left[\mathrm{C}_{16} \mathrm{mim}\right]\left[\mathrm{PF}_{6}\right]$ and $\left[\mathrm{C}_{14} \mathrm{mim}\right]\left[\mathrm{PF}_{6}\right]$. Chem. Mater., 15, 3089-3097.

DeCastro, C.; Sauvage, E.; Valkenberg, M. H. \& Holderich, W. F. (2000). Immobilised ionic liquids as Lewis acid catalysts for the alkylation of aromatic compounds with dodecene. J. Catal., 196, 86-94.

Deetlefs, M.; Hardacre, C.; Nieuwenhuyzen, M.; Sheppard, O. \& Soper, A. K. (2005). Structure of ionic liquid-benzene mixtures. J. Phys. Chem. B, 109, 1593-1598. 
Deetlefs, M.; Hardacre, C.; Nieuwenhuyzen, M.; Padua, A. A. H.; Sheppard, O. \& Soper, A. K. (2006). Liquid structure of the ionic liquid 1,3-dimethylimidazolium bis\{(trifluoromethyl)sulfonyl\}amide. J. Phys. Chem. B, 110, 12055-12061.

Descalzo, A. B.; Martinez-Manez, R.; Sancenon, R.; Hoffmann, K. \& Rurack, K. (2006). The supramolecular chemistry of organic-inorganic hybrid materials. Angew. Chem.-Int. Edit., 45, 5924-5948.

Dey, S.; Adhikari, A.; Das, D. K.; Sasmal, D. K. \& Bhattacharyya, K. (2009). Femtosecond solvation dynamics in a micron-sized aggregate of an ionic liquid and P123 triblock copolymer. J. Phys. Chem. B, 113, 959-965.

Dieter, K. M.; Dymek, C. J.; Heimer, N. E.; Rovang, J. W. \& Wilkes, J. S. (1988). Ionic structure and interactions in 1-methyl-3-ethylimidazolium chloride- $\mathrm{AlCl}_{3}$ moltensalts. J. Am. Chem. Soc., 110, 2722-2726.

Dietz, M. L. \& Dzielawa, J. A. (2001). Ion-exchange as a mode of cation transfer into roomtemperature ionic liquids containing crown ethers: implications for the "greenness" of ionic liquids as diluents in liquid-liquid extraction. Chem. Commun., 2124-2125.

Dietz, M. L.; Dzielawa, J. A.; Laszak, I.; Young, B. A. \& Jensen, M. P. (2003). Influence of solvent structural variations on the mechanism of facilitated ion transfer into roomtemperature ionic liquids. Green Chem., 5, 682-685.

Dietz, M. L. \& Stepinski, D. C. (2005). A ternary mechanism for the facilitated transfer of metal ions into room-temperature ionic liquids (RTILs): implications for the "greenness" of RTILs as extraction solvents. Green Chem., 7, 747-750.

Dietz, M. L.; Jakab, S.; Yamato, K. \& Bartsch, R. A. (2008). Stereochemical effects on the mode of facilitated ion transfer into room-temperature ionic liquids. Green Chem., 10, 174-176.

Dong, B.; Li, N.; Zheng, L. Q.; Yu, L. \& Inoue, T. (2007). Surface adsorption and micelle formation of surface active ionic liquids in aqueous solution. Langmuir, 23, 41784182.

Dong, B.; Zhang, J.; Zheng, L. Q.; Wang, S. Q.; Li, X. W. \& Inoue, T. R. (2008a). Salt-induced viscoelastic wormlike micelles formed in surface active ionic liquid aqueous solution. J. Colloid Interface Sci., 319, 338-343.

Dong, B.; Zhao, X. Y.; Zheng, L. Q.; Zhang, J.; Li, N. \& Inoue, T. (2008b). Aggregation behavior of long-chain imidazolium ionic liquids in aqueous solution: Micellization and characterization of micelle microenvironment. Colloid Surf. A-Physicochem. Eng. Asp., 317, 666-672.

Dorbritz, S.; Ruth, W. \& Kragl, U. (2005). Investigation on aggregate formation of ionic liquids. Adv. Synth. Catal., 347, 1273-1279.

Dupont, J.; Suarez, P. A. Z.; De Souza, R. F.; Burrow, R. A. \& Kintzinger, J. P. (2000). C-H- $\pi$ interactions in 1-n-butyl-3-methylimidazolium tetraphenylborate molten salt: Solid and solution structures. Chem.-Eur. J., 6, 2377-2381.

Dupont, J. (2004). On the solid, liquid and solution structural organization of imidazolium ionic liquids. J. Braz. Chem. Soc., 15, 341-350.

Eastoe, J.; Gold, S.; Rogers, S. E.; Paul, A.; Welton, T.; Heenan, R. K. \& Grillo, I. (2005). Ionic liquid-in-oil microemulsions. J. Am. Chem. Soc., 127, 7302-7303.

El Seoud, O. A.; Pires, P. A. R.; Abdel-Moghny, T. \& Bastos, E. L. (2007). Synthesis and micellar properties of surface-active ionic liquids: 1-Alkyl-3-methylimidazolium chlorides. J. Colloid Interface Sci., 313, 296-304. 
Evans, D. F.; Yamauchi, A.; Roman, R. \& Casassa, E. Z. (1982). Micelle formation in ethylammonium nitrate, a low-melting fused salt. J. Colloid Interface Sci., 88, 89-96.

Evans, D. F.; Kaler, E. W. \& Benton, W. J. (1983a). Liquid-crystals in a fused salt - $\beta, \alpha-$ distearoylphosphotidylcholine in n-ethylammonium nitrate. J. Phys. Chem., 87, 533535.

Evans, D. F.; Yamauchi, A.; Wei, G. J. \& Bloomfield, V. A. (1983b). Micelle size in ethylammonium nitrate as determined by classical and quasi-elastic lightscattering. J. Phys. Chem., 87, 3537-3541.

Feher, E.; Major, B.; Belafi-Bako, K. \& Gubicza, L. (2007). On the background of enhanced stability and reusability of enzymes in ionic liquids. Biochem. Soc. Trans., 35, 16241627.

Firestone, M. A.; Dzielawa, J. A.; Zapol, P.; Curtiss, L. A.; Seifert, S. \& Dietz, M. L. (2002). Lyotropic liquid-crystalline gel formation in a room-temperature ionic liquid. Langmuir, 18, 7258-7260.

Firestone, M. A.; Dietz, M. L.; Seifert, S.; Trasobares, S.; Miller, D. J. \& Zaluzec, N. J. (2005). Ionogel-templated synthesis and organization of anisotropic gold nanoparticles. Small, 1, 754-760.

Fletcher, K. A. \& Pandey, S. (2004). Surfactant aggregation within room-temperature ionic liquid 1-ethyl-3-methylimidazolium bis(trifluoromethylsulfonyl)imide. Langmuir, 20, 33-36.

Francois, Y.; Varenne, A.; Sirieix-Plenet, J. \& Gareil, P. (2007). Determination of aqueous inclusion complexation constants and stoichiometry of alkyl(methyl) methylimidazolium-based ionic liquid cations and neutral cyclodextrins by affinity capillary electrophoresis. J. Sep. Sci., 30, 751-760.

Friberg, S. E.; Yin, Q.; Pavel, F.; Mackay, R. A.; Holbrey, J. D.; Seddon, K. R. \& Aikens, P. A. (2000). Solubilization of an ionic liquid, 1-butyl-3-methylimidazolium hexafluorophosphate, in a surfactant-water system. J. Dispersion Sci. Technol., 21, 185-197.

Fujii, K.; Seki, S.; Fukuda, S.; Takamuku, T.; Kohara, S.; Kameda, Y.; Umebayashi, Y. \& Ishiguro, S. (2008a). Liquid structure and conformation of a low-viscosity ionic liquid, N-methyl-N-propyl-pyrrolidinium bis(fluorosulfonyl) imide studied by high-energy X-ray scattering. J. Mol. Liq., 143, 64-69.

Fujii, K.; Soejima, Y.; Kyoshoin, Y.; Fukuda, S.; Kanzaki, R.; Umebayashi, Y.; Yamaguchi, T.; Ishiguro, S. I. \& Takamuku, T. (2008b). Liquid structure of room-temperature ionic liquid, 1-ethyl-3-methylimidazolium bis-(trifluoromethanesulfonyl) imide. J. Phys. Chem. B, 112, 4329-4336.

Fukuda, S.; Takeuchi, M.; Fujii, K.; Kanzaki, R.; Takamuku, T.; Chiba, K.; Yamamoto, H.; Umebayashi, Y. \& Ishiguro, S. (2008). Liquid structure of N-butyl-Nmethylpyrrolidinium bis-(trifluoromethanesulfonyl) amide ionic liquid studied by large angle X-ray scattering and molecular dynamics simulations. J. Mol. Liq., 143, 2-7.

Fuller, J.; Carlin, R. T.; Delong, H. C. \& Haworth, D. (1994). Structure of 1-ethyl-3methylimidazolium hexafluorophosphate - model for room-temperature moltensalts. J. Chem. Soc.-Chem. Commun., 299-300. 
Gao, H. X.; Li, J. C.; Han, B. X.; Chen, W. N.; Zhang, J. L.; Zhang, R. \& Yan, D. D. (2004). Microemulsions with ionic liquid polar domains. Phys. Chem. Chem. Phys., 6, 29142916.

Gao, Y.; Li, N.; Zheng, L. Q.; Zhao, X. Y.; Zhang, S. H.; Han, B. X.; Hou, W. G. \& Li, G. Z. (2006a). A cyclic voltammetric technique for the detection of micro-regions of bmimPF$_{6} /$ Tween $20 / \mathrm{H}_{2} \mathrm{O}$ microemulsions and their performance characterization by UV-Vis spectroscopy. Green Chem., 8, 43-49.

Gao, Y.; Zhang, J.; Xu, H. Y.; Zhao, X. Y.; Zheng, L. Q.; Li, X. W. \& Yu, L. (2006b). Structural studies of 1-butyl-3-methylimidazolium tetrafluoroborate/TX-100/p-xylene ionic liquid microemulsions. ChemPhysChem, 7, 1554-1561.

Gao, Y.; Zhao, X.; Dong, B.; Zheng, L.; Li, N. \& Zhang, S. (2006c). Inclusion complexes of $\beta$ cyclodextrin with ionic liquid surfactants. J. Phys. Chem. B, 110, 8576-8581.

Gao, Y.; Li, N.; Zheng, L. Q.; Bai, X. T.; Yu, L.; Zhao, X. Y.; Zhang, J.; Zhao, M. W. \& Li, Z. (2007a). Role of solubilized water in the reverse ionic liquid microemulsion of 1butyl-3-methylimidazolium tetrafluoroborate/TX-100/benzene. J. Phys. Chem. B, 111, 2506-2513.

Gao, Y.; Li, N.; Zheng, L. Q.; Zhao, X. Y.; Zhang, J.; Cao, Q.; Zhao, M. W.; Li, Z. \& Zhang, G. Y. (2007b). The effect of water on the microstructure of 1-butyl-3-methylimidazolium tetrafluoroborate/TX-100/benzene ionic liquid microemulsions. Chem.-Eur. J., 13, 2661-2670.

Gao, Y.; Hilfert, L.; Voigt, A. \& Sundmachert, K. (2008a). Decrease of droplet size of the reverse microemulsion 1-butyl-3-methylimidazolium tetrafluoroborate/Triton X100/cyclohexane by addition of water. J. Phys. Chem. B, 112, 3711-3719.

Gao, Y. A.; Li, Z. H.; Du, J. M.; Han, B. X.; Li, G. Z.; Hou, W. G.; Shen, D.; Zheng, L. Q. \& Zhang, G. Y. (2005a). Preparation and characterization of inclusion complexes of $\beta$ cyclodextrin with ionic liquid. Chem.-Eur. J., 11, 5875-5880.

Gao, Y. A.; Voigt, A.; Hilfert, L. \& Sundmacher, K. (2008b). Nanodroplet cluster formation in ionic liquid microemulsions. ChemPhysChem, 9, 1603-1609.

Gao, Y. A.; Li, N.; Zhang, S. H.; Zheng, L. Q.; Li, X. W.; Dong, B. \& Yu, L. (2009a). Organic solvents induce the formation of oil-in-ionic liquid microemulsion aggregations. J. Phys. Chem. B, 113, 1389-1395.

Gao, Y. N.; Han, S. B.; Han, B. X.; Li, G. Z.; Shen, D.; Li, Z. H.; Du, J. M.; Hou, W. G. \& Zhang, G. Y. (2005b). TX-100/water/1-butyl-3-methylimidazolium hexafluorophosphate microemulsions. Langmuir, 21, 5681-5684.

Gao, Y. N.; Wang, S. Q.; Zheng, L. Q.; Han, S. B.; Zhang, X.; Lu, D. M.; Yu, L.; Ji, Y. Q. \& Zhang, G. Y. (2006d). Microregion detection of ionic liquid microemulsions. J. Colloid Interface Sci., 301, 612-616.

Gao, Y. N.; Li, N.; Li, X. W.; Zhang, S. H.; Zheng, L. Q.; Bai, X. T. \& Yu, L. (2009b). Microstructures of micellar aggregations formed within 1-butyl-3-methylimidazolium type ionic liquids. J. Phys. Chem. B, 113, 123-130.

Gaudet, M. V.; Peterson, D. C. \& Zaworotko, M. J. (1988). Ternary hydrogen halide base benzene mixtures - a new generation of liquid clathrates. J. Incl. Phenom., 6, 425-428.

Ge, L. L.; Chen, L. P. \& Guo, R. (2007). Microstructure and lubrication properties of lamellar liquid crystal in Brij 30/[Bmim] $\left[\mathrm{PF}_{6}\right] / \mathrm{H}_{2} \mathrm{O}$ system. Tribol. Lett., 28, 123-130. 
Getsis, A. \& Mudring, A. V. (2008). Imidazolium based ionic liquid crystals: structure, photophysical and thermal behaviour of $\left[\mathrm{C}_{\mathrm{n}} \operatorname{mim}\right] \mathrm{Br} \cdot \mathrm{xH}_{2} \mathrm{O}(\mathrm{n}=12,14 ; \mathrm{x}=0,1)$. Cryst. Res. Technol., 43, 1187-1196.

Gjikaj, M.; Brockner, W.; Namyslo, J. \& Adam, A. (2008). Crown-ether enclosure generated by ionic liquid components - synthesis, crystal structure and Raman spectra of compounds of imidazolium based salts and 18-crown-6. Crystengcomm, 10, 103-110.

Golovanov, D. G.; Lyssenko, K. A.; Antipin, M. Y.; Vygodskii, Y. S.; Lozinskaya, E. I. \& Shaplov, A. S. (2005). Extremely short C-H $\cdots$ F contacts in the 1-methyl-3propylimidazolium $\mathrm{SiF}_{6}$ - the reason for ionic "liquid" unexpected high melting point. Crystengcomm, 7, 53-56.

Goossens, K.; Nockemann, P.; Driesen, K.; Goderis, B.; Gorller-Walrand, C.; Van Hecke, K.; Van Meervelt, L.; Pouzet, E.; Binnemans, K. \& Cardinaels, T. (2008). Imidazolium ionic liquid crystals with pendant mesogenic groups. Chem. Mater., 20, 157-168.

Goossens, K.; Lava, K.; Nockemann, P.; Van Hecke, K.; Van Meervelt, L.; Driesen, K.; Gorller-Walrand, C.; Binnemans, K. \& Cardinaels, T. (2009). Pyrrolidinium ionic liquid crystals. Chem. Eur. J., 15, 656-674.

Gopalan, A. I.; Lee, K. P. \& Ragupathy, D. (2009). Development of a stable cholesterol biosensor based on multi-walled carbon nanotubes-gold nanoparticles composite covered with a layer of chitosan-room-temperature ionic liquid network. Biosens. Bioelectron., 24, 2211-2217.

Gordon, C. M.; Holbrey, J. D.; Kennedy, A. R. \& Seddon, K. R. (1998). Ionic liquid crystals: hexafluorophosphate salts. J. Mater. Chem., 8, 2627-2636.

Gowda, G. A. N.; Chen, H.; Khetrapal, C. L. \& Weiss, R. G. (2004). Amphotropic ionic liquid crystals with low order parameters. Chem. Mater., 16, 2101-2106.

Greaves, T. L.; Weerawardena, A.; Fong, C. \& Drummond, C. J. (2007a). Formation of amphiphile self-assembly phases in protic ionic liquids. J. Phys. Chem. B, 111, 40824088.

Greaves, T. L.; Weerawardena, A.; Fong, C. \& Drummond, C. J. (2007b). Many protic ionic liquids mediate hydrocarbon-solvent interactions and promote amphiphile selfassembly. Langmuir, 23, 402-404.

Gutel, T.; Garcia-Anton, J.; Pelzer, K.; Philippot, K.; Santini, C. C.; Chauvin, Y.; Chaudret, B. \& Basset, J. M. (2007). Influence of the self-organization of ionic liquids on the size of ruthenium nanoparticles: effect of the temperature and stirring. J. Mater. Chem., $17,3290-3292$.

Gutowski, K. E. \& Maginn, E. J. (2008). Amine-functionalized task-specific ionic liquids: a mechanistic explanation for the dramatic increase in viscosity upon complexation with $\mathrm{CO}_{2}$ from molecular simulation. J. Am. Chem. Soc., 130, 14690-14704.

Hao, J. C.; Song, A. X.; Wang, J. Z.; Chen, X.; Zhuang, W. C.; Shi, F.; Zhou, F. \& Liu, W. M. (2005). Self-assembled structure in room-temperature ionic liquids. Chem.-Eur. J., 11, 3936-3940.

Hao, J. C. \& Zemb, T. (2007). Self-assembled structures and chemical reactions in roomtemperature ionic liquids. Curr. Opin. Colloid Interface Sci., 12, 129-137.

Hardacre, C.; Holbrey, J. D.; McCormac, P. B.; McMath, S. E. J.; Nieuwenhuyzen, M. \& Seddon, K. R. (2001). Crystal and liquid crystalline polymorphism in 1-alkyl-3methylimidazolium tetrachloropalladate(II) salts. J. Mater. Chem., 11, 346-350. 
Hardacre, C.; Holbrey, J. D.; McMath, S. E. J.; Bowron, D. T. \& Soper, A. K. (2003). Structure of molten 1,3-dimethylimidazolium chloride using neutron diffraction. J. Chem. Phys., 118, 273-278.

He, C. Y.; Long, Y. Y.; Pan, J. L.; Li, K. \& Liu, F. (2008a). Molecularly imprinted silica prepared with immiscible ionic liquid as solvent and porogen for selective recognition of testosterone. Talanta, 74, 1126-1131.

He, Y. F.; Fu, P.; Shen, X. H. \& Gao, H. C. (2008b). Cyclodextrin-based aggregates and characterization by microscopy. Micron, 39, 495-516.

He, Y. F. \& Shen, X. H. (2008). Interaction between $\beta$-cyclodextrin and ionic liquids in aqueous solutions investigated by a competitive method using a substituted $3 \mathrm{H}-$ indole probe. J. Photochem. Photobiol. A-Chem., 197, 253-259.

He, Y. F.; Chen, Q. D.; Xu, C.; Zhang, J. J. \& Shen, X. H. (2009). Interaction between ionic liquids and $\beta$-cyclodextrin: a discussion of association pattern. J. Phys. Chem. B, 113, 231-238.

He, Y. Y.; Li, Z. B.; Simone, P. \& Lodge, T. P. (2006). Self-assembly of block copolymer micelles in an ionic liquid. J. Am. Chem. Soc., 128, 2745-2750.

Hirayama, N.; Okamura, H.; Kidani, K. \& Imura, H. (2008). Ionic liquid synergistic cationexchange system for the selective extraction of lanthanum(III) using 2thenoyltrifluoroacetone and 18-crown-6. Anal. Sci., 24, 697-699.

Holbrey, J. D. \& Seddon, K. R. (1999). The phase behaviour of 1-alkyl-3-methylimidazolium tetrafluoroborates; ionic liquids and ionic liquid crystals. J. Chem. Soc.-Dalton Trans., 2133-2139.

Holbrey, J. D.; Reichert, W. M.; Nieuwenhuyzen, M.; Sheppard, O.; Hardacre, C. \& Rogers, R. D. (2003). Liquid clathrate formation in ionic liquid-aromatic mixtures. Chem. Commun., 476-477.

Holbrey, J. D.; Reichert, W. M. \& Rogers, R. D. (2004). Crystal structures of imidazolium bis(trifluoromethanesulfonyl)imide "ionic liquid" salts: the first organic salt with a cis-TFSI anion conformation. Dalton Trans., 2267-2271.

$\mathrm{Hu}$, Z. H. \& Margulis, C. J. (2006). Heterogeneity in a room-temperature ionic liquid: Persistent local environments and the red-edge effect. Proc. Natl. Acad. Sci. U. S. A., 103, 831-836.

Huang, J.; Riisager, A.; Wasserscheid, P. \& Fehrmann, R. (2006). Reversible physical absorption of $\mathrm{SO}_{2}$ by ionic liquids. Chem. Commun., 4027-4029.

Huddleston, J. G.; Visser, A. E.; Reichert, W. M.; Willauer, H. D.; Broker, G. A. \& Rogers, R. D. (2001). Characterization and comparison of hydrophilic and hydrophobic room temperature ionic liquids incorporating the imidazolium cation. Green Chem., 3, 156-164.

Inazumi, N.; Yamamoto, S. \& Sueishi, Y. (2007). A characteristic effect of pressure on inclusion complexation of phenothiazine dyes with p-sulfonatocalix[6]arene in a room-temperature ionic liquid. J. Incl. Phenom. Macrocycl. Chem., 59, 33-39.

Inoue, T.; Ebina, H.; Dong, B. \& Zheng, L. Q. (2007). Electrical conductivity study on micelle formation of long-chain imidazolium ionic liquids in aqueous solution. J. Colloid Interface Sci., 314, 236-241.

Inoue, T. \& Misono, T. (2008). Cloud point phenomena for POE-type nonionic surfactants in a model room temperature ionic liquid. J. Colloid Interface Sci., 326, 483-489. 
Ishida, Y.; Sasaki, D.; Miyauchi, H. \& Saigo, K. (2004). Design and synthesis of novel imidazolium-based ionic liquids with a pseudo crown-ether moiety: diastereomeric interaction of a racemic ionic liquid with enantiopure europium complexes. Tetrahedron Lett., 45, 9455-9459.

Iwata, K.; Okajima, H.; Saha, S. \& Hamaguchi, H. O. (2007). Local structure formation in alkyl-imidazolium-based ionic liquids as revealed by linear and nonlinear Raman spectroscopy. Accounts Chem. Res., 40, 1174-1181.

Jensen, M. P.; Neuefeind, J.; Beitz, J. V.; Skanthakumar, S. \& Soderholm, L. (2003). Mechanisms of metal ion transfer into room-temperature ionic liquids: The role of anion exchange. J. Am. Chem. Soc., 125, 15466-15473.

Jiao, D. Z.; Zhao, N. \& Scherman, O. A. (2010). A "green" method for isolation of cucurbit[7] uril via a solid state metathesis reaction. Chem. Commun., 46, 2007-2009.

Jing, B.; Chen, X.; Hao, J. C.; Qiu, H. Y.; Chai, Y. C. \& Zhang, G. D. (2007). Supramolecular self-assembly of polypseudorotaxanes in ionic liquid. Colloid Surf. A-Physicochem. Eng. Asp., 292, 51-55.

Jungnickel, C.; Luczak, J.; Ranke, J.; Fernandez, J. F.; Muller, A. \& Thoming, J. (2008). Micelle formation of imidazolium ionic liquids in aqueous solution. Colloid Surf. APhysicochem. Eng. Asp., 316, 278-284.

Kanzaki, R.; Mitsugi, T.; Fukuda, S.; Fujii, K.; Takeuchi, M.; Soejima, Y.; Takamuku, T.; Yamaguchi, T.; Umebayashi, Y. \& Ishiguro, S. I. (2009). Ion-ion interaction in room temperature ionic liquid 1-ethyl-3-methylimidazolium tetrafluoroborate studied by large angle $\mathrm{X}$-ray scattering experiment and molecular dynamics simulations. $J$. Mol. Liq., 147, 77-82.

Katayanagi, H.; Hayashi, S.; Hamaguchi, H. O. \& Nishikawa, K. (2004). Structure of an ionic liquid, 1-n-butyl-3-methylimidazolium iodide, studied by wide-angle X-ray scattering and Raman spectroscopy. Chem. Phys. Lett., 392, 460-464.

Kim, D.; Jon, S.; Lee, H. K.; Baek, K.; Oh, N. K.; Zin, W. C. \& Kim, K. (2005). Anion-directed self-organization of thermotropic liquid crystalline materials containing a guanidinium moiety. Chem. Commun., 5509-5511.

Kimizuka, N. \& Nakashima, T. (2001). Spontaneous self-assembly of glycolipid bilayer membranes in sugar-philic ionic liquids and formation of ionogels. Langmuir, 17, 6759-6761.

Kolman, V.; Marek, R.; Strelcova, Z.; Kulhanek, P.; Necas, M.; Svec, J. \& Sindelar, V. (2009). Electron density shift in imidazolium derivatives upon complexation with cucurbit[6]uril. Chem.-Eur. J., 15, 6926-6931.

Kowsari, M. H.; Alavi, S.; Ashrafizaadeh, M. \& Najafi, B. (2010). Molecular dynamics study of congruent melting of the equimolar ionic liquid-benzene inclusion crystal [emim] $\left[\mathrm{NTf}_{2}\right] \cdot \mathrm{C}_{6} \mathrm{H}_{6}$. J. Chem. Phys., 132, 044507.

Kragl, U.; Eckstein, M. \& Kaftzik, N. (2002). Enzyme catalysis in ionic liquids. Curr. Opin. Biotechnol., 13, 565-571.

Kumar, S. \& Pal, S. K. (2005). Synthesis and characterization of novel imidazolium-based ionic discotic liquid crystals with a triphenylene moiety. Tetrahedron Lett., 46, 26072610.

Lachwa, J.; Bento, I.; Duarte, M. T.; Lopes, J. N. C. \& Rebelo, L. P. N. (2006). Condensed phase behaviour of ionic liquid-benzene mixtures: congruent melting of a [emim] $\left[\mathrm{NTf}_{2}\right] \cdot \mathrm{C}_{6} \mathrm{H}_{6}$ inclusion crystal. Chem. Commun., 2445-2447. 
Langmaier, J.; Trojanek, A. \& Samec, Z. (2009). Amperometric Ion-Selective Electrode for alkali metal cations based on a room-temperature ionic liquid membrane. Electroanalysis, 21, 1977-1983.

Leclercq, L.; Suisse, I.; Nowogrocki, G. \& Agbossou-Niedercorn, F. (2007). Halide-free highly-pure imidazolium triflate ionic liquids: Preparation and use in palladiumcatalysed allylic alkylation. Green Chem., 9, 1097-1103.

Leclercq, L. \& Schmitzer, A. R. (2008). Multiple equilibria in the complexation of dibenzylimidazolium bromide salts by cyclodextrins: Toward controlled selfassembly. J. Phys. Chem. B, 112, 11064-11070.

Leclercq, L.; Suisse, I.; Nowogrocki, G. \& Agbossou-Niedercorn, F. (2008). On the solid state inclusion of tetrabutylammonium cation in the imidazolium/trifluoromethanesulfonate H-bonds network observed in ionic co-crystals. J. Mol. Struct., 892, 433-437.

Leclercq, L.; Lacour, M.; Sanon, S. H. \& Schmitzer, A. R. (2009a). Thermoregulated microemulsions by cyclodextrin sequestration: A new approach to efficient catalyst recovery. Chem.-Eur. J., 15, 6327-6331.

Leclercq, L.; Noujeim, N. \& Schmitzer, A. R. (2009b). Development of N,N'-diaromatic diimidazolium cations: Arene interactions for highly organized crystalline materials. Cryst. Growth Des., 9, 4784-4792.

Leclercq, L. \& Schmitzer, A. (2009a). Supramolecular effects involving the incorporation of guest substrates in imidazolium ionic liquid networks: Recent advances and future developments. Supramol. Chem., 21, 245-263.

Leclercq, L. \& Schmitzer, A. R. (2009b). Supramolecular encapsulation of 1,3-bis(1adamantyl)imidazolium chloride by $\beta$-cyclodextrins: towards inhibition of $\mathrm{C}(2)$ H/D exchange. J. Phys. Org. Chem., 22, 91-95.

Leclercq, L.; Simard, M. \& Schmitzer, A. R. (2009c). 1,3-Dibenzylimidazolium salts: A paradigm of water and anion effect on the supramolecular H-bonds network. $J$. Mol. Struct., 918, 101-107.

Lee, C. K.; Huang, H. W. \& Lin, I. J. B. (2000). Simple amphiphilic liquid crystalline Nalkylimidazolium salts. A new solvent system providing a partially ordered environment. Chem. Commun., 1911-1912.

Lee, C. K.; Peng, H. H. \& Lin, I. J. B. (2004). Liquid crystals of N,N'-dialkylimidazolium salts comprising $\mathrm{Pd}^{2+}$ and $\mathrm{Cu}^{2+}$ ions. Chem. Mater., 16, 530-536.

Lee, K. M.; Lee, C. K. \& Lin, I. J. B. (1997). First example of interdigitated U-shape benzimidazolium ionic liquid crystals. Chem. Commun., 899-900.

Lee, U. H.; Kudo, T. \& Honma, I. (2009). High-ion conducting solidified hybrid electrolytes by the self-assembly of ionic liquids and $\mathrm{TiO}_{2}$. Chem. Commun., 3068-3070.

Lehn, J. M. (1988). Supramolecular chemistry - scope and perspectives molecules, supermolecules, and molecular devices. Angew. Chem.-Int. Edit. Engl., 27, 89-112.

Lehn, J. M. (1995). Supramolecular Chemistry: Concepts and Perspectives, VCH, 3527293116, Weinheim.

Lei, S.; Zhang, J. \& Huang, J. B. (2007). Promotion of the surface activity and aggregation ability of sodium dodecylsulfate in aqueous solution by ionic liquid 1-butyl-3methyl-imidazolium tetrafluoroborate. Acta Phys.-Chim. Sin., 23, 1657-1661. 
Li, F. H.; Wang, Z. H.; Shan, C. S.; Song, J. F.; Han, D. X. \& Niu, L. (2009a). Preparation of gold nanoparticles/functionalized multiwalled carbon nanotube nanocomposites and its glucose biosensing application. Biosens. Bioelectron., 24, 1765-1770.

Li, H. G.; Zhang, Q. A.; Zhao, Q.; Liu, M.; Liu, J. \& Sun, D. Z. Studies on interaction of ionic liquids with cyclodextrins in aqueous solution. Indian J. Chem. Sect A-Inorg. BioInorg. Phys. Theor. Anal. Chem., 49, 752-756.

Li, J. C.; Zhang, J. L.; Gao, H. X.; Han, B. X. \& Gao, L. (2005a). Nonaqueous microemulsioncontaining ionic liquid [bmim] $\left[\mathrm{PF}_{6}\right]$ as polar microenvironment. Colloid Polym. Sci., 283, 1371-1375.

Li, L. B.; Groenewold, J. \& Picken, S. J. (2005b). Transient phase-induced nucleation in ionic liquid crystals and size-frustrated thickening. Chem. Mater., 17, 250-257.

Li, N.; Cao, Q.; Gao, Y. A.; Zhang, J.; Zheng, L. Q.; Bai, X. T.; Dong, B.; Li, Z.; Zhao, M. W. \& $\mathrm{Yu}, \mathrm{L}$. (2007a). States of water located in the continuous organic phase of 1-butyl-3methylimidazolium tetrafluoroborate/Triton X-100/triethylamine reverse microemulsions. ChemPhysChem, 8, 2211-2217.

Li, N.; Gao, Y. A.; Zheng, L. Q.; Zhang, J.; Yu, L. \& Li, X. W. (2007b). Studies on the micropolarities of bmimBF 4 /TX-100/toluene ionic liquid microemulsions and their behaviors characterized by UV-visible spectroscopy. Langmuir, 23, 1091-1097.

Li, N.; Liu, J.; Zhao, X. Y.; Gao, Y. A.; Zheng, L. Q.; Zhang, J. \& Yu, L. (2007c). Complex formation of ionic liquid surfactant and $\beta$-cyclodextrin. Colloid Surf. A-Physicochem. Eng. Asp., 292, 196-201.

Li, N.; Zhang, S. H.; Zheng, L. Q.; Dong, B.; Li, X. W. \& Yu, L. (2008a). Aggregation behavior of long-chain ionic liquids in an ionic liquid. Phys. Chem. Chem. Phys., 10, 4375-4377.

Li, N.; Zhang, S. H.; Zheng, L. Q.; Wu, J. P.; Li, X. W. \& Yu, L. (2008b). Aggregation behavior of a fluorinated surfactant in 1-butyl-3-methylimidazolium ionic liquids. J. Phys. Chem. B, 112, 12453-12460.

Li, X. W.; Zhang, J.; Dong, B.; Zheng, L. Q. \& Tung, C. H. (2009b). Characterization of lyotropic liquid crystals formed in the mixtures of 1-alkyl-3-methylimidazolium bromide/p-xylene/water. Colloid Surf. A-Physicochem. Eng. Asp., 335, 80-87.

Li, X. W.; Zhang, J.; Zheng, L. Q.; Chen, B.; Wu, L. Z.; Lv, F. F.; Dong, B. \& Tung, C. H. (2009c). Microemulsions of N-alkylimidazolium ionic liquid and their performance as microreactors for the photocycloaddition of 9-substituted anthracenes. Langmuir, $25,5484-5490$.

Li, X. X.; Xu, X. D.; Dan, Y. Y.; Feng, J.; Ge, L. \& Zhang, M. L. (2008c). The crystallization of lysozyme in the system of ionic liquid [BMIm] $\left[\mathrm{BF}_{4}\right]$-water. Cryst. Res. Technol., 43, 1062-1068.

Lin, I. J. B. \& Vasam, C. S. (2005). Metal-containing ionic liquids and ionic liquid crystals based on imidazolium moiety. J. Organomet. Chem., 690, 3498-3512.

Ling, I.; Alias, Y.; Sobolev, A. N. \& Raston, C. L. (2009). Constructing multicomponent materials containing cavitands, and phosphonium and imidazolium cations. Cryst. Growth Des., 9, 4497-4503.

Ling, I.; Alias, Y.; Sobolev, A. N. \& Raston, C. L. (2010a). Multi-component bi-layers featuring [1-octyl-2,3-dimethylimidazolium boolean and p-sulfonatocalix[4]arene] supermolecules. New J. Chem., 34, 414-419. 
Ling, I.; Alias, Y.; Sobolev, A. N. \& Raston, C. L. (2010b). Calixarene C-8-imidazolium interplay as a design strategy for penetrating organic bi-layers. Crystengcomm, 12, 573-578.

Liu, H.; Wang, H. Z.; Tao, G. H. \& Kou, Y. (2005). Novel imidazolium-based ionic liquids with a crown-ether moiety. Chem. Lett., 34, 1184-1185.

Liu, J. H.; Cheng, S. Q.; Zhang, J. L.; Feng, X. Y.; Fu, X. G. \& Han, B. X. (2007). Reverse micelles in carbon dioxide with ionic-liquid domains. Angew. Chem.-Int. Edit., 46, 3313-3315.

Liu, L.; Zhao, N. \& Scherman, O. A. (2008). Ionic liquids as novel guests for cucurbit[6]uril in neutral water. Chem. Commun., 1070-1072.

Lopes, J. \& Padua, A. A. H. (2006). Nanostructural organization in ionic liquids. J. Phys. Chem. B, 110, 3330-3335.

Lu, L.; Sharma, N.; Gowda, G. A. N.; Khetrapal, C. L. \& Weiss, R. G. (1997). Enantiotropic nematic phases of quaternary ammonium halide salts based on trioctadecylamine. Liq. Cryst., 22, 23-28.

Luczak, J.; Hupka, J.; Thoming, J. \& Jungnickel, C. (2008). Self-organization of imidazolium ionic liquids in aqueous solution. Colloid Surf. A-Physicochem. Eng. Asp., 329, 125133.

Luczak, J.; Jungnickel, C.; Joskowska, M.; Thoming, J. \& Hupka, J. (2009). Thermodynamics of micellization of imidazolium ionic liquids in aqueous solutions. J. Colloid Interface Sci., 336, 111-116.

Luo, H. M.; Dai, S. \& Bonnesen, P. V. (2004a). Solvent extraction of $\mathrm{Sr}^{2+}$ and $\mathrm{Cs}^{+}$based on room-temperature ionic liquids containing monoaza-substituted crown ethers. Anal. Chem., 76, 2773-2779.

Luo, H. M.; Dai, S.; Bonnesen, P. V.; Buchanan, A. C.; Holbrey, J. D.; Bridges, N. J. \& Rogers, R. D. (2004b). Extraction of cesium ions from aqueous solutions using calix[4]arenebis(tert-octylbenzo-crown-6) in ionic liquids. Anal. Chem., 76, 3078-3083.

Luo, H. M.; Dai, S.; Bonnesen, P. V. \& Buchanan, A. C. (2006). Separation of fission products based on ionic liquids: Task-specific ionic liquids containing an aza-crown ether fragment. J. Alloy. Compd., 418, 195-199.

Luo, H. M.; Yu, M. \& Dai, S. (2007). Solvent extraction of $\mathrm{Sr}^{2+}$ and $\mathrm{Cs}^{+}$based on hydrophobic protic ionic liquids. Z. Naturfors. Sect. A-J. Phys. Sci., 62, 281-291.

Ma, K.; Shahkhatuni, A. A.; Somashekhar, B. S.; Gowda, G. A. N.; Tong, Y.; Khetrapal, C. L. \& Weiss, R. G. (2008). Room-temperature and low-ordered, amphotropic-lyotropic ionic liquid crystal phases induced by alcohols in phosphonium halides. Langmuir, 24, 9843-9854.

Ma, L.; Chen, W. X.; Li, H. \& Xu, Z. D. (2009). Synthesis and characterization of $\mathrm{MoS}_{2}$ nanostructures with different morphologies via an ionic liquid-assisted hydrothermal route. Mater. Chem. Phys., 116, 400-405.

Mathevet, F.; Masson, P.; Nicoud, J. F. \& Skoulios, A. (2005). Smectic liquid crystals from supramolecular guanidinium alkanesulfonates. J. Am. Chem. Soc., 127, 9053-9061.

Megyesi, M.; Biczok, L. \& Jablonkai, I. (2008). Highly sensitive fluorescence response to inclusion complex formation of berberine alkaloid with cucurbit[7]uril. J. Phys. Chem. C, 112, 3410-3416.

Mele, A.; Tran, C. D. \& Lacerda, S. H. D. (2003). The structure of a room-temperature ionic liquid with and without trace amounts of water: The role of $\mathrm{C}-\mathrm{H} \cdots \mathrm{O}$ and $\mathrm{C}-\mathrm{H} \cdots \mathrm{F}$ 
interactions in 1-n-butyl-3-methylimidazolium tetrafluoroborate. Angew. Chem.-Int. Edit., 42, 4364-4366.

Mele, A.; Romano, G.; Giannone, M.; Ragg, E.; Fronza, G.; Raos, G. \& Marcon, V. (2006). The local structure of ionic liquids: Cation-cation NOE interactions and internuclear

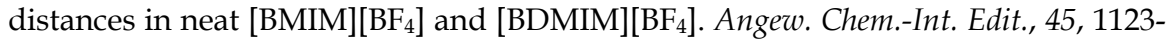
1126.

Merrigan, T. L.; Bates, E. D.; Dorman, S. C. \& Davis, J. H. (2000). New fluorous ionic liquids function as surfactants in conventional room-temperature ionic liquids. Chem. Commun., 2051-2052.

Metrangolo, P.; Meyer, F.; Pilati, T.; Resnati, G. \& Terraneo, G. (2008). Halogen bonding in supramolecular chemistry. Angew. Chem.-Int. Edit., 47, 6114-6127.

Miskolczy, Z.; Sebok-Nagy, K.; Biczok, L. \& Gokturk, S. (2004). Aggregation and micelle formation of ionic liquids in aqueous solution. Chem. Phys. Lett., 400, 296-300.

Miskolczy, Z. \& Biczok, L. (2009). Inclusion complex formation of ionic liquids with 4sulfonatocalixarenes studied by competitive binding of berberine alkaloid fluorescent probe. Chem. Phys. Lett., 477, 80-84.

Miskolczy, Z.; Biczok, L.; Megyesi, M. \& Jablonkai, I. (2009). Inclusion complex formation of ionic liquids and other cationic organic compounds with cucurbit[7]uril studied by 4',6-diamidino-2-phenylindole fluorescent probe. J. Phys. Chem. B, 113, 1645-1651.

Modaressi, A.; Sifaoui, H.; Grzesiak, B.; Solimando, R.; Domanska, U. \& Rogalski, M. (2007a). CTAB aggregation in aqueous solutions of ammonium based ionic liquids; conductimetric studies. Colloid Surf. A-Physicochem. Eng. Asp., 296, 104-108.

Modaressi, A.; Sifaoui, H.; Mielcarz, M.; Domanska, U. \& Rogalski, M. (2007b). Influence of the molecular structure on the aggregation of imidazolium ionic liquids in aqueous solutions. Colloid Surf. A-Physicochem. Eng. Asp., 302, 181-185.

Mohmeyer, N.; Kuang, D. B.; Wang, P.; Schmidt, H. W.; Zakeeruddin, S. M. \& Gratzel, M. (2006). An efficient organogelator for ionic liquids to prepare stable quasi-solidstate dye-sensitized solar cells. J. Mater. Chem., 16, 2978-2983.

Moniruzzaman, M.; Noriho, K.; Nakashima, K. \& Goto, M. (2008). Formation of reverse micelles in a room-temperature ionic liquid. ChemPhysChem, 9, 689-692.

Montes-Navajas, P.; Corma, A. \& Garcia, H. (2008). Supramolecular ionic liquids based on host-guest cucurbituril imidazolium complexes. J. Mol. Catal. A-Chem., 279, 165-169.

Moreno, M.; Castiglione, F.; Mele, A.; Pasqui, C. \& Raos, G. (2008). Interaction of water with the model ionic liquid $[\mathrm{bmim}]\left[\mathrm{BF}_{4}\right]$ : Molecular dynamics simulations and comparison with NMR data. J. Phys. Chem. B, 112, 7826-7836.

Mukai, T.; Yoshio, M.; Kato, T. \& Ohno, H. (2004). Effect of methyl groups onto imidazolium cation ring on liquid crystallinity and ionic conductivity of amphiphilic ionic liquids. Chem. Lett., 33, 1630-1631.

Najdanovic-Visak, V.; Esperanca, J.; Rebelo, L. P. N.; da Ponte, M. N.; Guedes, H. J. R.; Seddon, K. R.; de Sousa, H. C. \& Szydlowski, J. (2003). Pressure, isotope, and water co-solvent effects in liquid-liquid equilibria of (ionic liquid plus alcohol) systems. J. Phys. Chem. B, 107, 12797-12807.

Nakashima, T. \& Kimizuka, N. (2002). Vesicles in salt: Formation of bilayer membranes from dialkyldimethylammonium bromides in ether-containing ionic liquids. Chem. Lett., 1018-1019. 
Neve, F.; Crispini, A. \& Francescangeli, O. (2000). Structural studies on layered alkylpyridinium iodopalladate networks. Inorg. Chem., 39, 1187-1194.

Neve, F.; Francescangeli, O.; Crispini, A. \& Charmant, J. (2001). $\mathrm{A}_{2}\left[\mathrm{MX}_{4}\right]$ copper(II) pyridinium salts. From ionic liquids to layered solids to liquid crystals. Chem. Mater., 13, 2032-2041.

Niu, J. G.; Qiu, H. D.; Li, J.; Liu, X. \& Jiang, S. X. (2009). 1-Hexadecyl-3-methylimidazolium ionic liquid as a new cationic surfactant for separation of phenolic compounds by MEKC. Chromatographia, 69, 1093-1096.

Nockemann, P.; Servaes, K.; Van Deun, R.; Van Hecke, K.; Van Meervelt, L.; Binnemans, K. \& Gorller-Walrand, C. (2007). Speciation of uranyl complexes in ionic liquids by optical spectroscopy. Inorg. Chem., 46, 11335-11344.

Noro, A.; Matsushita, Y. \& Lodge, T. P. (2008). Thermoreversible supramacromolecular ion gels via hydrogen bonding. Macromolecules, 41, 5839-5844.

Noro, A.; Matsushita, Y. \& Lodge, T. P. (2009). Gelation mechanism of thermoreversible supramacromolecular ion gels via hydrogen bonding. Macromolecules, 42, 58025810.

Noujeim, N.; Jouvelet, B. \& Schmitzer, A. R. (2009). Formation of inclusion complexes between 1,1'-dialkyl-3,3'-(1,4-phenylene)bisimidazolium dibromide salts and cucurbit[7]uril. J. Phys. Chem. B, 113, 16159-16168.

Okamura, H.; Hirayama, N.; Morita, K.; Shimojo, K.; Naganawa, H. \& Imura, H. (2010). Synergistic effect of 18-crown-6 derivatives on chelate extraction of lanthanoids(III) into an ionic liquid with 2-thenoyltrifluoroacetone. Anal. Sci., 26, 607-611.

Oshovsky, G. V.; Reinhoudt, D. N. \& Verboom, W. (2007). Supramolecular chemistry in water. Angew. Chem.-Int. Edit., 46, 2366-2393.

Ozawa, R.; Hayashi, S.; Saha, S.; Kobayashi, A. \& Hamaguchi, H. (2003). Rotational isomerism and structure of the 1-butyl-3-methylimidazolium cation in the ionic liquid state. Chem. Lett., 32, 948-949.

Pal, S. K. \& Kumar, S. (2006). Microwave-assisted synthesis of novel imidazolium-based ionic liquid crystalline dimers. Tetrahedron Lett., 47, 8993-8997.

Paramasivam, I.; Macak, J. M.; Selvam, T. \& Schmuki, P. (2008). Electrochemical synthesis of self-organized $\mathrm{TiO}_{2}$ nanotubular structures using an ionic liquid [BMIM][BF 4 . Electrochim. Acta, 54, 643-648.

Park, C. L.; Jee, A. Y.; Lee, M. Y. \& Lee, S. G. (2009a). Gelation, functionalization, and solution behaviors of nanodiamonds with ionic liquids. Chem. Commun., 5576-5578.

Park, H. S.; Choi, B. G.; Yang, S. H.; Shin, W. H.; Kang, J. K.; Jung, D. \& Hong, W. H. (2009b). Ionic-liquid-assisted sonochemical synthesis of carbon-nanotube-based nanohybrids: Control in the structures and interfacial characteristics. Small, 5, 17541760 .

Park, S. H.; Demberelnyamba, D.; Jang, S. H. \& Byun, M. W. (2006). Ionic liquid-type crown ether as a novel medium for a liquid/liquid extraction of radioactive metal ion ${ }^{85} \mathrm{Sr}^{2+}$. Chem. Lett., 35, 1024-1025.

Patrascu, C.; Gauffre, F.; Nallet, F.; Bordes, R.; Oberdisse, J.; de Lauth-Viguerie, N. \& Mingotaud, C. (2006). Micelles in ionic liquids: Aggregation behavior of alkyl poly(ethyleneglycol)-ethers in 1-butyl-3-methyl-imidazolium type ionic liquids. ChemPhysChem, 7, 99-101. 
Pedireddi, V. R.; Shimpi, M. R. \& Yakhmi, J. V. (2005). Room-temperature ionic liquids: For a difference in the supramolecular synthesis. Indo-French Symposium on Fibrillar Networks as Advanced Materials, pp. 83-87, Strasbourg, FRANCE, Sep 21-23, Wiley-V C H Verlag Gmbh.

Pickett, C. J. (1985). A simple hydrocarbon electrolyte - completing the electron-transfer series $\left[\mathrm{Fe}_{4} \mathrm{~S}_{4}(\mathrm{SPh})_{4}\right]^{1-/ 2-/ 3-/ 4-}$. J. Chem. Soc.-Chem. Commun., 323-326.

Pino, V.; Yao, C. \& Anderson, J. L. (2009). Micellization and interfacial behavior of imidazolium-based ionic liquids in organic solvent-water mixtures. J. Colloid Interface Sci., 333, 548-556.

Popov, K.; Ronkkomaki, H.; Hannu-Kuure, M.; Kuokkanen, T.; Lajunen, M.; Vendilo, A.; Oksman, P. \& Lajunen, L. H. J. (2007). Stability of crown-ether complexes with alkali-metal ions in ionic liquid-water mixed solvents. J. Incl. Phenom. Macrocycl. Chem., 59, 377-381.

Pott, T. \& Meleard, P. (2009). New insight into the nanostructure of ionic liquids: a small angle X-ray scattering (SAXS) study on liquid tri-alkyl-methyl-ammonium bis(trifluoromethanesulfonyl)amides and their mixtures. Phys. Chem. Chem. Phys., 11, 5469-5475.

Qiu, Z. M. \& Texter, J. (2008). Ionic liquids in microemulsions. Curr. Opin. Colloid Interface Sci., 13, 252-262.

Rebelo, L. P. N.; Lopes, J. N. C.; Esperanca, J.; Guedes, H. J. R.; Lachwa, J.; Najdanovic-Visak, V. \& Visak, Z. P. (2007). Accounting for the unique, doubly dual nature of ionic liquids from a molecular thermodynamic, and modeling standpoint. Accounts Chem. Res., 40, 1114-1121.

Rickert, P. G.; Stepinski, D. C.; Rausch, D. J.; Bergeron, R. M.; Jakab, S. \& Dietz, M. L. (2007). Solute-induced dissolution of hydrophobic ionic liquids in water. Talanta, 72, 315320.

Rogers, R. D.; Bridges, N. J.; Holbrey, J. D.; Luo, H.; Dai, S. \& Bonnesen, P. V. (2004). The role of ion exchange vs solvent extraction processes in metal ion partitioning in ionic liquid/aqueous systems: Cesium extractions with calix[4]arene-bis(tert-octylbenzocrown-6) in imidazolium bistrifylimide ionic liquids. 227th National Meeting of the American-Chemical Society, pp. 227-IEC, Anaheim, CA, Mar 28-Apr 01, Amer Chemical Soc.

Saha, S.; Hayashi, S.; Kobayashi, A. \& Hamaguchi, H. (2003). Crystal structure of 1-butyl-3methylimidazolium chloride. A clue to the elucidation of the ionic liquid structure. Chem. Lett., 32, 740-741.

Samitsu, S.; Araki, J.; Kataoka, T. \& Ito, K. (2006). New solvent for polyrotaxane. II. Dissolution behavior of polyrotaxane in ionic liquids and preparation of ionic liquid-containing slide-ring gels. J. Polym. Sci. Pt. B-Polym. Phys., 44, 1985-1994.

Sauer, S.; Steinke, N.; Baro, A.; Laschat, S.; Giesselmann, F. \& Kantlehner, W. (2008). Guanidinium chlorides with triphenylene moieties displaying columnar mesophases. Chem. Mater., 20, 1909-1915.

Schroder, U.; Wadhawan, J. D.; Compton, R. G.; Marken, F.; Suarez, P. A. Z.; Consorti, C. S.; de Souza, R. F. \& Dupont, J. (2000). Water-induced accelerated ion diffusion: voltammetric studies in 1-methyl-3-[2,6-(S)-dimethylocten-2-yl]imidazolium tetrafluoroborate, 1-butyl-3-methylimidazolium tetrafluoroborate and hexafluorophosphate ionic liquids. New J. Chem., 24, 1009-1015. 
Scott, J. L.; MacFarlane, D. R.; Raston, C. L. \& Teoh, C. M. (2000). Clean, efficient syntheses of cyclotriveratrylene (CTV) and tris-(O-allyl)CTV in an ionic liquid. Green Chem., 2, 123-126.

Seddon, K. R.; Stark, A. \& Torres, M. J. (2000). Influence of chloride, water, and organic solvents on the physical properties of ionic liquids. Pure Appl. Chem., 72, 2275-2287.

Selvan, M. S.; McKinley, M. D.; Dubois, R. H. \& Atwood, J. L. (2000). Liquid-liquid equilibria for toluene plus heptane+1-ethyl-3-methylimidazolium triiodide and toluene plus heptane+1-butyl-3-methylimidazolium triiodide. J. Chem. Eng. Data, 45, 841-845.

Seo, S. H.; Park, J. H.; Tew, G. N. \& Chang, J. Y. (2007). Thermotropic liquid crystals of 1Himidazole amphiphiles showing hexagonal columnar and micellar cubic phases. Tetrahedron Lett., 48, 6839-6844.

Seth, D.; Chakraborty, A.; Setua, P. \& Sarkar, N. (2006). Interaction of ionic liquid with water in ternary microemulsions (Triton X-100/water/1-butyl-3-methylimidazolium hexafluorophosphate) probed by solvent and rotational relaxation of coumarin 153 and coumarin 151. Langmuir, 22, 7768-7775.

Seth, D.; Chakraborty, A.; Setua, P. \& Sarkar, N. (2007a). Interaction of ionic liquid with water with variation of water content in 1-butyl-3-methyl-imidazolium hexafluorophosphate $\left([\mathrm{bmim}]\left[\mathrm{PF}_{6}\right]\right) / \mathrm{TX}-100 /$ water ternary microemulsions monitored by solvent and rotational relaxation of coumarin 153 and coumarin 490 . J. Chem. Phys., 126, 224512.

Seth, D; Setua, P.; Chakraborty, A. \& Sarkar, N. (2007b). Solvent relaxation of a roomtemperature ionic liquid $[\mathrm{bmim}]\left[\mathrm{PF}_{6}\right]$ confined in a ternary microemulsion. J. Chem. Sci., 119, 105-111.

Sha, M. L.; Wu, G. Z.; Liu, Y. S.; Tang, Z. F. \& Fang, H. P. (2009). Drastic phase transition in ionic liquid [Dmim] Cl confined between graphite walls: New phase formation. $J$. Phys. Chem. C, 113, 4618-4622.

Shiflett, M. B. \& Yokozeki, A. (2008). Liquid-liquid equilibria in binary mixtures containing fluorinated benzenes and ionic liquid 1-ethyl-3-methylimidazolium bis(trifluoromethylsulfonyl)imide. J. Chem. Eng. Data, 53, 2683-2691.

Shiflett, M. B.; Niehaus, A. M. S. \& Yokozeki, A. (2009). Liquid-liquid equilibria in binary mixtures containing chlorobenzene, bromobenzene, and iodobenzene with ionic liquid 1-ethyl-3-methylimidazolim bis(trifluoromethylsulfonyl)imide. J. Chem. Eng. Data, 54, 2090-2094.

Shiflett, M. B. \& Niehaus, A. M. S. (2010). Liquid-liquid equilibria in binary mixtures containing substituted benzenes with ionic liquid 1-ethyl-3-methylimidazolium bis(trifluoromethylsulfonyl)imide. J. Chem. Eng. Data, 55, 346-353.

Shigeto, S. \& Hamaguchi, H. (2006). Evidence for mesoscopic local structures in ionic liquids: CARS signal spatial distribution of $\left[\mathrm{C}_{n} \mathrm{mim}\right]\left[\mathrm{PF}_{6}\right](\mathrm{n}=4,6,8)$. Chem. Phys. Lett., 427, 329-332.

Shimizu, K.; Gomes, M. F. C.; Padua, A. A. H.; Rebelo, L. P. N. \& Lopes, J. N. C. (2009). On the role of the dipole and quadrupole moments of aromatic compounds in the solvation by ionic liquids. J. Phys. Chem. B, 113, 9894-9900.

Shimojo, K. \& Goto, M. (2004a). First application of calixarenes as extractants in roomtemperature ionic liquids. Chem. Lett., 33, 320-321.

Shimojo, K. \& Goto, M. (2004b). Solvent extraction and stripping of silver ions in roomtemperature ionic liquids containing calixarenes. Anal. Chem., 76, 5039-5044. 
Shimojo, K.; Kamiya, N.; Tani, F.; Naganawa, H.; Naruta, Y. \& Goto, M. (2006a). Extractive solubilization, structural change, and functional conversion of cytochrome $\mathrm{c}$ in ionic liquids via crown ether complexation. Anal. Chem., 78, 7735-7742.

Shimojo, K.; Nakashima, K.; Kamiya, N. \& Goto, M. (2006b). Crown ether-mediated extraction and functional conversion of cytochrome $\mathrm{c}$ in ionic liquids. Biomacromolecules, 7, 2-5.

Shimojo, K.; Okamura, H.; Hirayama, N.; Umetani, S.; Imura, H. \& Naganawa, H. (2009). Cooperative intramolecular interaction of diazacrown ether bearing $\beta$-diketone fragments on an ionic liquid extraction system. Dalton Trans., 4850-4852.

Sieffert, N. \& Wipff, G. (2006a). Alkali cation extraction by calix[4]crown-6 to roomtemperature ionic liquids. The effect of solvent anion and humidity investigated by molecular dynamics simulations. J. Phys. Chem. A, 110, 1106-1117.

Sieffert, N. \& Wipff, G. (2006b). Comparing an ionic liquid to a molecular solvent in the cesium cation extraction by a calixarene: A molecular dynamics study of the aqueous interfaces. J. Phys. Chem. B, 110, 19497-19506.

Sieffert, N. \& Wipff, G. (2007). The effect of a solvent modifier in the cesium extraction by a calix[4] arene: a molecular dynamics study of the oil phase and the oil-water interface. Phys. Chem. Chem. Phys., 9, 3763-3775.

Sifaoui, H.; Lugowska, K.; Domanska, U.; Modaressi, A. \& Rogalski, M. (2007). Ammonium ionic liquid as modulator of the critical micelle concentration of ammonium surfactant at aqueous solution: Conductimetric and dynamic light scattering (DLS) studies. J. Colloid Interface Sci., 314, 643-650.

Singh, K.; Marangoni, D. G.; Quinn, J. G. \& Singer, R. D. (2009). Spontaneous vesicle formation with an ionic liquid amphiphile. J. Colloid Interface Sci., 335, 105-111.

Singh, T. \& Kumar, A. (2007). Aggregation behavior of ionic liquids in aqueous solutions: Effect of alkyl chain length, cations, and anions. J. Phys. Chem. B, 111, 7843-7851.

Singh, T. \& Kumar, A. (2008). Self-aggregation of ionic liquids in aqueous media: A thermodynamic study. Colloid Surf. A-Physicochem. Eng. Asp., 318, 263-268.

Smirnova, S. V.; Torocheshnikova, II; Formanovsky, A. A. \& Pletnev, I. V. (2004). Solvent extraction of amino acids into a room temperature ionic liquid with dicyclohexano18-crown-6. Anal. Bioanal. Chem., 378, 1369-1375.

St-Jacques, A. D.; Wyman, I. W. \& Macartney, D. H. (2008). Encapsulation of charge-diffuse peralkylated onium cations in the cavity of cucurbit[7]uril. Chem. Commun., 49364938.

Stepinski, D. C.; Jensen, M. P.; Dzielawa, J. A. \& Dietz, M. L. (2005). Synergistic effects in the facilitated transfer of metal ions into room-temperature ionic liquids. Green Chem., 7, 151-158.

Stepinski, D. C.; Vandegrift, G. F.; Shkrob, I. A.; Wishart, J. F.; Kerr, K.; Dietz, M. L.; Qadah, D. T. D. \& Garvey, S. L. (2010). Extraction of tetra-oxo anions into a hydrophobic, ionic liquid-based solvent without concomitant ion exchange. Ind. Eng. Chem. Res., 49, 5863-5868.

Surette, J. K. D.; Green, L. \& Singer, R. D. (1996). 1-ethyl-3-methylimidazolium halogenoaluminate melts as reaction media for the Friedel-Crafts acylation of ferrocene. Chem. Commun., 2753-2754. 
Takamuku, T.; Kyoshoin, Y.; Shimomura, T.; Kittaka, S. \& Yamaguchi, T. (2009). Effect of water on structure of hydrophilic imidazolium-based ionic liquid. J. Phys. Chem. B, $113,10817-10824$.

Talaty, E. R.; Raja, S.; Storhaug, V. J.; Dolle, A. \& Carper, W. R. (2004). Raman and infrared spectra and a initio calculations of $\mathrm{C}_{2-4} \mathrm{MIM}$ imidazolium hexafluorophosphate ionic liquids. J. Phys. Chem. B, 108, 13177-13184.

Tamuralis, W.; Lis, L. J. \& Quinn, P. J. (1987). Structures and mechanisms of lipid phasetransitions in nonaqueous media - dipalmitoylphosphatidylcholine in fused salt. J. Phys. Chem., 91, 4625-4627.

Tan, L.; Dong, X. L.; Wang, H. \& Yang, Y. J. (2009). Gels of ionic liquid [ $\left.\mathrm{C}_{4} \mathrm{mim}\right]\left[\mathrm{PF}_{6}\right]$ formed by self-assembly of gelators and their electrochemical properties. Electrochem. Commun., 11, 933-936.

Tang, J.; Li, D.; Sun, C. Y.; Zheng, L. Z. \& Li, J. H. (2006). Temperature dependant selfassembly of surfactant Brij 76 in room temperature ionic liquid. Colloid Surf. APhysicochem. Eng. Asp., 273, 24-28.

Taubert, A. (2004). CuCl nanoplatelets from an ionic liquid-crystal precursor. Angew. Chem.Int. Edit., 43, 5380-5382.

Thomaier, S. \& Kunz, W. (2007). Aggregates in mixtures of ionic liquids. J. Mol. Liq., 130, 104-107.

Tittarelli, F.; Masson, P. \& Skoulios, A. (1997). Structural compatibility of smectic sublayers: Liquid crystals from oxynitrostilbene derivatives of dialkyldimethylammonium bromides. Liq. Cryst., 22, 721-726.

Triolo, A.; Russina, O.; Bleif, H. J. \& Di Cola, E. (2007). Nanoscale segregation in room temperature ionic liquids. J. Phys. Chem. B, 111, 4641-4644.

Tsuda, T.; Hussey, C. L.; Luo, H. M. \& Dai, S. (2006). Recovery of cesium extracted from simulated tank waste with an ionic liquid: Water and oxygen effects. J. Electrochem. Soc., 153, D171-D176.

Ueki, T.; Watanabe, M. \& Lodge, T. P. (2009). Doubly thermosensitive self-assembly of diblock copolymers in ionic liquids. Macromolecules, 42, 1315-1320.

Urahata, S. M. \& Ribeiro, M. C. C. (2004). Structure of ionic liquids of 1-alkyl-3methylimidazolium cations: A systematic computer simulation study. J. Chem. Phys., 120, 1855-1863.

van Rantwijk, F.; Lau, R. M. \& Sheldon, R. A. (2003). Biocatalytic transformations in ionic liquids. Trends Biotechnol., 21, 131-138.

Vanyur, R.; Biczok, L. \& Miskolczy, Z. (2007). Micelle formation of 1-alkyl-3methylimidazolium bromide ionic liquids in aqueous solution. Colloid Surf. APhysicochem. Eng. Asp., 299, 256-261.

Vendilo, A. G.; Ronkkomaki, H.; Hannu-Kuure, M.; Lajunen, M.; Asikkala, J.; Chernikova, E. A.; Lajunen, L. H. J.; Tuomi, T. \& Popo, K. I. (2009). Thermodynamics of complex formation in ionic liquids: cesium complexes with 18-crown-6. Mendeleev Commun., 19, 196-197.

Vendilo, A. G.; Djigailo, D. I.; Ronkkomaki, H.; Lajunen, M.; Chernikova, E. A.; Lajunen, L. H. J.; Pletnev, I. V. \& Popov, K. I. (2010a). A correlation of caesium-18-crown-6 complex formation constants with the extraction capability for hydrophobic ionic liquids. Mendeleev Commun., 20, 122-124. 
Vendilo, A. G.; Ronkkomaki, H.; Hannu-Kuure, M.; Lajunen, M.; Asikkala, J.; Krasovsky, V. G.; Chernikova, E. A.; Oksman, P.; Lajunen, L. H. J.; Tuomi, T. \& Popov, K. I. (2010b). Thermodynamics of cesium complexes formation with 18-crown-6 in ionic liquids. J. Incl. Phenom. Macrocycl. Chem., 66, 223-230.

Visser, A. E.; Swatloski, R. P.; Reichert, W. M.; Griffin, S. T. \& Rogers, R. D. (2000). Traditional extractants in nontraditional solvents: Groups 1 and 2 extraction by crown ethers in room-temperature ionic liquids. Ind. Eng. Chem. Res., 39, 3596-3604.

Visser, A. E.; Swatloski, R. P.; Reichert, W. M.; Mayton, R.; Sheff, S.; Wierzbicki, A.; Davis, J. H. \& Rogers, R. D. (2001). Task-specific ionic liquids for the extraction of metal ions from aqueous solutions. Chem. Commun., 135-136.

Wang, H. F.; Zhu, Y. Z.; Yan, X. P.; Gao, R. Y. \& Zheng, J. Y. (2006). A room temperature ionic liquid (RTIL)-mediated, non-hydrolytic sol-gel methodology to prepare molecularly imprinted, silica-based hybrid monoliths for chiral separation. Adv. Mater., 18, 3266-3270.

Wang, H. Y.; Wang, J. J.; Zhang, S. B. \& Xuan, X. P. (2008). Structural effects of anions and cations on the aggregation behavior of ionic liquids in aqueous solutions. J. Phys. Chem. B, 112, 16682-16689.

Wang, J. J.; Wang, H. Y.; Zhang, S. L.; Zhang, H. H. \& Zhao, Y. (2007). Conductivities, volumes, fluorescence, and aggregation behavior of ionic liquids $\left[\mathrm{C}_{4} \mathrm{mim}\right]\left[\mathrm{BF}_{4}\right]$ and $\left[\mathrm{C}_{\mathrm{n}} \operatorname{mim}\right] \mathrm{Br}(\mathrm{n}=4,6,8,10,12)$ in aqueous solutions. J. Phys. Chem. B, 111, 6181-6188.

Wang, L. Y.; Chen, X.; Chai, Y. C.; Hao, J. C.; Sui, Z. M.; Zhuang, W. C. \& Sun, Z. W. (2004). Lyotropic liquid crystalline phases formed in an ionic liquid. Chem. Commun., 28402841.

Wang, S. O.; Xu, Z. X.; Fang, G. Z.; Zhang, Y.; Liu, B. \& Zhu, H. P. (2009). Development of a biomimetic enzyme-linked immunosorbent assay method for the determination of estrone in environmental water using novel molecularly imprinted films of controlled thickness as artificial antibodies. J. Agric. Food Chem., 57, 4528-4534.

Wang, Y. T. \& Voth, G. A. (2005). Unique spatial heterogeneity in ionic liquids. J. Am. Chem. Soc., 127, 12192-12193.

Wang, Z. N.; Liu, F.; Gao, Y.; Zhuang, W. C.; Xu, L. M.; Han, B. X.; Li, G. Z. \& Zhang, G. Y. (2005). Hexagonal liquid crystalline phases formed in ternary systems of Brij 97water-lonic liquids. Langmuir, 21, 4931-4937.

Wang, Z. N. \& Zhou, W. (2009). Lamellar liquid crystals of Brij 97 aqueous solutions containing different additives. J. Solut. Chem., 38, 659-668.

Wathier, M. \& Grinstaff, M. W. (2008). Synthesis and properties of supramolecular ionic networks. J. Am. Chem. Soc., 130, 9648-9649.

Weingartner, H. (2008). Understanding ionic liquids at the molecular level: Facts, problems, and controversies. Angew. Chem.-Int. Edit., 47, 654-670.

Welton, T. (1999). Room-temperature ionic liquids. Solvents for synthesis and catalysis. Chem. Rev., 99, 2071-2083.

Widegren, J. A.; Saurer, E. M.; Marsh, K. N. \& Magee, J. W. (2005). Electrolytic conductivity of four imidazolium-based room-temperature ionic liquids and the effect of a water impurity. J. Chem. Thermodyn., 37, 569-575.

Wu, B. H.; Hu, D.; Kuang, Y. J.; Liu, B.; Zhang, X. H. \& Chen, J. H. (2009a). Functionalization of carbon nanotubes by an ionic-liquid polymer: Dispersion of $\mathrm{Pt}$ and $\mathrm{PtRu}$ 
nanoparticles on carbon nanotubes and their electrocatalytic oxidation of methanol. Angew. Chem.-Int. Edit., 48, 4751-4754.

Wu, J. P.; Li, N.; Zheng, L. Q.; Li, X. W.; Gao, Y. A. \& Inoue, T. (2008). Aggregation behavior of polyoxyethylene (20) sorbitan monolaurate (Tween 20) in imidazolium based ionic liquids. Langmuir, 24, 9314-9322.

Wu, J. P.; Zhang, J.; Zheng, L. Q.; Zhao, X. Y.; Li, N. \& Dong, B. (2009b). Characterization of lyotropic liquid crystalline phases formed in imidazolium based ionic liquids. Colloid Surf. A-Physicochem. Eng. Asp., 336, 18-22.

Xiao, D.; Rajian, J. R.; Cady, A.; Li, S. F.; Bartsch, R. A. \& Quitevis, E. L. (2007). Nanostructural organization and anion effects on the temperature dependence of the optical Kerr effect spectra of ionic liquids. J. Phys. Chem. B, 111, 4669-4677.

Xiao, S. F.; Lu, X. M.; Lu, Q. H. \& Su, B. (2008). Photosensitive liquid-crystalline supramolecules self-assembled from ionic liquid crystal and polyelectrolyte for laser-induced optical anisotropy. Macromolecules, 41, 3884-3892.

$\mathrm{Xu}, \mathrm{C}$; Shen, X. H.; Chen, Q. D. \& Gao, H. C. (2009). Investigation on the extraction of strontium ions from aqueous phase using crown ether-ionic liquid systems. Sci. China Ser. B-Chem., 52, 1858-1864.

Xu, C.; Yuan, L. Y.; Shen, X. H. \& Zhai, M. L. (2010). Efficient removal of caesium ions from aqueous solution using a calix crown ether in ionic liquids: mechanism and radiation effect. Dalton Trans., 39, 3897-3902.

Yasuda, T.; Tanabe, K.; Tsuji, T.; Coti, K. K.; Aprahamian, I.; Stoddart, J. F. \& Kato, T. (2010). A redox-switchable 2 rotaxane in a liquid-crystalline state. Chem. Commun., 46, 1224-1226.

Yazaki, S.; Funahashi, M. \& Kato, T. (2008a). An electrochromic nanostructured liquid crystal consisting of $\pi$-conjugated and ionic moieties. J. Am. Chem. Soc., 130, 1320613207.

Yazaki, S.; Kamikawa, Y.; Yoshio, M.; Hamasaki, A.; Mukai, T.; Ohno, H. \& Kato, T. (2008b). Ionic liquid crystals: Self-assembly of imidazolium salts containing an L-glutamic acid moiety. Chem. Lett., 37, 538-539.

Yazaki, S.; Funahashi, M.; Kagimoto, J.; Ohno, H. \& Kato, T. (2010). Nanostructured liquid crystals combining ionic and electronic functions. J. Am. Chem. Soc., 132, 7702-7708.

Yoshio, M.; Mukai, T.; Ohno, H. \& Kato, T. (2004). One-dimensional ion transport in selforganized columnar ionic liquids. J. Am. Chem. Soc., 126, 994-995.

Yoshio, M.; Kagata, T.; Hoshino, K.; Mukai, T.; Ohno, H. \& Kato, T. (2006). One-dimensional ion-conductive polymer films: Alignment and fixation of ionic channels formed by self-organization of polymerizable columnar liquid crystals. J. Am. Chem. Soc., 128, 5570-5577.

Yoshio, M.; Ichikawa, T.; Shimura, H.; Kagata, T.; Hamasaki, A.; Mukai, T.; Ohno, H. \& Kato, T. (2007). Columnar liquid-crystalline imidazolium salts. Effects of anions and cations on mesomorphic properties and ionic conductivity. Bull. Chem. Soc. Jpn., 80, 1836-1841.

Yoshizawa, H.; Mihara, T. \& Koide, N. (2004). Thermal properties and ionic conductivity of imidazolium salt derivatives having a calamitic mesogen. Mol. Cryst. Liquid Cryst., 423, 61-72. 
Yuan, L. Y.; Peng, J.; Xu, L.; Zhai, M. L.; Li, J. Q. \& Wei, G. S. (2008). Influence of $\gamma$-radiation on the ionic liquid $\left[\mathrm{C}_{4} \mathrm{mim}\right]\left[\mathrm{PF}_{6}\right]$ during extraction of strontium ions. Dalton Trans., 6358-6360.

Yuan, L. Y.; Peng, J.; Xu, L.; Zhai, M. L.; Li, J. Q. \& Wei, G. S. (2009). Radiation effects on hydrophobic ionic liquid $\left[\mathrm{C}_{4} \mathrm{mim}\right]\left[\mathrm{NTf}_{2}\right]$ during extraction of strontium ions. J. Phys. Chem. B, 113, 8948-8952.

Zech, O.; Thomaier, S.; Bauduin, P.; Ruck, T.; Touraud, D. \& Kunz, W. (2009). Microemulsions with an ionic liquid surfactant and room temperature ionic liquids as polar pseudo-phase. J. Phys. Chem. B, 113, 465-473.

Zhang, G. D.; Chen, X. A.; Xie, Y. Z.; Zhao, Y. R. \& Qiu, H. Y. (2007). Lyotropic liquid crystalline phases in a ternary system of 1-hexadecyl-3-methylimidazolium chloride/1-decanol/water. J. Colloid Interface Sci., 315, 601-606.

Zhang, G. D.; Chen, X.; Zhao, Y. R.; Ma, F. M.; Jing, B. \& Qiu, H. Y. (2008a). Lyotropic liquidcrystalline phases formed by Pluronic P123 in ethylammonium nitrate. J. Phys. Chem. B, 112, 6578-6584.

Zhang, H. C.; Li, K.; Liang, H. J. \& Wang, J. J. (2008b). Spectroscopic studies of the aggregation of imidazolium-based ionic liquids. Colloid Surf. A-Physicochem. Eng. Asp., 329, 75-81.

Zhang, L. Q.; Xu, Z.; Wang, Y. \& Li, H. R. (2008c). Prediction of the solvation and structural properties of ionic liquids in water by two-dimensional correlation spectroscopy. $J$. Phys. Chem. B, 112, 6411-6419.

Zhang, Q. X.; Shan, C. S.; Wang, X. D.; Chen, L. L.; Niu, L. \& Chen, B. (2008d). New ionic liquid crystals based on azobenzene moiety with two symmetric imidazolium ion group substituents. Liq. Cryst., 35, 1299-1305.

Zhang, S. H.; Li, N.; Zheng, L. Q.; Li, X. W.; Gao, Y. A. \& Yu, L. (2008e). Aggregation behavior of pluronic triblock copolymer in 1-butyl-3-methylimidazolium type ionic liquids. J. Phys. Chem. B, 112, 10228-10233.

Zhang, W.; Yang, T.; Zhuang, X. M.; Guo, Z. Y. \& Jiao, K. (2009). An ionic liquid supported $\mathrm{CeO} 2$ nanoshuttles-carbon nanotubes composite as a platform for impedance DNA hybridization sensing. Biosens. Bioelectron., 24, 2417-2422.

Zhao, D. B.; Wu, M.; Kou, Y. \& Min, E. (2002). Ionic liquids: applications in catalysis. Catal. Today, 74, 157-189.

Zhao, N.; Liu, L.; Biedermann, F. \& Scherman, O. A. (2010). Binding studies on CB[6] with a series of 1-alkyl-3-methylimidazolium ionic liquids in an aqueous system. Chem.Asian J., 5, 530-537.

Zhao, Y.; Gao, S. J.; Wang, J. J. \& Tang, J. M. (2008a). Aggregation of ionic liquids [ $\left.\mathrm{C}_{\mathrm{n}} \mathrm{mim}\right] \mathrm{Br}$ $(\mathrm{n}=4,6,8,10,12)$ in $\mathrm{D}_{2} \mathrm{O}$ : A NMR study. J. Phys. Chem. B, 112, 2031-2039.

Zhao, Y.; Li, M. \& Lu, Q. H. (2008b). Tunable wettability of polyimide films based on electrostatic self-assembly of ionic liquids. Langmuir, 24, 3937-3943.

Zhao, Y. R.; Chen, X.; Jing, B.; Wang, X. D. \& Ma, F. M. (2009a). Novel gel phase formed by mixing a cationic surfactive ionic liquid $\left[\mathrm{C}_{16} \mathrm{mim}\right] \mathrm{Cl}$ and an anionic surfactant SDS in aqueous solution. J. Phys. Chem. B, 113, 983-988.

Zhao, Y. R.; Chen, X. \& Wang, X. D. (2009b). Liquid crystalline phases self-organized from a surfactant-like ionic liquid $\left[\mathrm{C}_{16} \mathrm{mim}\right] \mathrm{Cl}$ in ethylammonium nitrate. J. Phys. Chem. B, 113, 2024-2030. 
Zheng, L.; Guo, C.; Wang, J.; Liang, X. F.; Chen, S.; Ma, J. H.; Yang, B.; Jiang, Y. Y. \& Liu, H. Z. (2007). Effect of ionic liquids on the aggregation behavior of PEO-PPO-PEO block copolymers in aqueous solution. J. Phys. Chem. B, 111, 1327-1333.

Zheng, Y.; Xuan, X. P.; Wang, J. J. \& Fan, M. H. The enhanced dissolution $\beta$-cyclodextrin in some hydrophilic ionic liquids. J. Phys. Chem. A, 114, 3926-3931.

Zhou, Y. \& Antonietti, M. (2004). A series of highly ordered, super-microporus, lamellar silicas prepared by nanocasting with ionic liquids. Chem. Mater., 16, 544-550. 


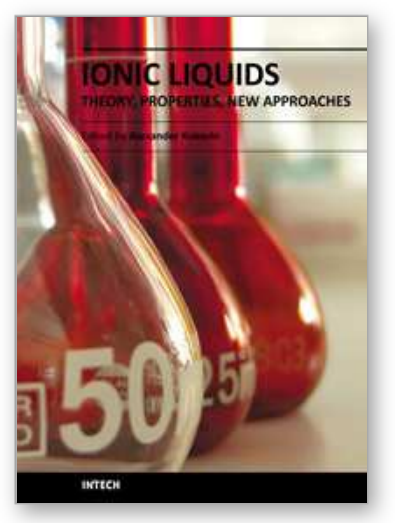

\section{Ionic Liquids: Theory, Properties, New Approaches}

Edited by Prof. Alexander Kokorin

ISBN 978-953-307-349-1

Hard cover, 738 pages

Publisher InTech

Published online 28, February, 2011

Published in print edition February, 2011

Ionic Liquids (ILs) are one of the most interesting and rapidly developing areas of modern physical chemistry, technologies and engineering. This book, consisting of 29 chapters gathered in 4 sections, reviews in detail and compiles information about some important physical-chemical properties of ILs and new practical approaches. This is the first book of a series of forthcoming publications on this field by this publisher. The first volume covers some aspects of synthesis, isolation, production, modification, the analysis methods and modeling to reveal the structures and properties of some room temperature ILs, as well as their new possible applications. The book will be of help to chemists, physicists, biologists, technologists and other experts in a variety of disciplines, both academic and industrial, as well as to students and PhD students. It may help to promote the progress in ILs development also.

\section{How to reference}

In order to correctly reference this scholarly work, feel free to copy and paste the following:

Xinghai Shen, Qingde Chen, Jingjing Zhang and Pei Fu (2011). Supramolecular Structures in the Presence of Ionic Liquids, Ionic Liquids: Theory, Properties, New Approaches, Prof. Alexander Kokorin (Ed.), ISBN: 978953-307-349-1, InTech, Available from: http://www.intechopen.com/books/ionic-liquids-theory-properties-newapproaches/supramolecular-structures-in-the-presence-of-ionic-liquids

\section{INTECH}

open science | open minds

\author{
InTech Europe \\ University Campus STeP Ri \\ Slavka Krautzeka 83/A \\ 51000 Rijeka, Croatia \\ Phone: +385 (51) 770447 \\ Fax: +385 (51) 686166 \\ www.intechopen.com
}

\author{
InTech China \\ Unit 405, Office Block, Hotel Equatorial Shanghai \\ No.65, Yan An Road (West), Shanghai, 200040, China \\ 中国上海市延安西路65号上海国际贵都大饭店办公楼 405 单元 \\ Phone: +86-21-62489820 \\ Fax: $+86-21-62489821$
}


(C) 2011 The Author(s). Licensee IntechOpen. This chapter is distributed under the terms of the Creative Commons Attribution-NonCommercialShareAlike-3.0 License, which permits use, distribution and reproduction for non-commercial purposes, provided the original is properly cited and derivative works building on this content are distributed under the same license. 